\title{
Azobisisobutyronitrile-Initiated Oxidative C-H Functionalization of Simple Alcohols with Diaryl(arylethynyl)phosphine Oxides: A Metal-free Approach toward Hydroxymethyl Benzo[b]phosphole Oxides and $6 H$-indeno[2,1-b]phosphindole 5-oxide Derivatives
}

\footnotetext{
Jiami Guo, $\uparrow$ Chenlu Mao, $\uparrow$ Bin Deng, $\uparrow$ Liyi Ye, $\uparrow$ Yingwu Yin, $\uparrow$ Yuxing Gao $\downarrow *$ and Song Tu†*

$†$ Department of Chemical and Biochemical Engineering, College of Chemistry and Chemical Engineering, Xiamen University, Xiamen 361005, Fujian, China

\$Department of Chemistry and Key Laboratory for Chemical Biology of Fujian Province, College of Chemistry and Chemical Engineering, Xiamen University, Xiamen 361005, Fujian, China.
}

Table of Contents

Page S2 1. Procedure for the Competing Kinetic Isotope Effect (KIE) Experiment

Page S3 2. Procedure for the Radical Trapping Study

Page S3 3. Optimization of the Reaction Conditions for the Synthesis of $4 \mathbf{a}$ from $\mathbf{3 a}$

Page S4 4. Crystallographic Detail of $\mathbf{3 m}$

Page S5 5. Crystallographic Detail of $\mathbf{4 f}$

Page S6-S25 6. ${ }^{31} \mathrm{P}$ NMR, ${ }^{1} \mathrm{H}$ NMR, ${ }^{13} \mathrm{C}$ NMR Spectra of Compounds 1a-1m

Page S26-S75 7. ${ }^{31} \mathrm{P}$ NMR, ${ }^{1} \mathrm{H}$ NMR, ${ }^{13} \mathrm{C}$ NMR Spectra of Compounds 3a-3u, 4a-4k, 5a and $6 \mathbf{a}$ 
1. Procedure for the Competing Kinetic Isotope Effect (KIE) Experiment

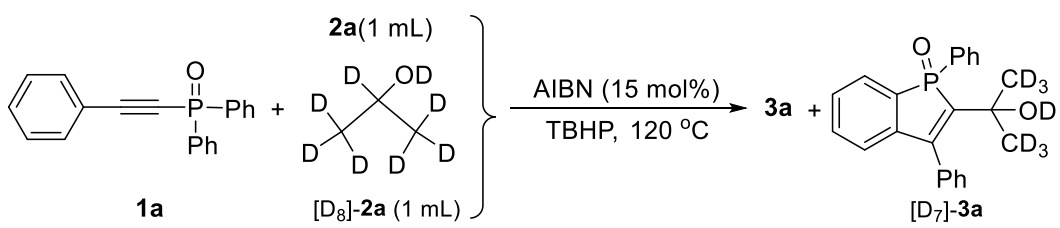

In an oven dried Schlenk tube equipped with a magnetic stir bar, diaryl(arylethynyl) phosphine oxides 1a (60.4 mg, $0.2 \mathrm{mmol})$, TBHP (5.0-6.0 $\mathrm{M}$ in decane, $1.0 \mathrm{mmol})$ were mixed in isopropanol $(1 \mathrm{~mL})$ and isopropanol- $\mathrm{D}_{8}(1 \mathrm{~mL})$, and stirred at $120{ }^{\circ} \mathrm{C}$ for $36 \mathrm{~h}$ under air. The mixture was cooled down to room temperature and purified by flash chromatography (petroleum ether/ethyl acetate $=3: 1-1: 1$ ) to afford the corresponding products.

Note: As shown in the ${ }^{1} \mathrm{H}$ NMR spectrum (see the following figure), the sum of the integral of $\mathbf{3 a}$ and $\left[\mathrm{D}_{7}\right]-\mathbf{3 a}$ at chemical shift 6.68-6.70 was integrated as 1.00. Compound 3a has three hydrogen atoms at chemical shift 1.12, while $\left[D_{7}\right]-3 \mathbf{a}$ has no $\mathrm{H}$ atoms. The amount of $\mathbf{3 a}$ could be defined as 2.46 , on the other hand, the sum of $\mathbf{3 a}$ and $\left[D_{7}\right]-3 \mathbf{a}$ is 3.00 , so the amount of $\left[D_{7}\right]-3 a$ is $0.54(3.00-2.46=0.54)$. As a result, the isotope effect value calculated from the product ratio and conversion of the reaction is $\mathrm{k}_{\mathrm{H}} / \mathrm{k}_{\mathrm{D}}=2.46 / 0.54=4.56$.
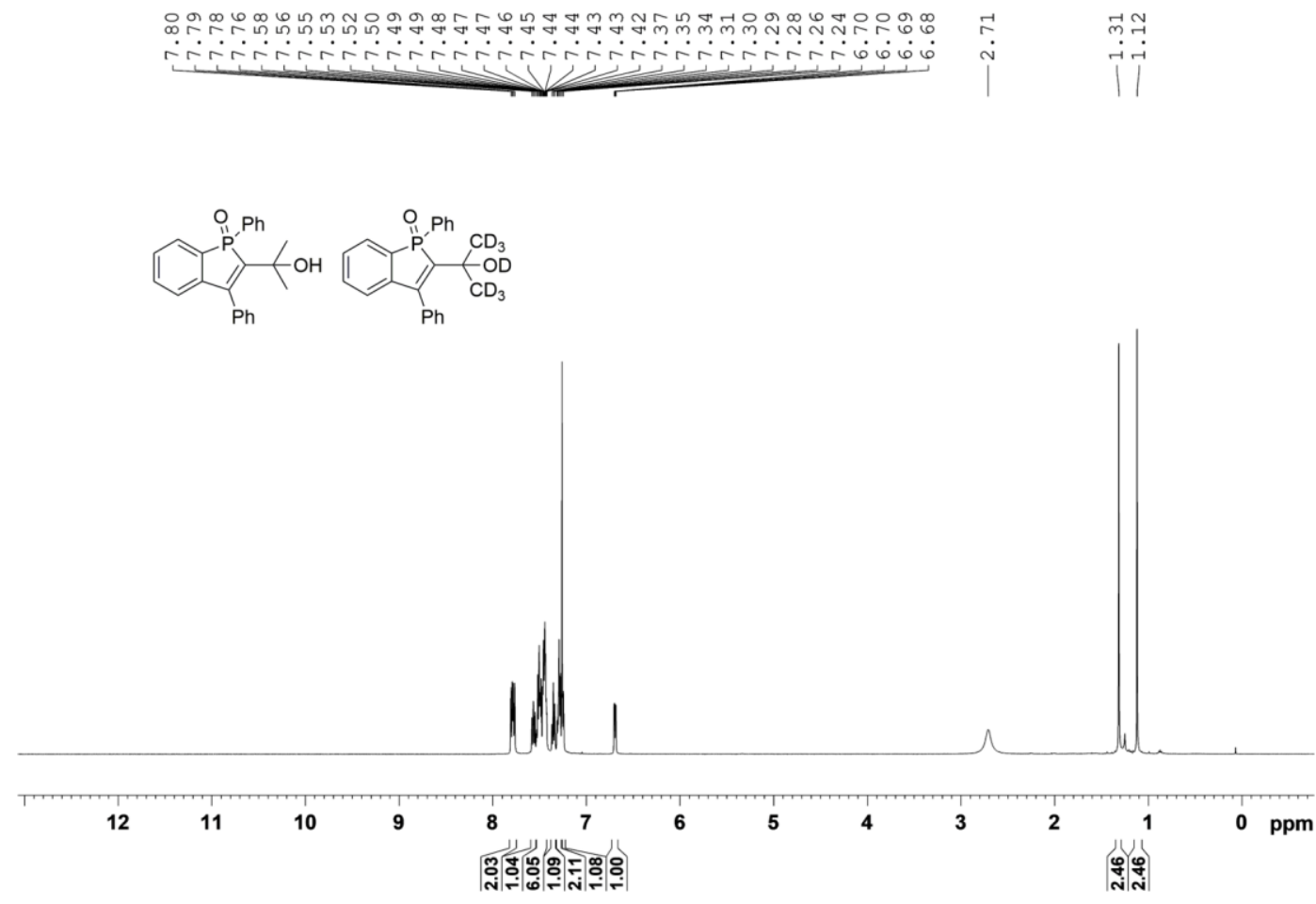
2. Procedure for the Radical Trapping Study

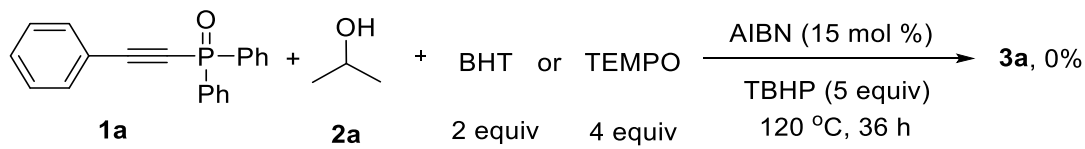

The reaction was carried out according to the general procedure, except 2 equiv of BHT (88.1 mg, $0.4 \mathrm{mmol})$ or 4 equiv of TEMPO (125.0 mg, $0.8 \mathrm{mmol})$ was added. At the end of the reaction, the target product 3a was not observed.

3. Optimization of the Reaction Conditions for the Synthesis of $4 a$ from $3 a^{a}$

\begin{tabular}{|c|c|c|c|c|}
\hline entry & temp $\left({ }^{\circ} \mathrm{C}\right)$ & solvent & acid & yield $(\%)$ \\
\hline 1 & 120 & DCM & $\mathrm{TfOH}$ & 0 \\
\hline 2 & 120 & DCM & $\mathrm{TsOH}$ & 0 \\
\hline 3 & 120 & DCM & TFA & 0 \\
\hline 4 & 100 & DCM & $\mathrm{TfOH}$ & 0 \\
\hline 5 & 45 & DCM & $\mathrm{TfOH}$ & 31 \\
\hline 6 & 45 & HFIP & $\mathrm{TfOH}$ & 78 \\
\hline 7 & 90 & HFIP & TfOH & 96 \\
\hline $8^{b}$ & & HFIP & TfOH & 80 \\
\hline
\end{tabular}

${ }^{a}$ Reaction conditions: 3a $(0.2 \mathrm{mmol})$, acid $(50 \mathrm{~mol} \%)$, solvent $(1 \mathrm{~mL})$, under air for 24

h. Isolated yields; ${ }^{b}$ One-pot process: 1a $(0.2 \mathrm{mmol})$, isopropanol 2a $(2 \mathrm{~mL})$, AIBN (15 mol \%), TBHP (70\% in water, 5 equiv) at $120{ }^{\circ} \mathrm{C}$ under air; after $36 \mathrm{~h}$, removed solvent under vacuum; then added TfOH (50 mol \%) and HFIP(1 mL) and stirred for $24 \mathrm{~h}$ at $90{ }^{\circ} \mathrm{C}$ under air. 


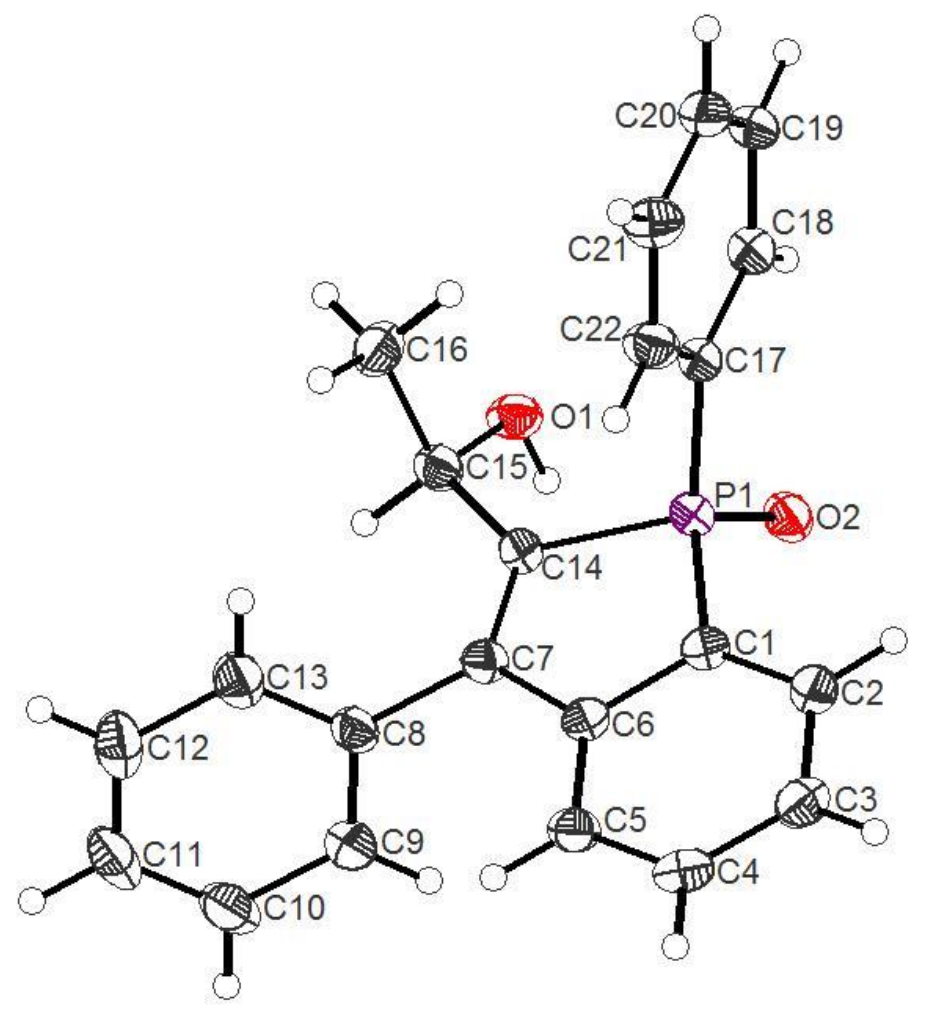

Crystals were obtained by slow volatilization of mixture solution of $3 \mathbf{m}$ in $n$-hexane and $\mathrm{CH}_{2} \mathrm{Cl}_{2}$ $(3: 1, \mathrm{v} / \mathrm{v}$, concentration $2 \mathrm{~mol} / \mathrm{L})$ at room temperature.

Single crystal X-ray structure of compound 3m, showing 50\% probability displacement ellipsoids (arbitrary spheres for $\mathrm{H}$ atoms). Compound $\mathbf{3 m}$ crystallizes in the monoclinic -P 1 space group with two $\mathbf{3 m}$ per unit cell. There is one independent molecule in the asymmetric unit of $\mathbf{3 m}$.

Detector with graphite-monochromated CuKa radiation $(\lambda=1.54184 \AA)$ at $100 \mathrm{~K}$. All of the Data were corrected for absorption effects using the multi-scan technique. The structures were solved by direct methods using OLEX2 (Version 1.2.7) program package. Non-H atoms were refined anisotropically unless otherwise stated. Hydrogen atoms were introduced at their geometric positions and refined as riding atoms unless otherwise stated. Some crystal data for $\mathbf{3 m}$ : C22 H19 O2 P ; M = 346.34, monoclinic, space group -P 1, colorless plate, $a=9.5029$ (4) $\AA, b=$ $10.3608(5) \AA, c=11.0975(4) \AA, \alpha=99.412(4)^{\circ}, \beta=113.277(4)^{\circ}, \gamma=107.356(4)^{\circ}, V=907.31$ (7) $\AA 3, \mathrm{Z}=2, \mathrm{D}_{\mathrm{x}}=1.268 \mathrm{~g} \cdot \mathrm{cm}-3, \mathrm{~F}(000)=364.0, \mathrm{~T}=100 \mathrm{~K}$. Final $\mathrm{R} * 3014$ with $\mathrm{I}>2 \sigma(\mathrm{I})+=$ $0.0491, w R 2(3410)=0.1509$. Further details on the crystal structure investigation have been deposited at the Cambridge Crystallographic Data Centre as the deposition number CCDC 1970577. 


\section{Crystallographic Detail of $4 \mathrm{f}$}

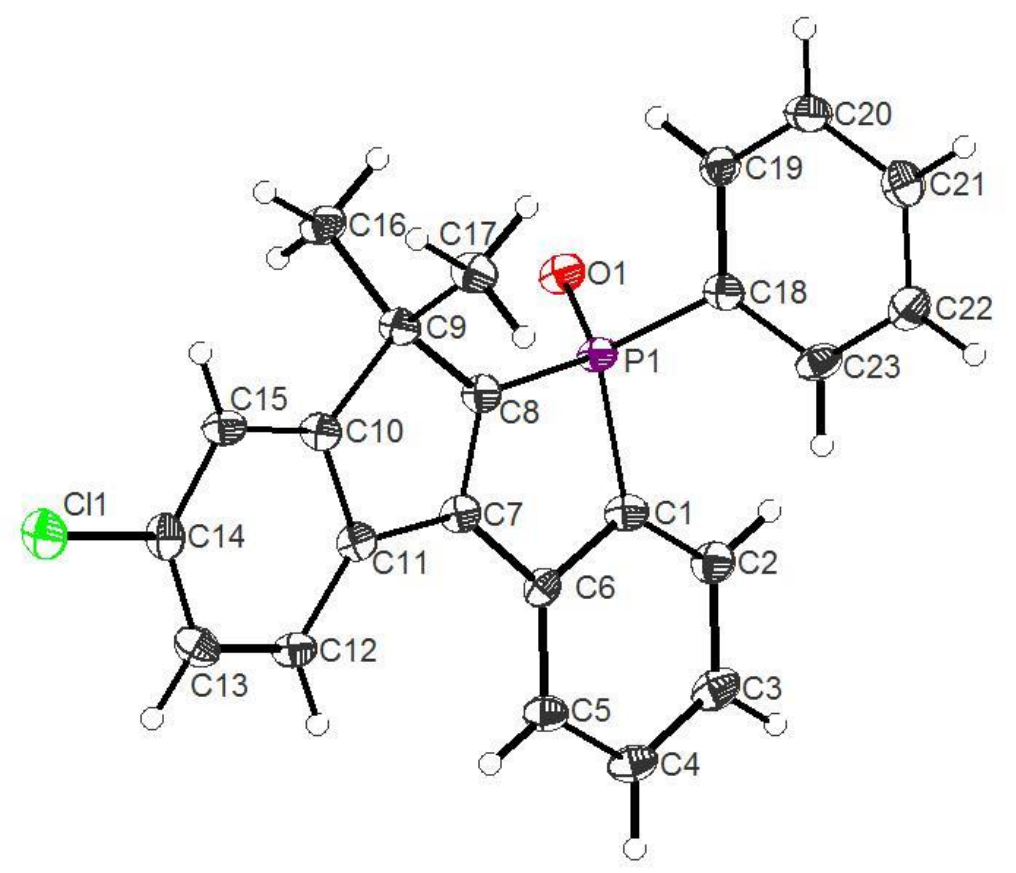

Crystals were obtained by slow volatilization of mixture solution of $\mathbf{4 f}$ in $n$-hexane and $\mathrm{CH}_{2} \mathrm{Cl}_{2}$ (3:1, v/v, concentration $2 \mathrm{~mol} / \mathrm{L})$ at room temperature.

Single crystal X-ray structure of compound $\mathbf{4 f}$, showing $50 \%$ probability displacement ellipsoids (arbitrary spheres for $\mathrm{H}$ atoms). Compound $\mathbf{4 f}$ crystallizes in the monoclinic -P 2ybc space group with four $\mathbf{4 f}$ per unit cell. There is one independent molecule in the asymmetric unit of $4 \mathbf{f}$.

Detector with graphite-monochromated CuKa radiation $(\lambda=1.54184 \AA)$ at $150 \mathrm{~K}$. All of the Data were corrected for absorption effects using the multi-scan technique. The structures were solved by direct methods using OLEX2 (Version 1.2.7) program package. Non-H atoms were refined anisotropically unless otherwise stated. Hydrogen atoms were introduced at their geometric positions and refined as riding atoms unless otherwise stated. Some crystal data for $\mathbf{4 f}$ : C23 H18 O P Cl ; M = 376.79, monoclinic, space group -P 2ybc, colorless plate, a = 7.6089(2) A, $\mathrm{b}=14.0410(3) \AA, \mathrm{c}=17.1323(4) \AA, \alpha=90^{\circ}, \beta=93.246(2)^{\circ}, \gamma=90^{\circ}, \mathrm{V}=1827.42(8) \AA 3, \mathrm{Z}=4$, $D_{x}=1.370 \mathrm{~g} \cdot \mathrm{cm}-3, \mathrm{~F}(000)=784.0, \mathrm{~T}=150 \mathrm{~K}$. Final $\mathrm{R} * 2889$ with $\mathrm{I}>2 \sigma(\mathrm{I})+=0.0408$, wR2 $(3277)=0.1158$. Further details on the crystal structure investigation have been deposited at the Cambridge Crystallographic Data Centre as the deposition number CCDC 1970574. 
6. ${ }^{31}$ P NMR. ${ }^{1} \mathrm{H}$ NMR. ${ }^{13}$ CNMR Spectrum of Compounds 1a-1m

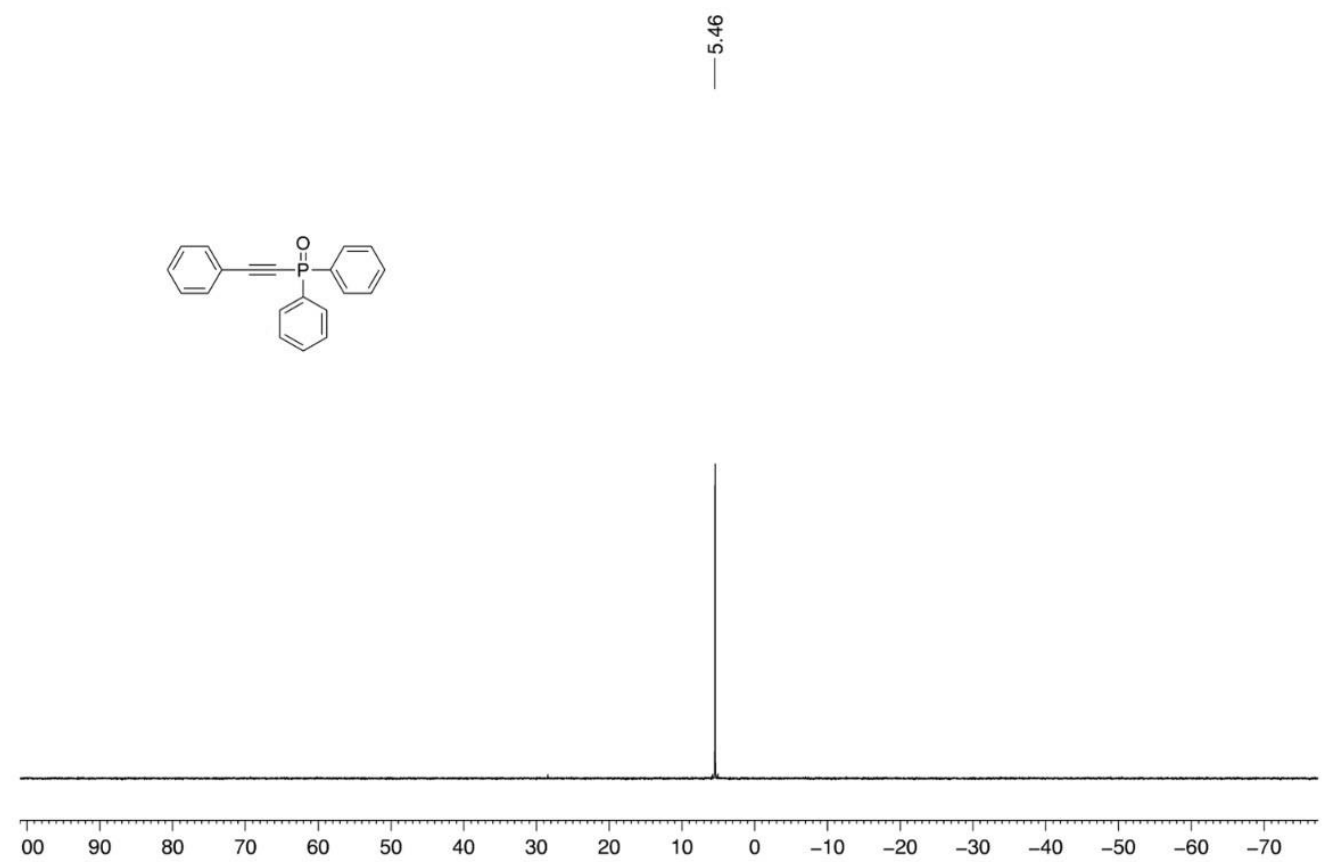

${ }^{31} \mathrm{P}$ NMR (400 MHz) spectrum of compound $\mathbf{1 a}$ in $\mathrm{CDCl}_{3}$

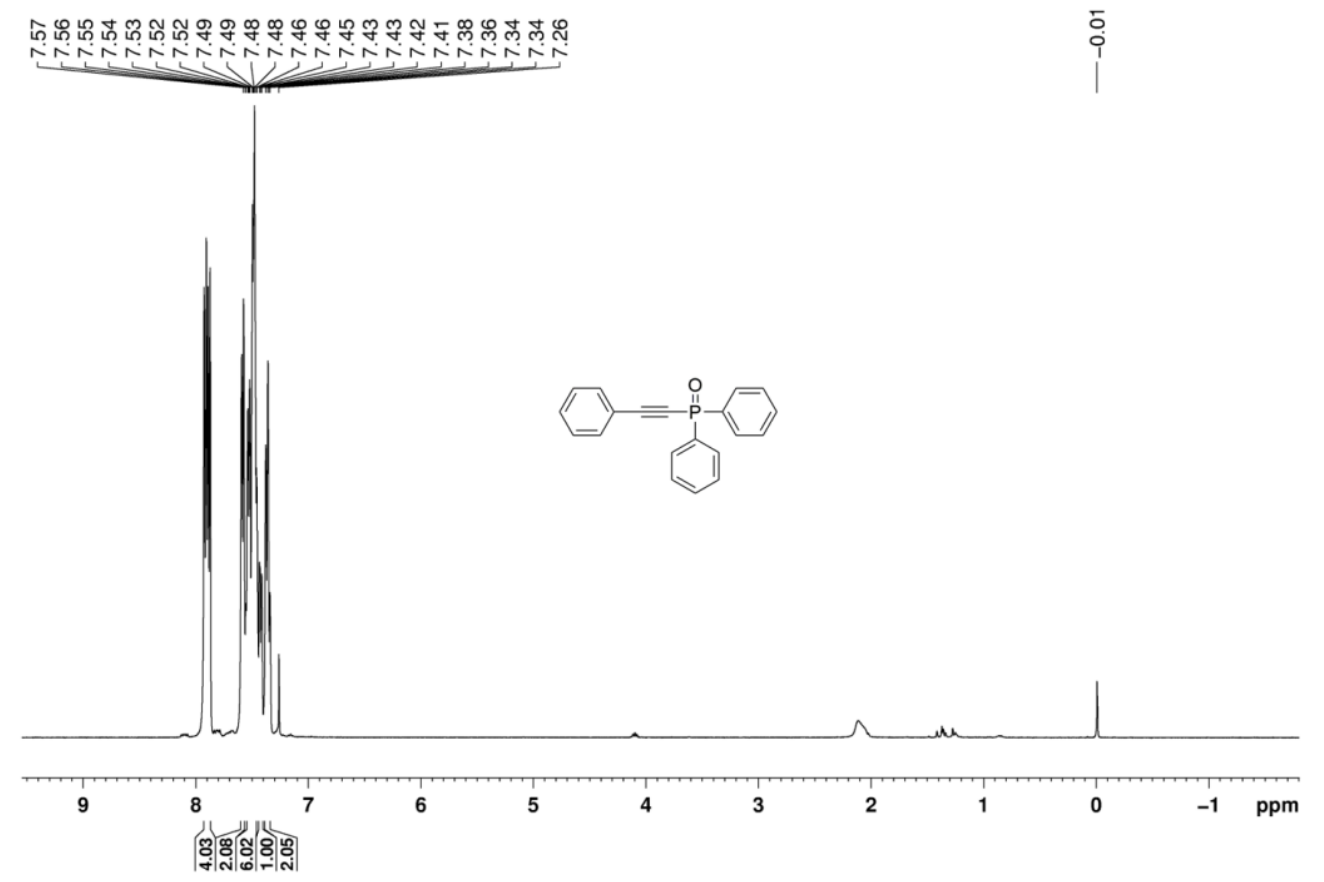

${ }^{1} \mathrm{H}$ NMR (400 MHz) spectrum of compound $\mathbf{1 a}$ in $\mathrm{CDCl}_{3}$ 


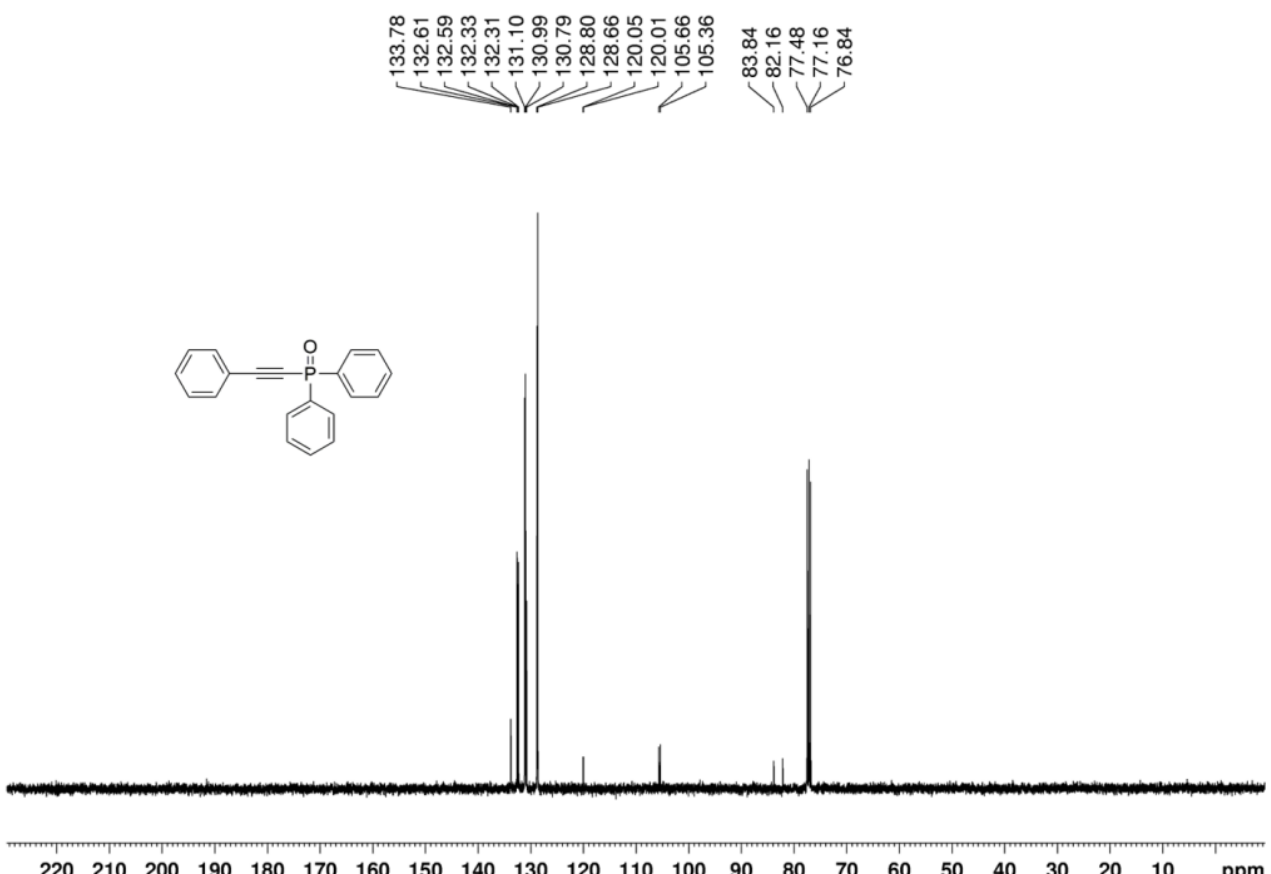

${ }^{13} \mathrm{C}$ NMR (400 MHz) spectrum of compound 1a in $\mathrm{CDCl}_{3}$

|
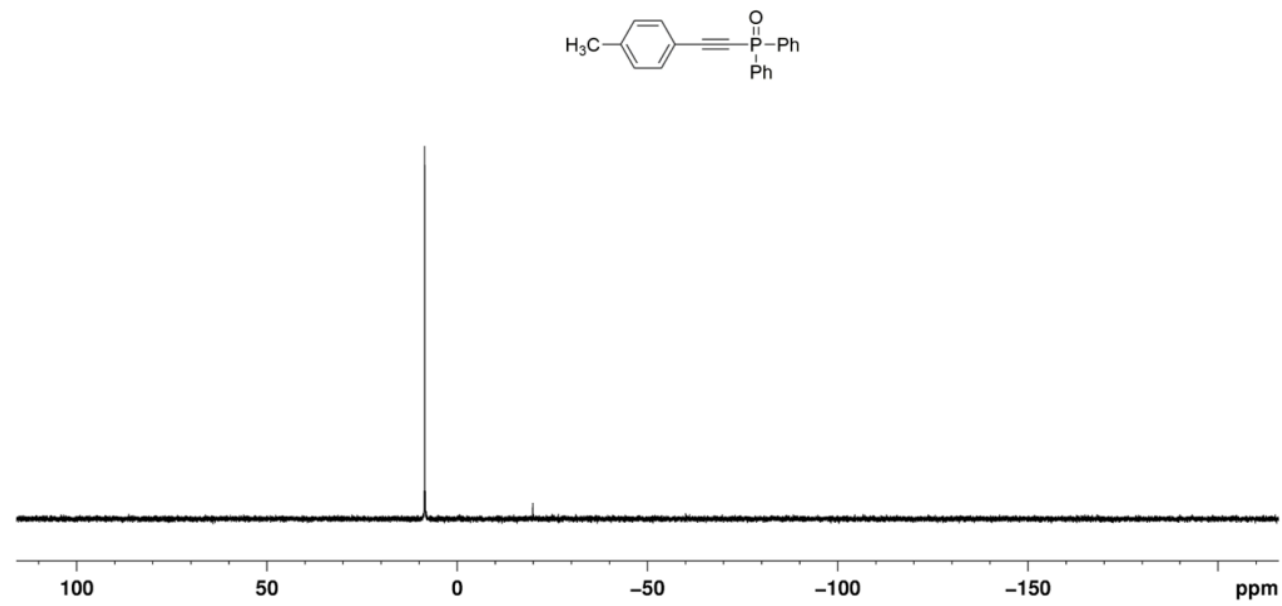

${ }^{31} \mathrm{P}$ NMR (400 MHz) spectrum of compound $\mathbf{1 b}$ in $\mathrm{CDCl}_{3}$ 

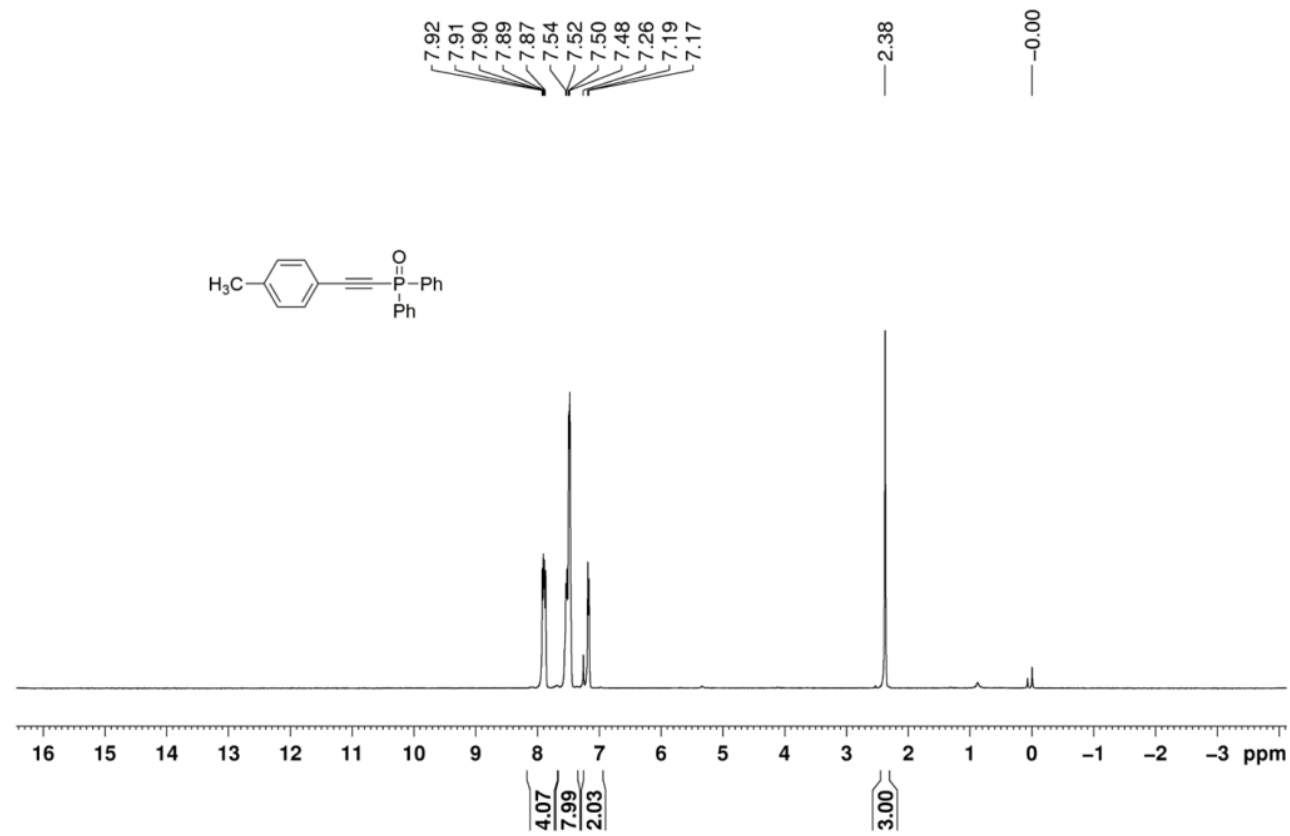

${ }^{1} \mathrm{H}$ NMR (400 MHz) spectrum of compound $\mathbf{1 b}$ in $\mathrm{CDCl}_{3}$

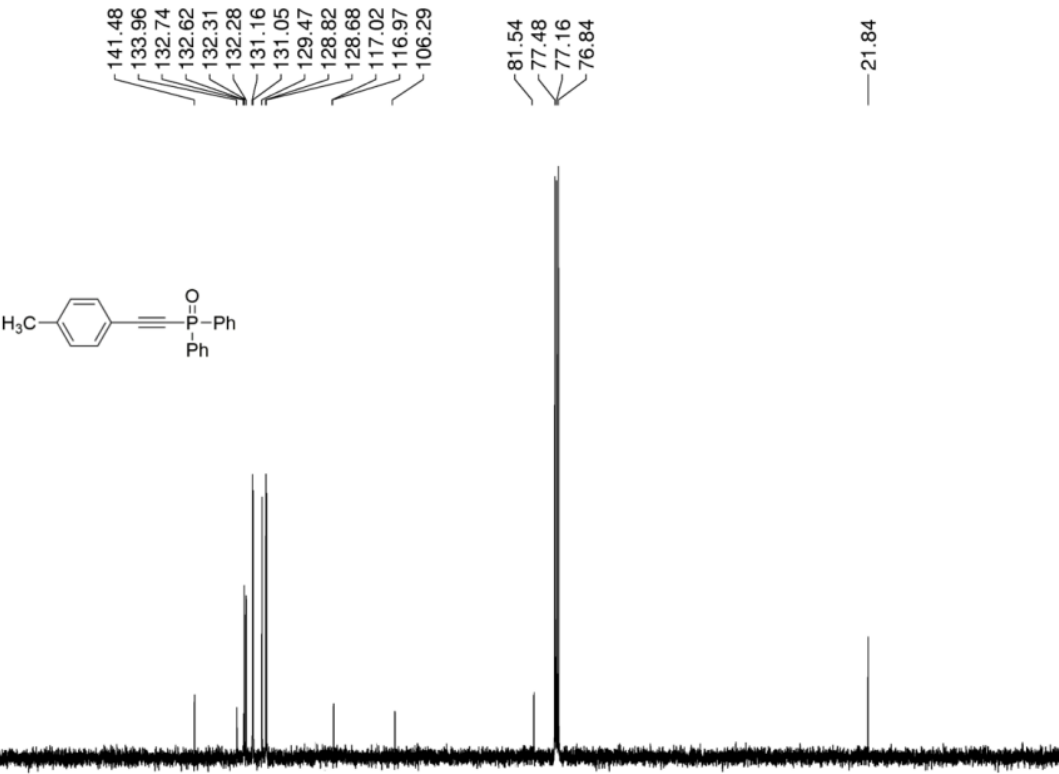

$\begin{array}{llllllllllllllllllllll}200 & 190 & 180 & 170 & 160 & 150 & 140 & 130 & 120 & 110 & 100 & 90 & 80 & 70 & 60 & 50 & 40 & 30 & 20 & 10 & 0 & \mathrm{ppm}\end{array}$

${ }^{13} \mathrm{C}$ NMR (400 MHz) spectrum of compound $\mathbf{1 b}$ in $\mathrm{CDCl}_{3}$ 


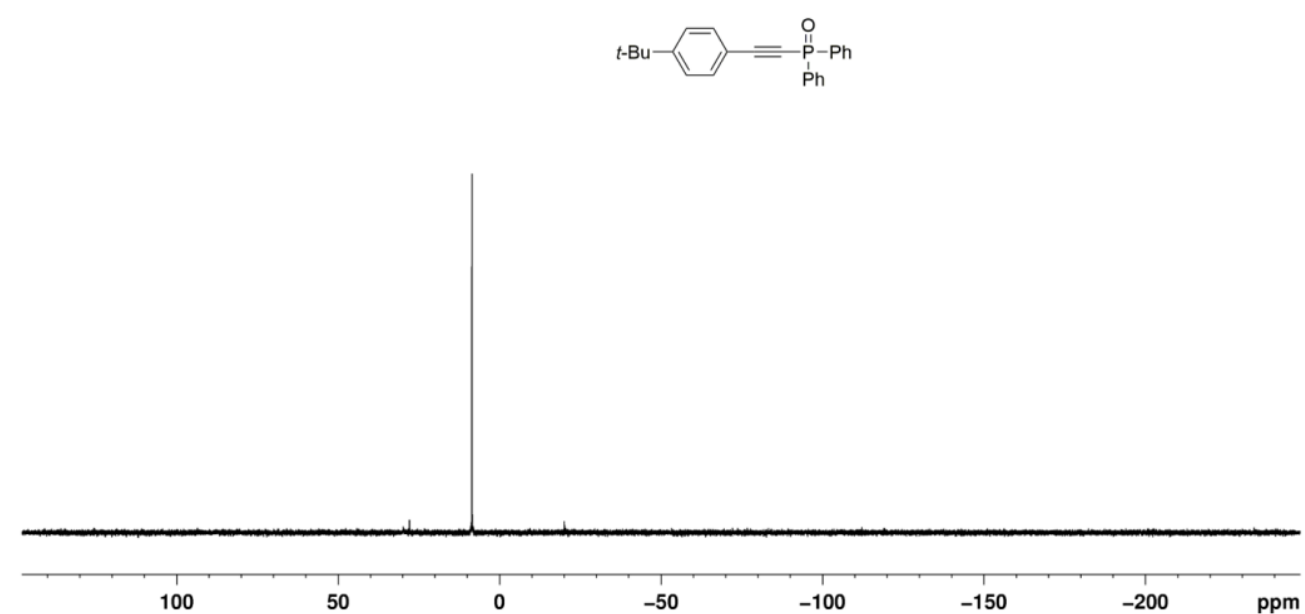

${ }^{31} \mathrm{P}$ NMR (400 MHz) spectrum of compound $\mathbf{1 c}$ in $\mathrm{CDCl}_{3}$

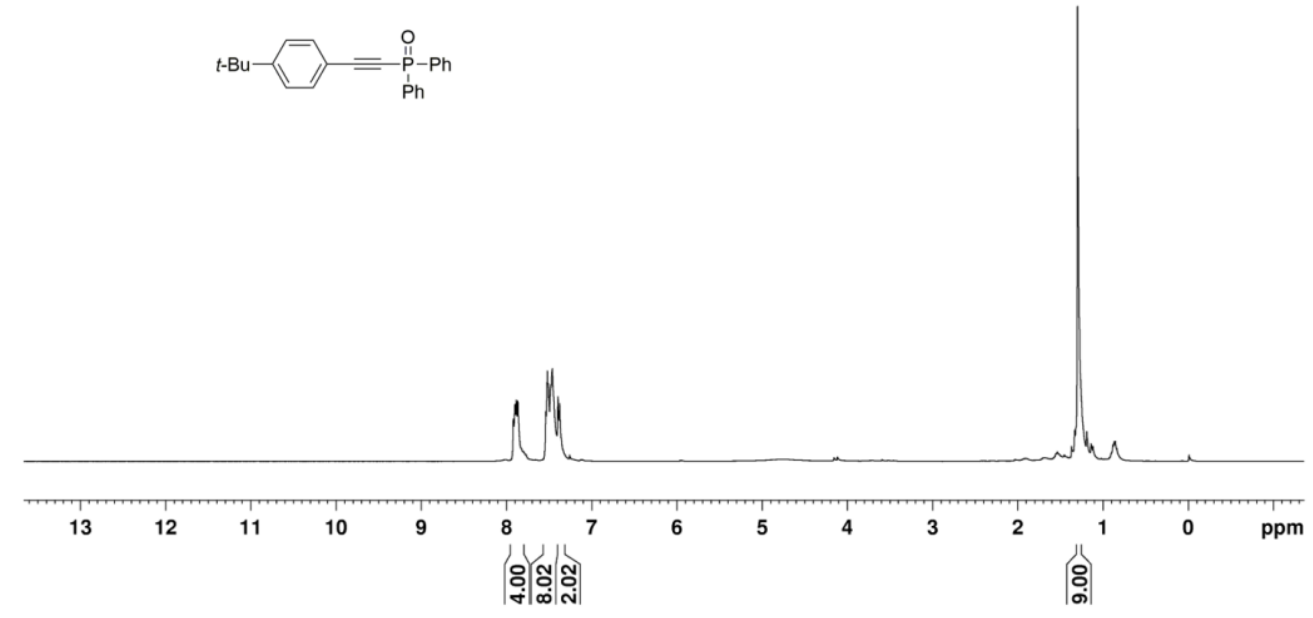

${ }^{1} \mathrm{H}$ NMR (400 MHz) spectrum of compound $1 \mathrm{c}$ in $\mathrm{CDCl}_{3}$ 


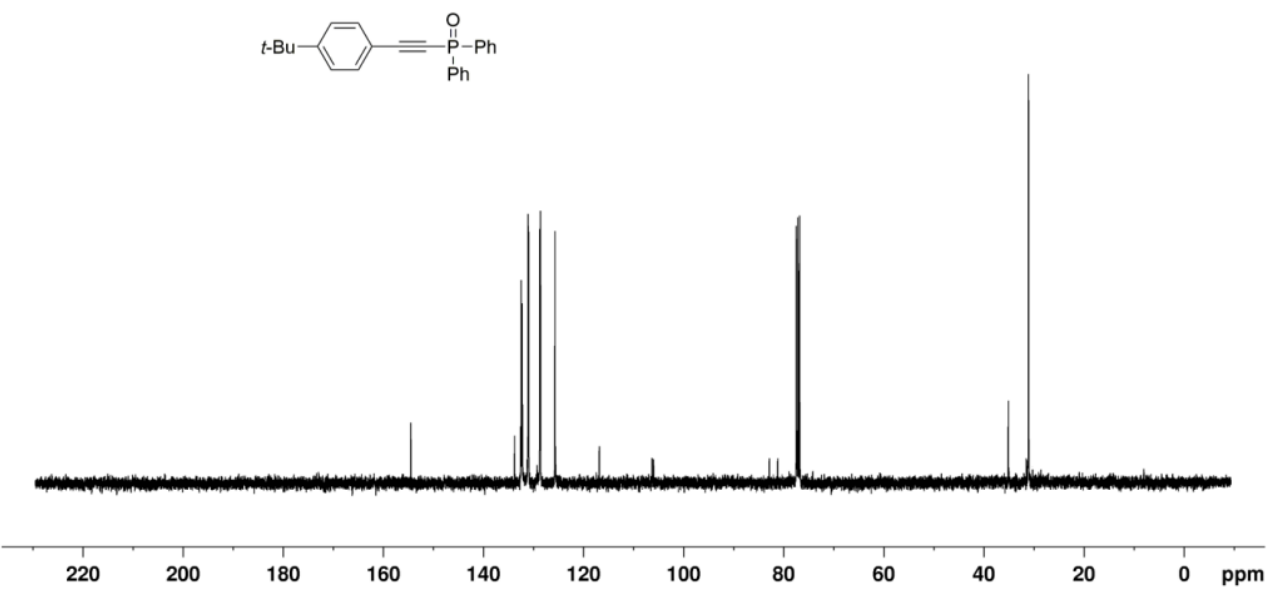

${ }^{13} \mathrm{C}$ NMR (400 MHz) spectrum of compound $\mathbf{1 c}$ in $\mathrm{CDCl}_{3}$

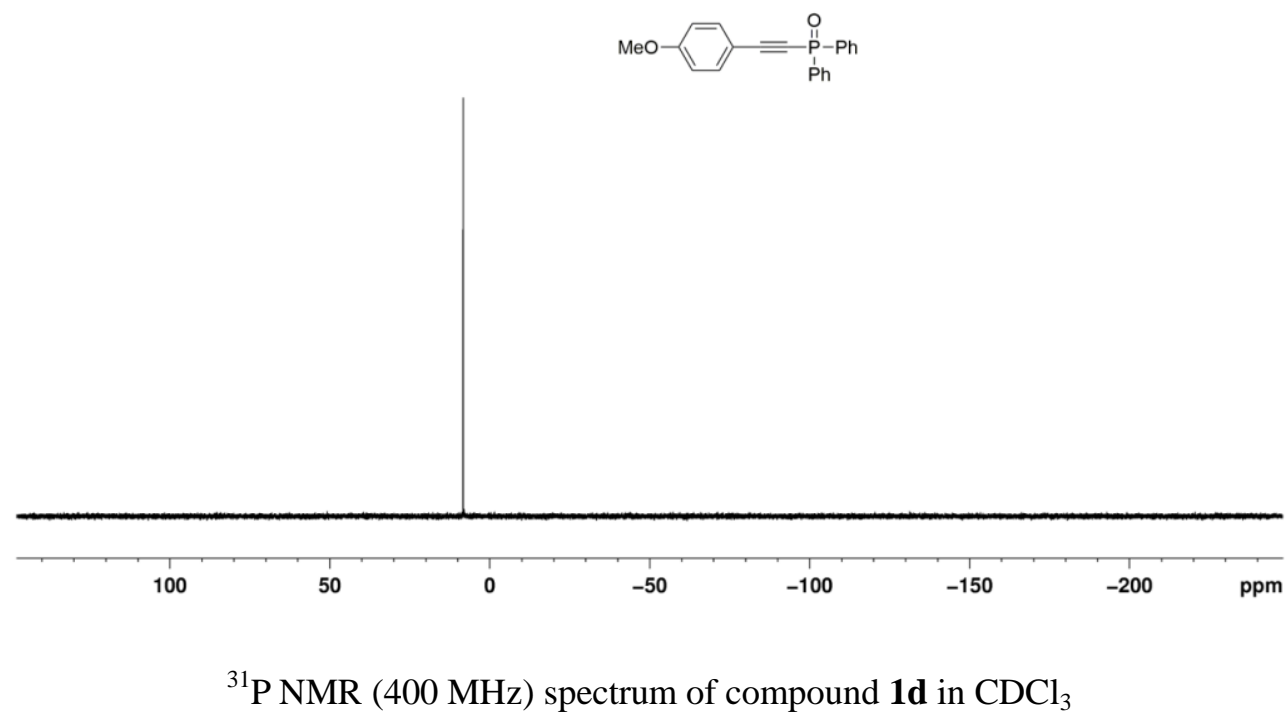




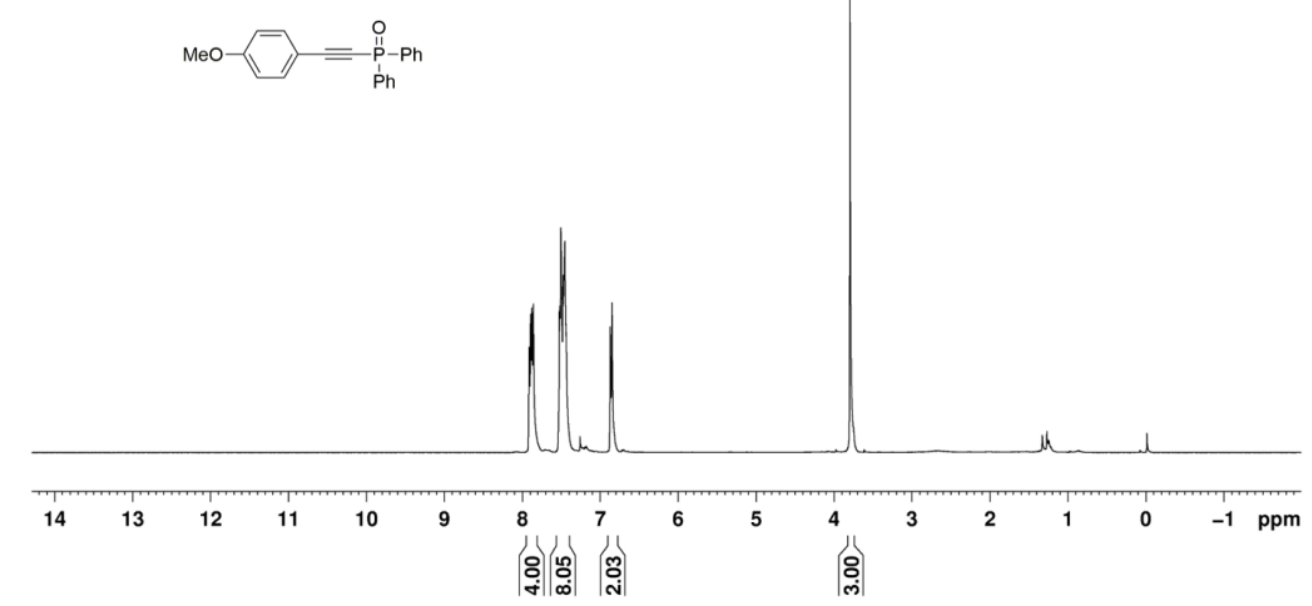

${ }^{1} \mathrm{H}$ NMR (400 MHz) spectrum of compound $\mathbf{1 d}$ in $\mathrm{CDCl}_{3}$

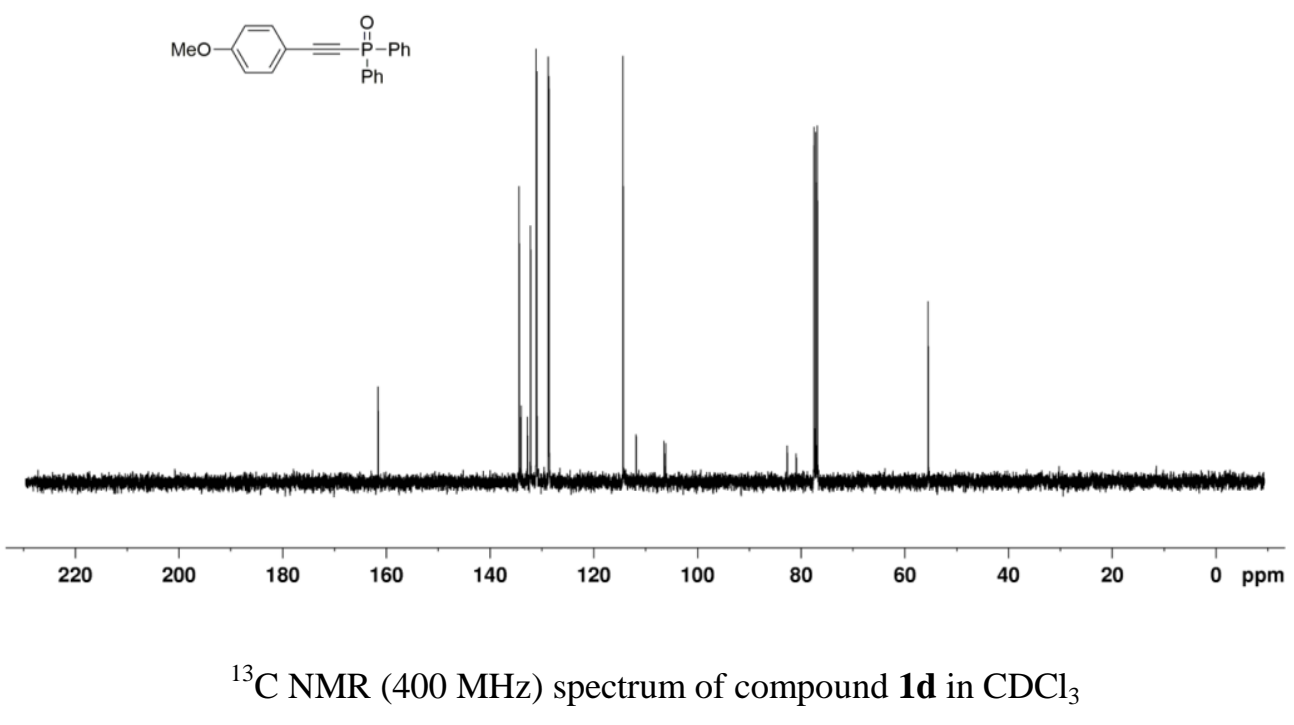




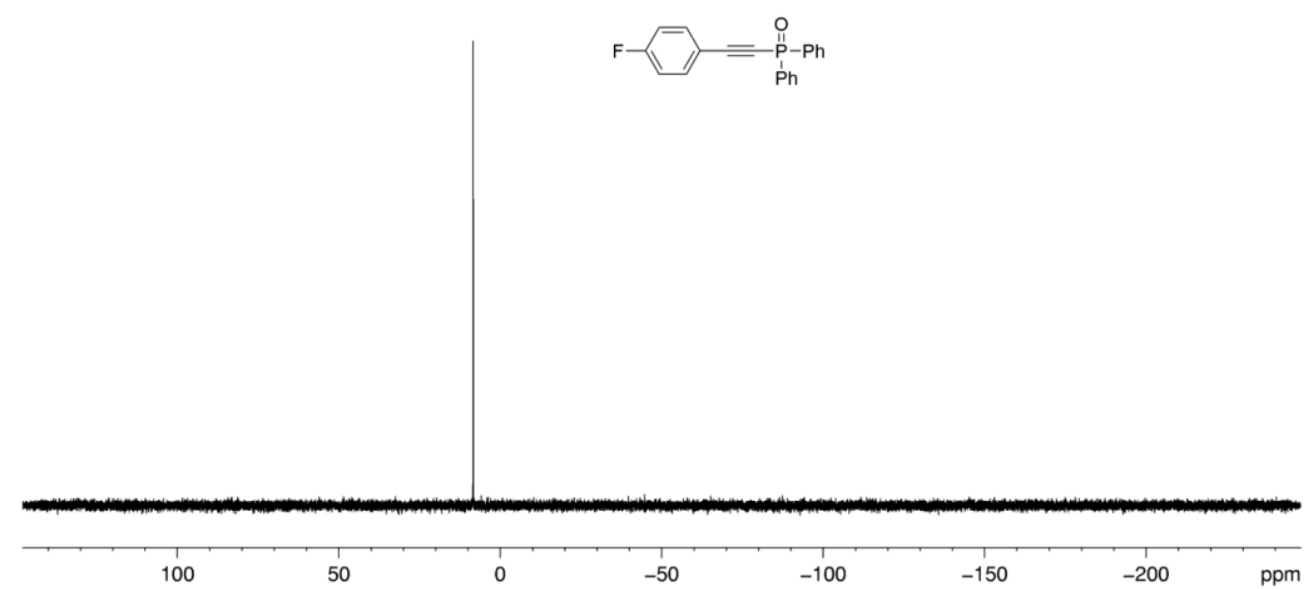

${ }^{31} \mathrm{P}$ NMR (400 MHz) spectrum of compound $\mathbf{1 e}$ in $\mathrm{CDCl}_{3}$

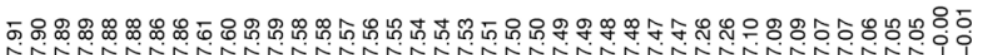

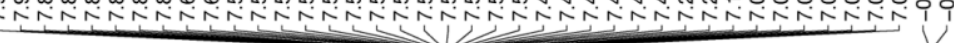

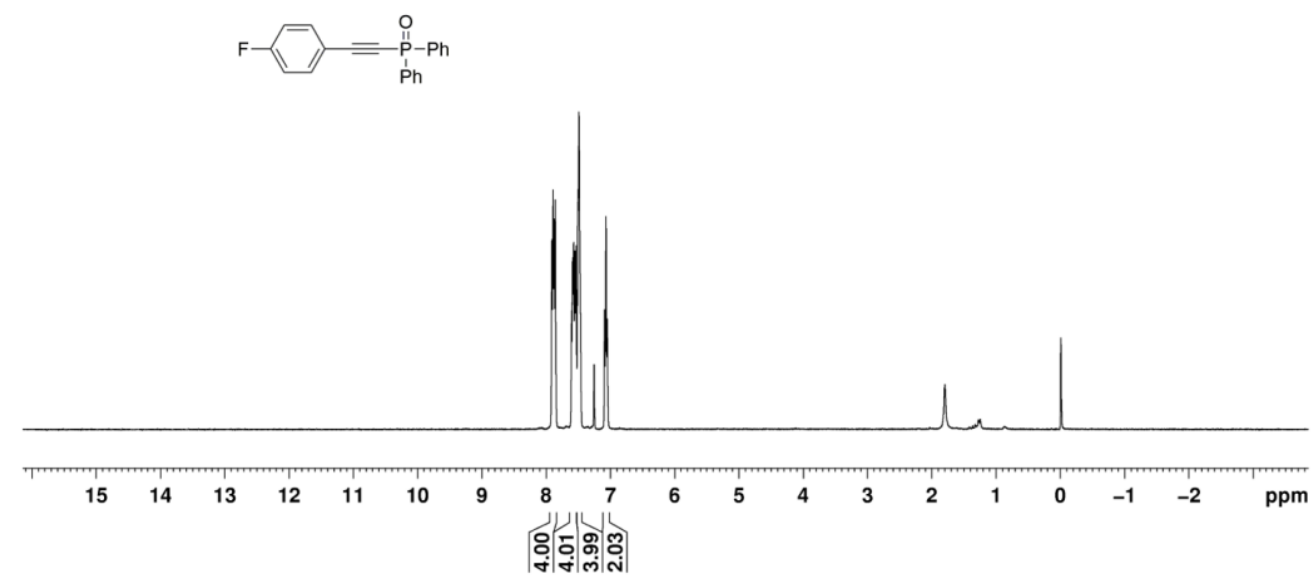

${ }^{1} \mathrm{H}$ NMR (400 MHz) spectrum of compound $\mathbf{1 e}$ in $\mathrm{CDCl}_{3}$ 


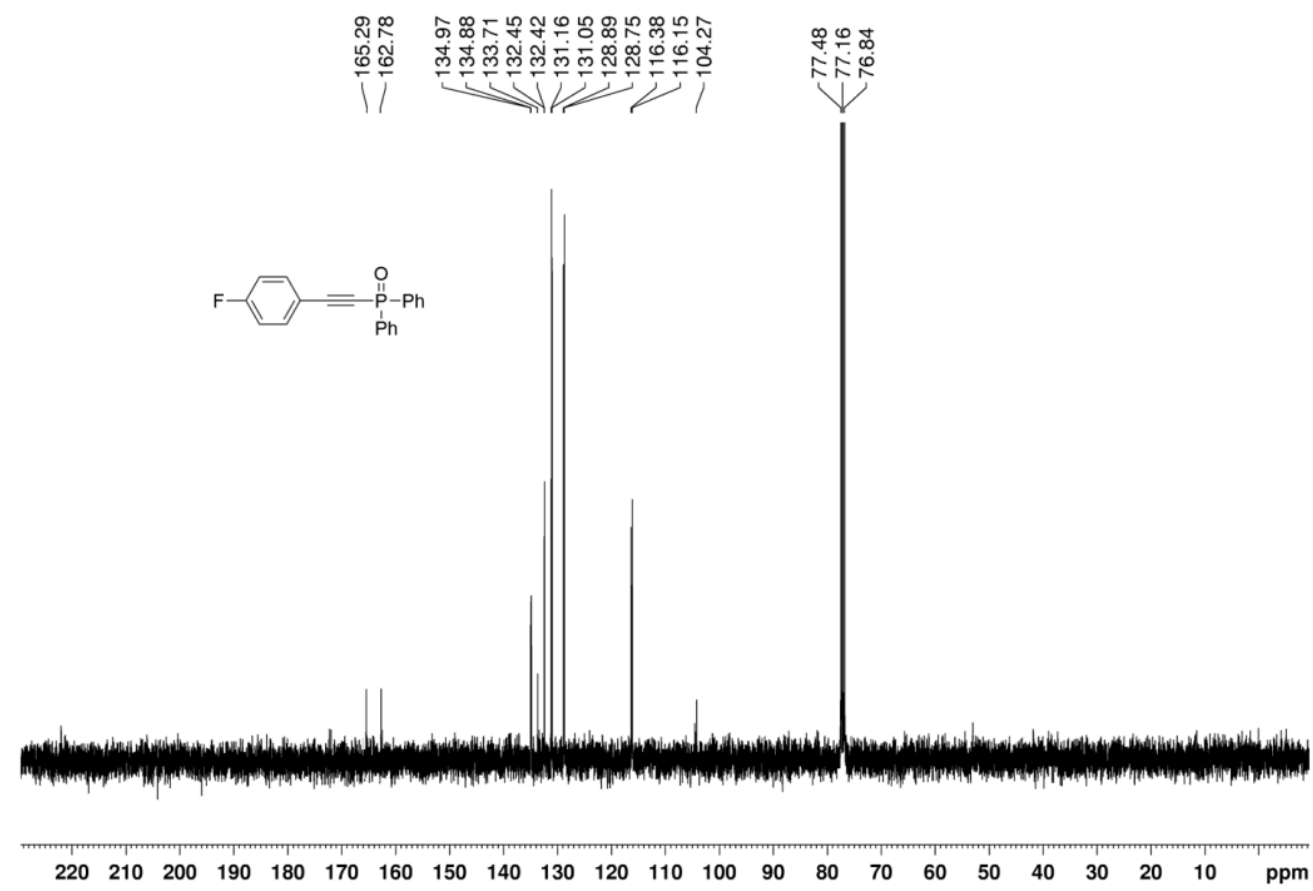

${ }^{13} \mathrm{C}$ NMR (400 MHz) spectrum of compound $\mathbf{1 e}$ in $\mathrm{CDCl}_{3}$

ल
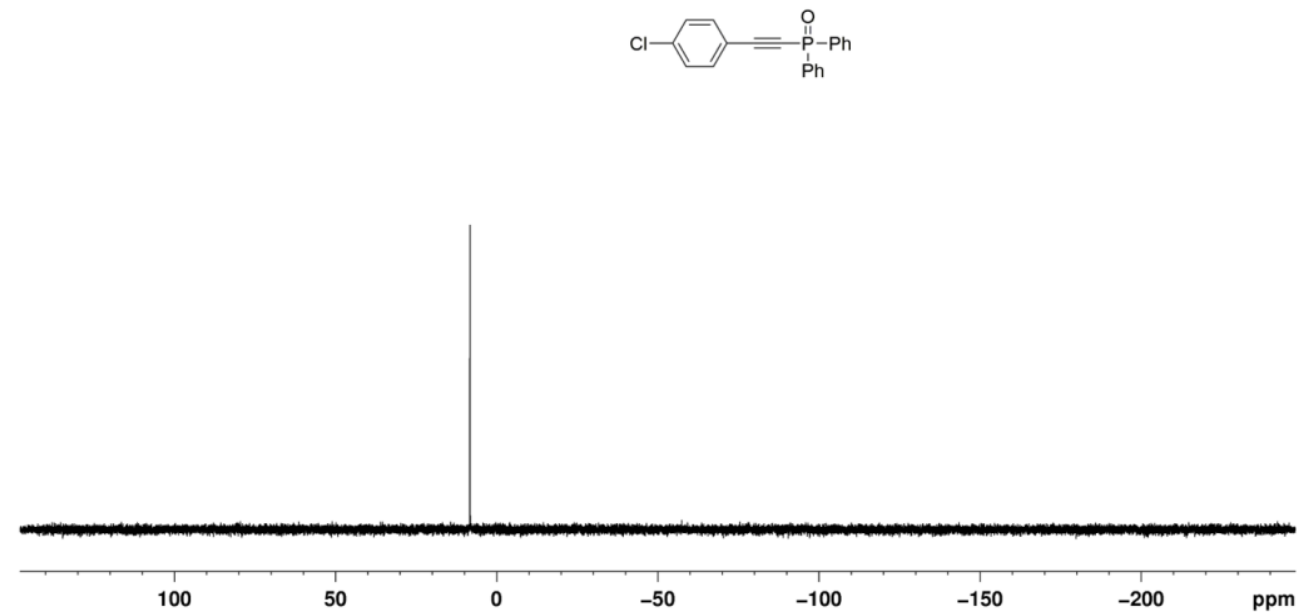

${ }^{31} \mathrm{P}$ NMR (400 MHz) spectrum of compound $\mathbf{1 f}$ in $\mathrm{CDCl}_{3}$ 


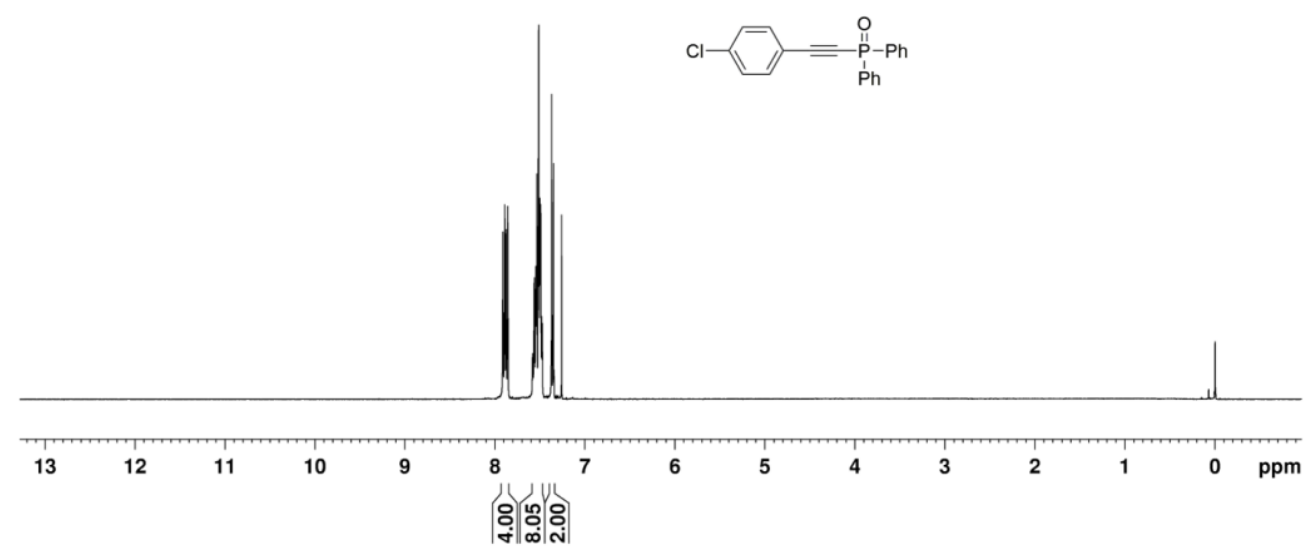

${ }^{1} \mathrm{H}$ NMR (400 MHz) spectrum of compound $\mathbf{1 f}$ in $\mathrm{CDCl}_{3}$

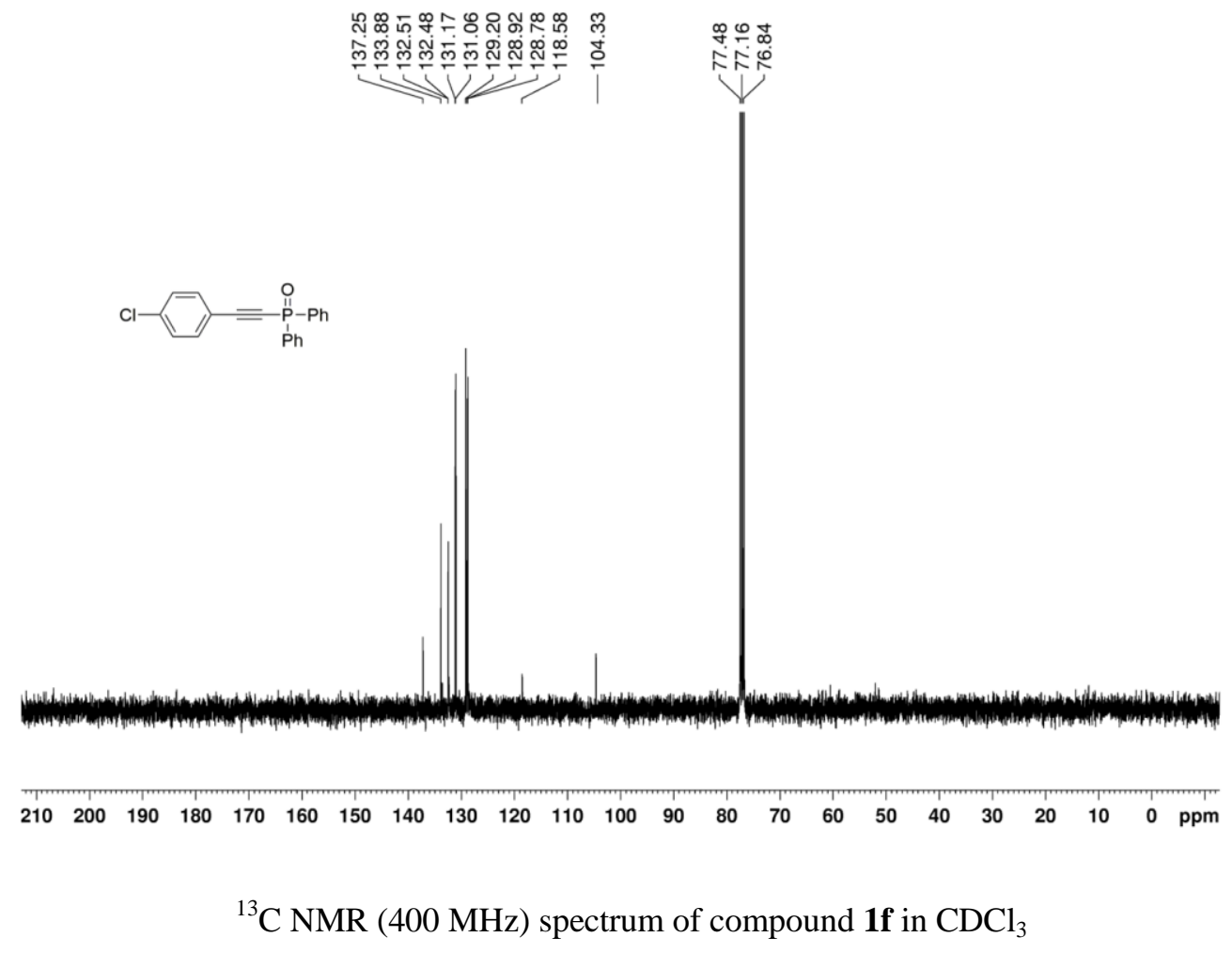




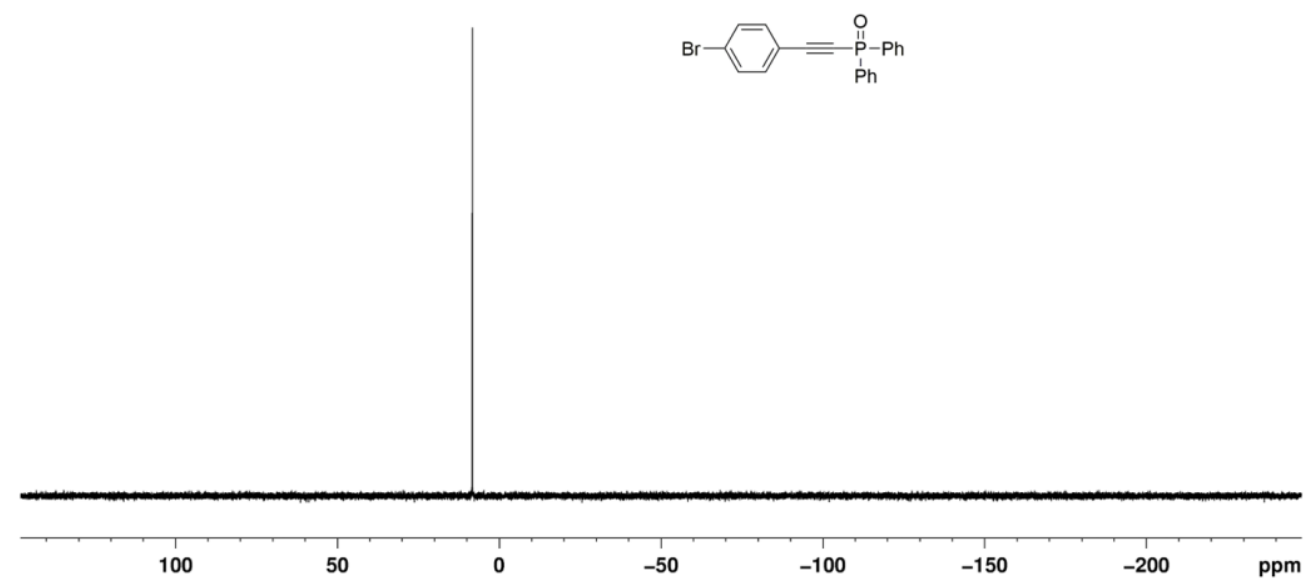

${ }^{31} \mathrm{P}$ NMR (400 MHz) spectrum of compound $\mathbf{1 g}$ in $\mathrm{CDCl}_{3}$

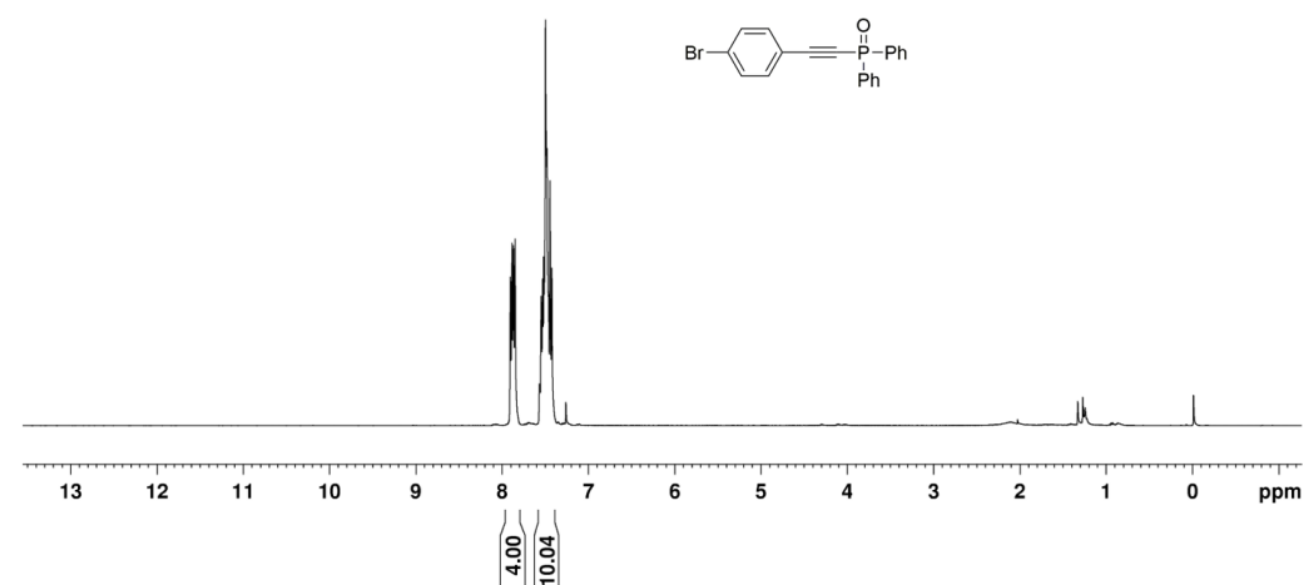

${ }^{1} \mathrm{H}$ NMR (400 MHz) spectrum of compound $\mathbf{1 g}$ in $\mathrm{CDCl}_{3}$ 


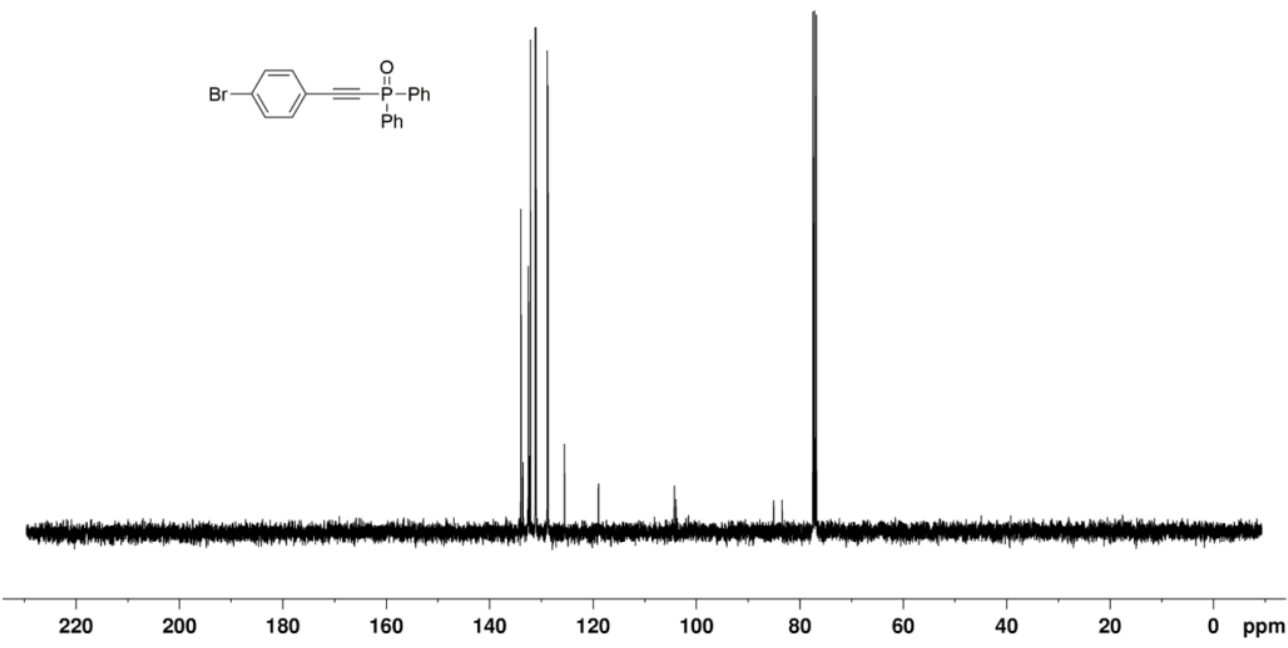

${ }^{13} \mathrm{C}$ NMR (400 MHz) spectrum of compound $\mathbf{1 g}$ in $\mathrm{CDCl}_{3}$

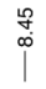

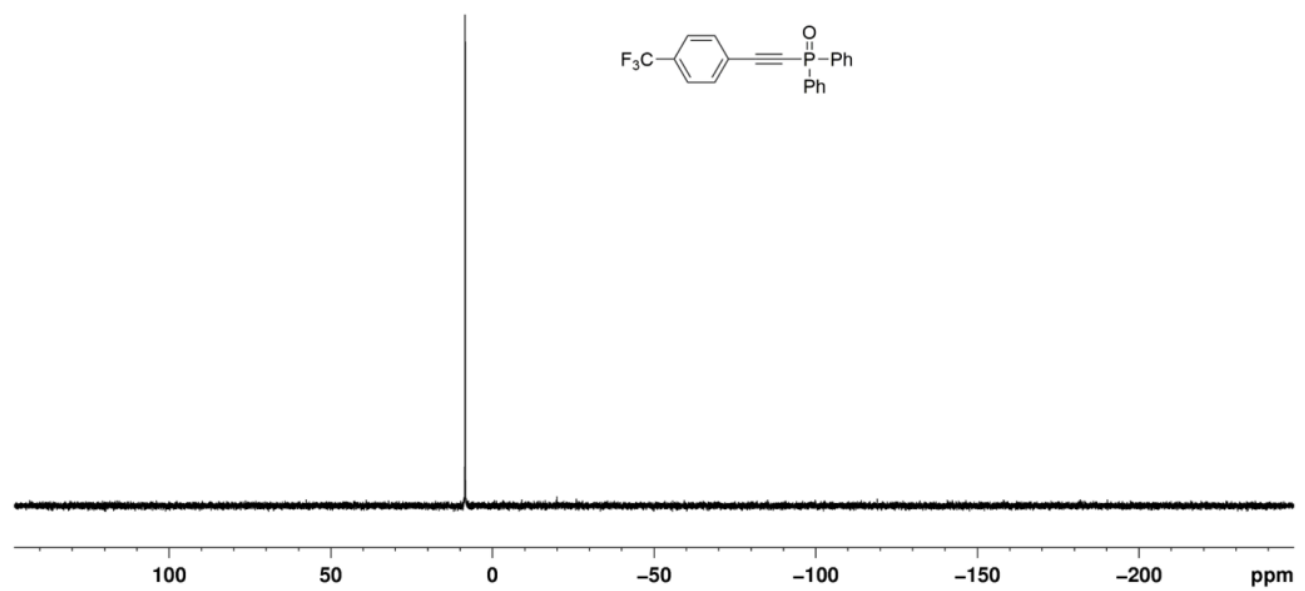

${ }^{31} \mathrm{P}$ NMR (400 MHz) spectrum of compound $\mathbf{1 h}$ in $\mathrm{CDCl}_{3}$ 


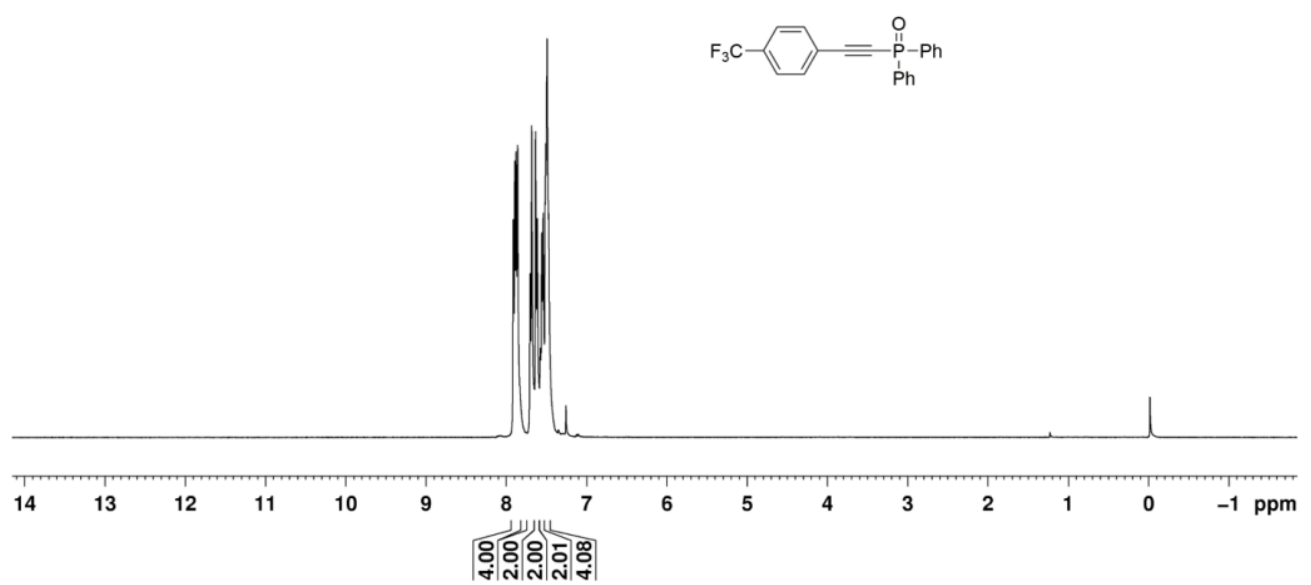

${ }^{1} \mathrm{H}$ NMR (400 MHz) spectrum of compound $\mathbf{1 h}$ in $\mathrm{CDCl}_{3}$

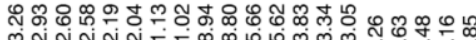

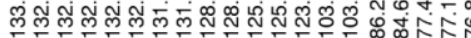

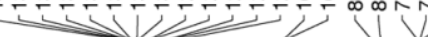

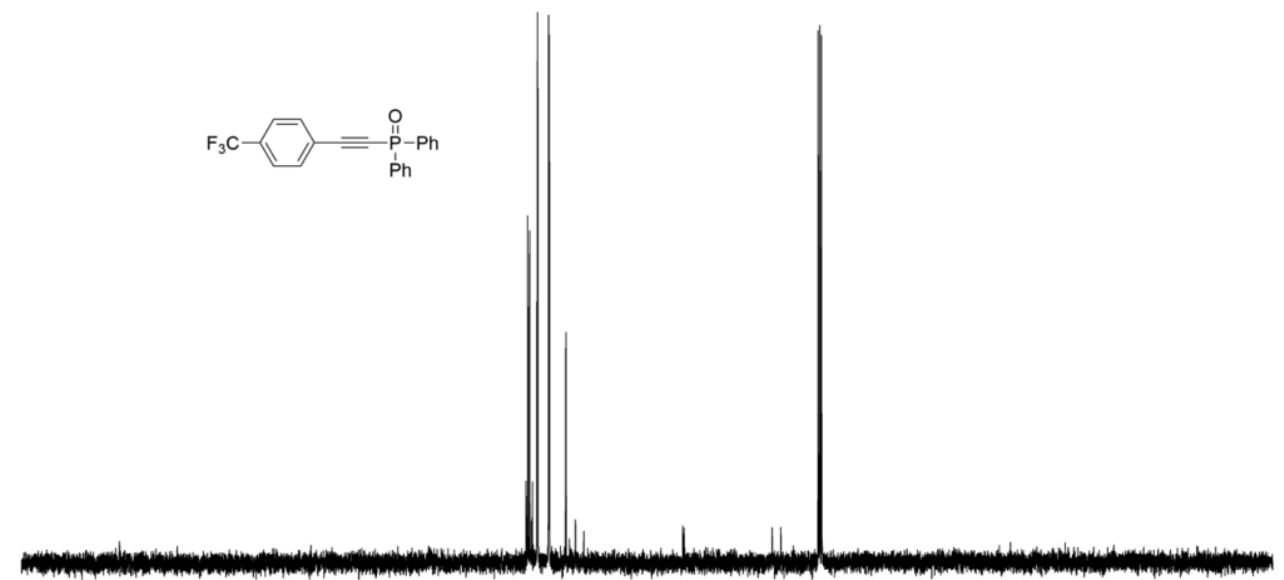

$\begin{array}{llllllllllllllllllllllll}220 & 210 & 200 & 190 & 180 & 170 & 160 & 150 & 140 & 130 & 120 & 110 & 100 & 90 & 80 & 70 & 60 & 50 & 40 & 30 & 20 & 10 & 0 & \mathrm{ppm}\end{array}$

${ }^{13} \mathrm{C}$ NMR (400 MHz) spectrum of compound $\mathbf{1 h}$ in $\mathrm{CDCl}_{3}$ 


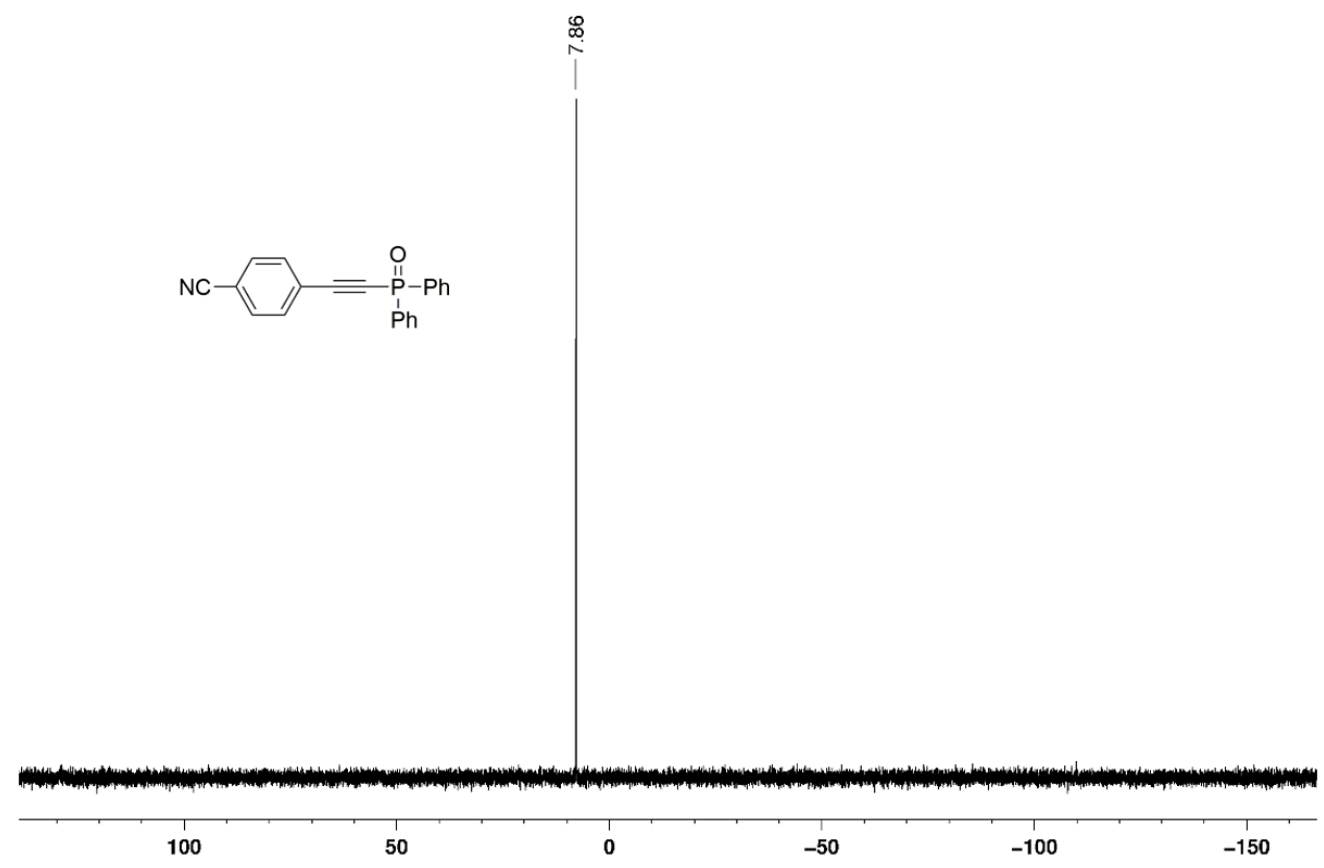

${ }^{31} \mathrm{P}$ NMR (400 MHz) spectrum of compound $\mathbf{1 i}$ in $\mathrm{CDCl}_{3}$

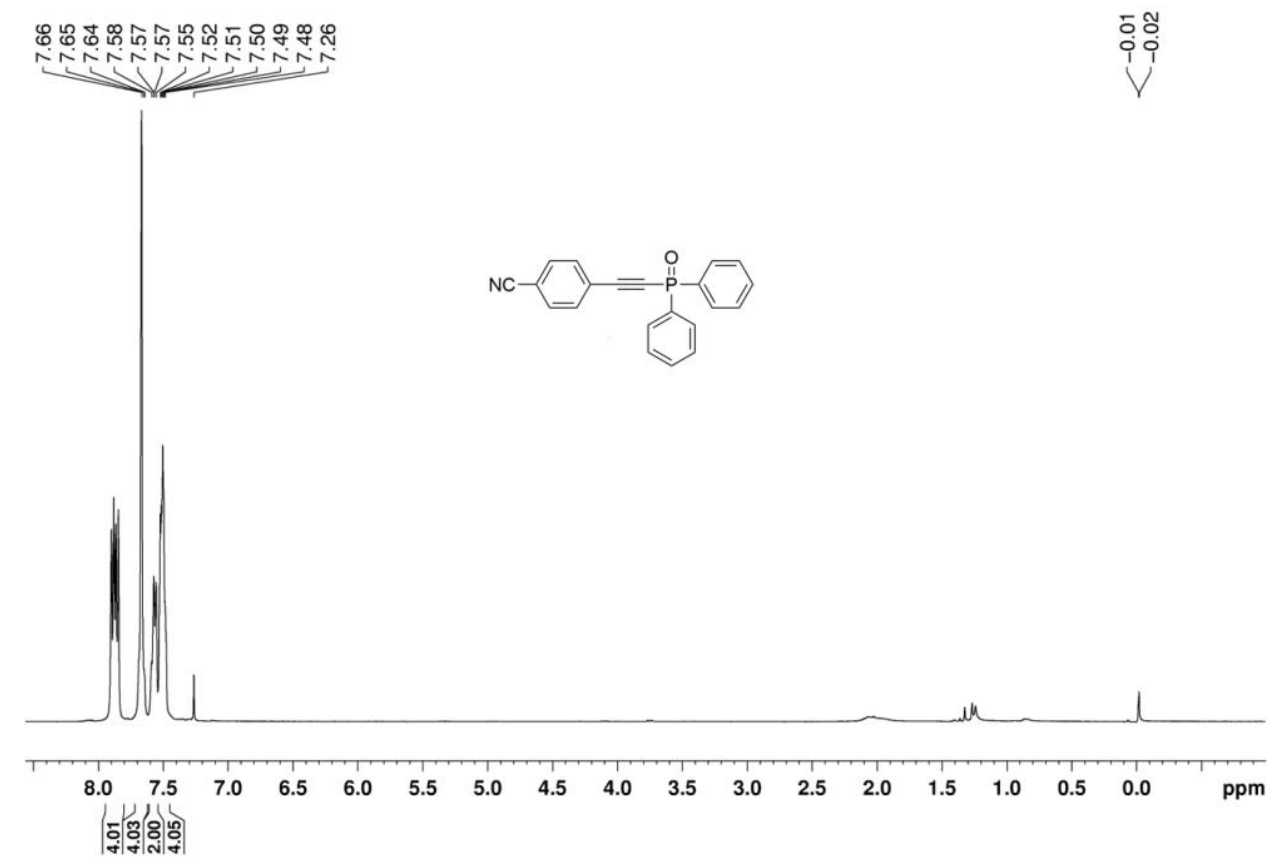

${ }^{1} \mathrm{H}$ NMR (400 MHz) spectrum of compound $\mathbf{1 i}$ in $\mathrm{CDCl}_{3}$ 


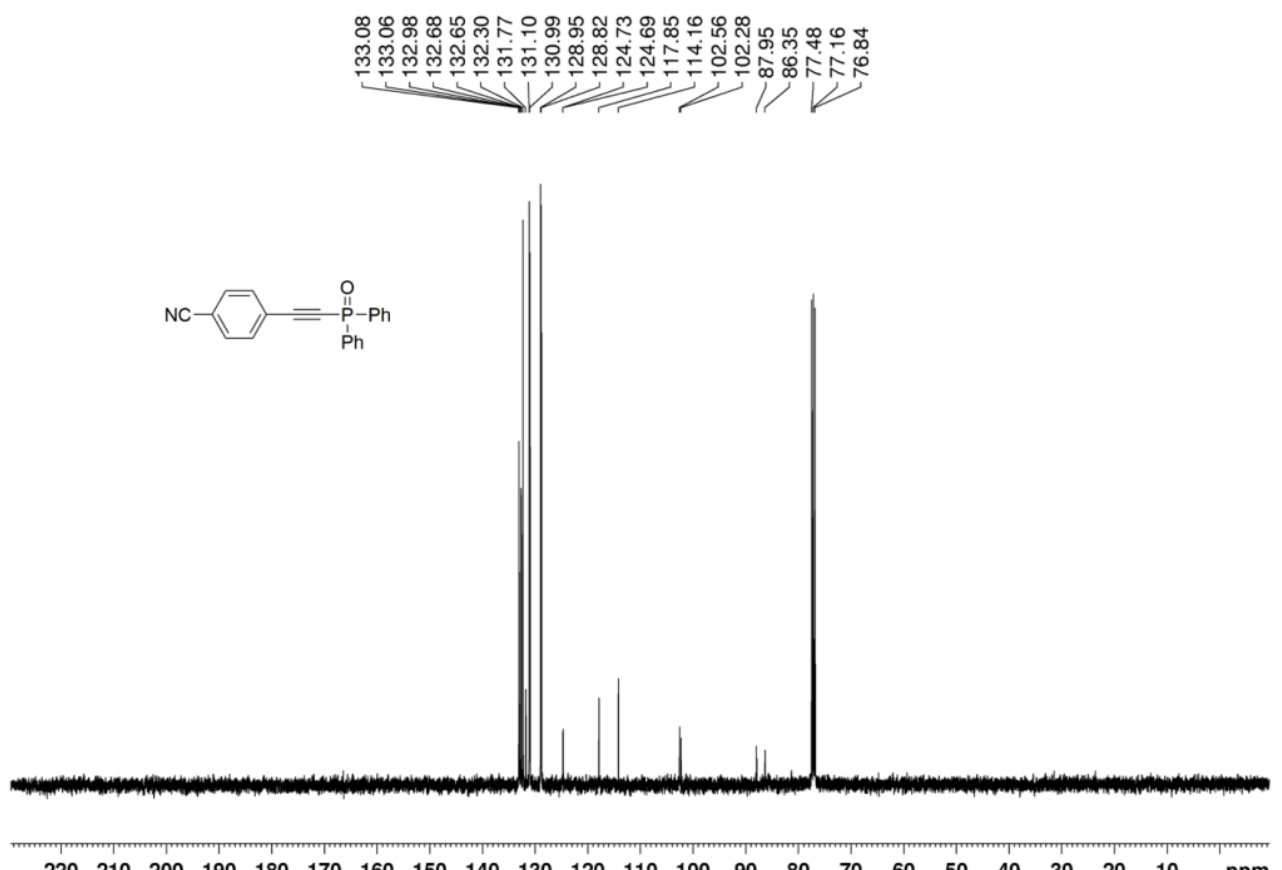

${ }^{13} \mathrm{C}$ NMR (400 MHz) spectrum of compound $\mathbf{1 i}$ in $\mathrm{CDCl}_{3}$

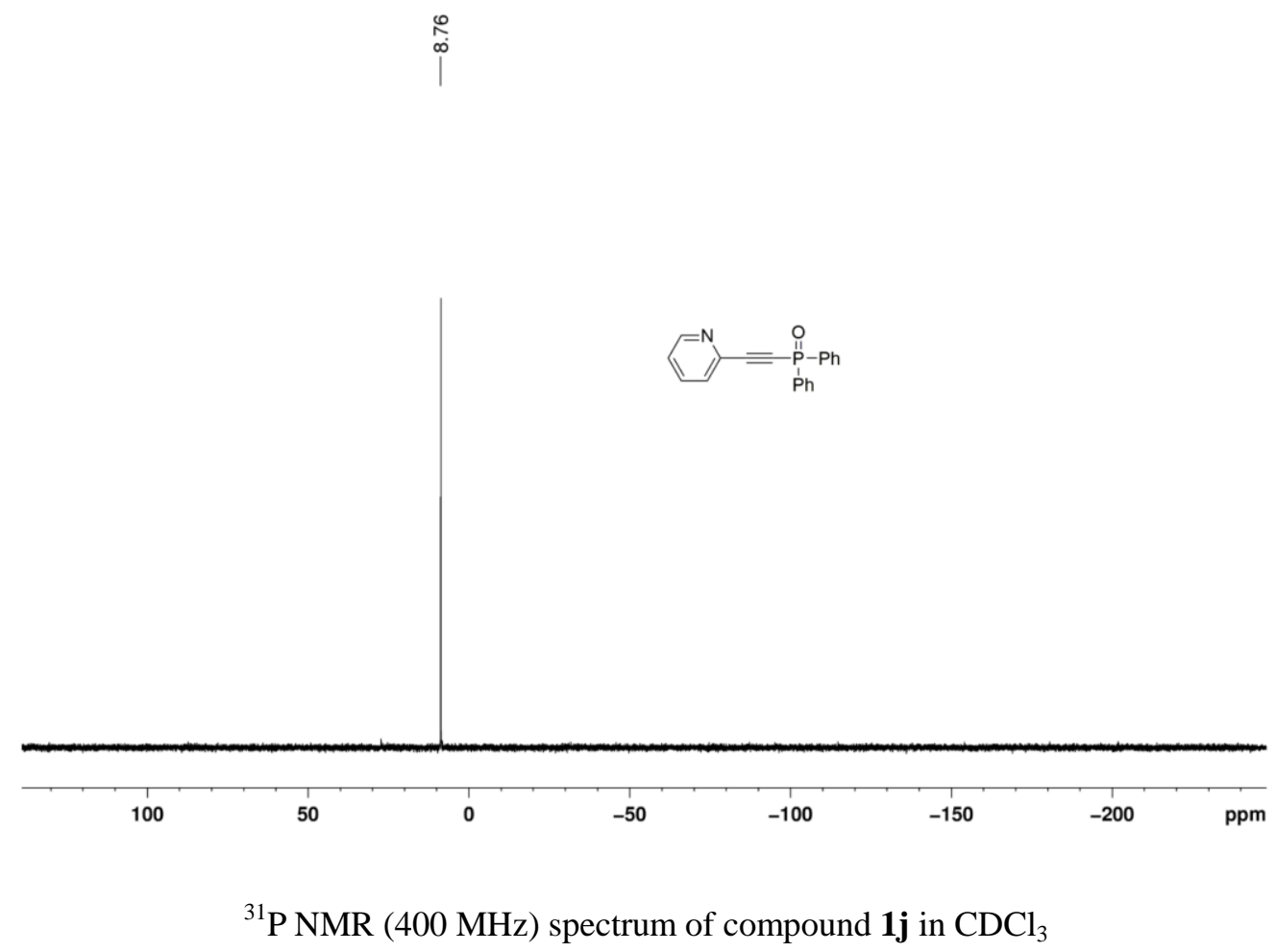




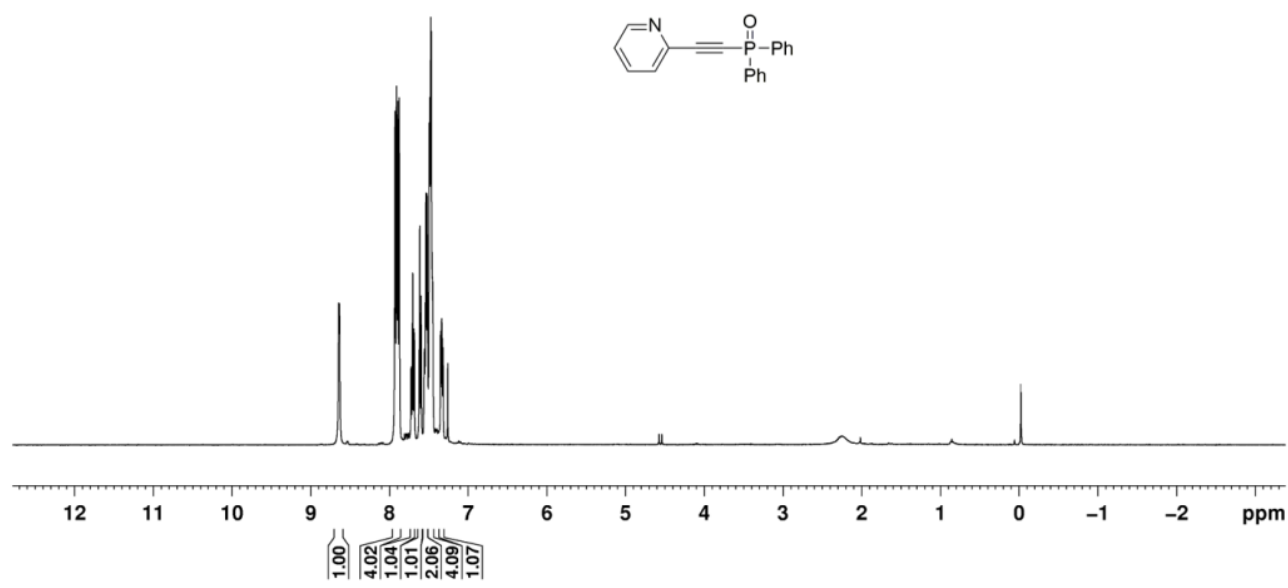

${ }^{1} \mathrm{H}$ NMR (400 MHz) spectrum of compound $\mathbf{1 j}$ in $\mathrm{CDCl}_{3}$

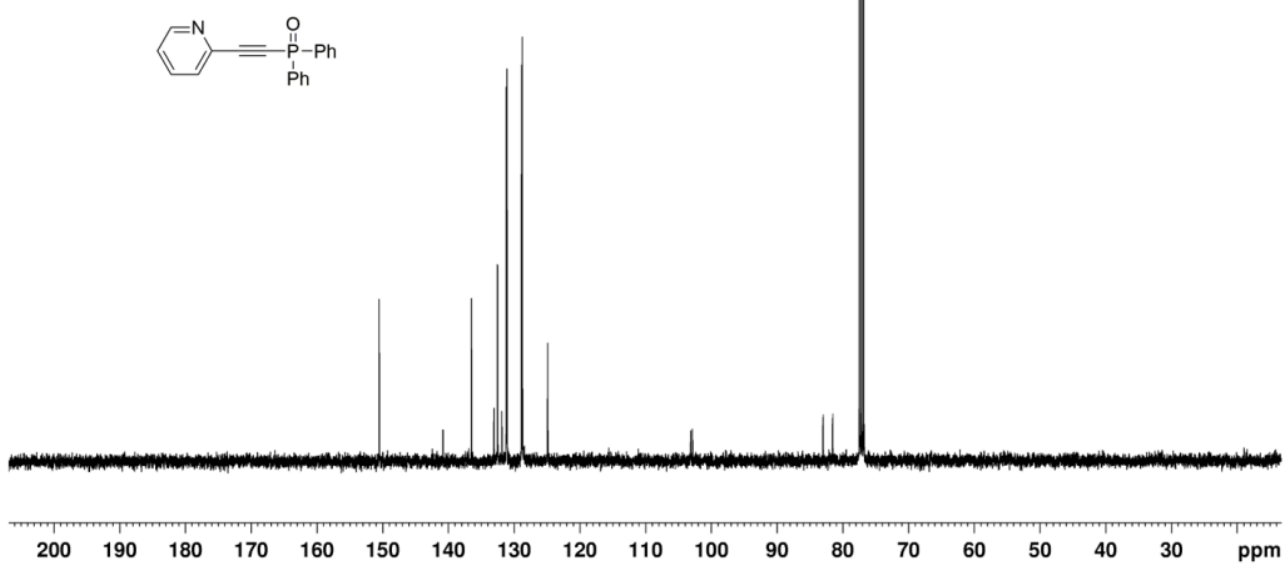

${ }^{13} \mathrm{C}$ NMR (400 MHz) spectrum of compound $\mathbf{1} \mathbf{j}$ in $\mathrm{CDCl}_{3}$ 


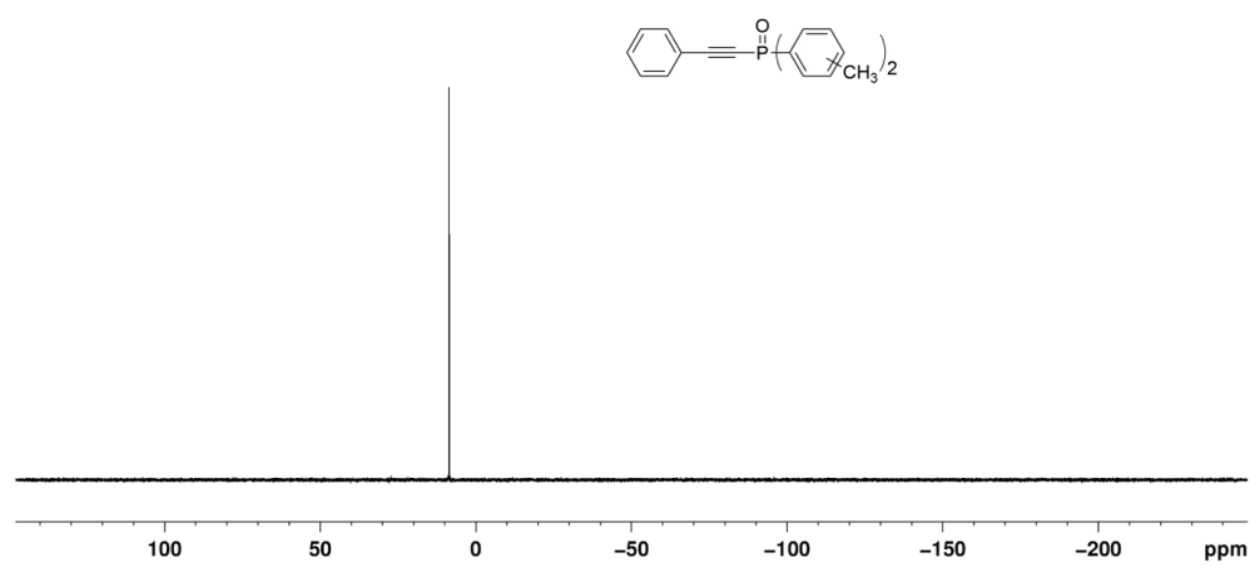

${ }^{31} \mathrm{P}$ NMR (400 MHz) spectrum of compound $\mathbf{1 k}$ in $\mathrm{CDCl}_{3}$

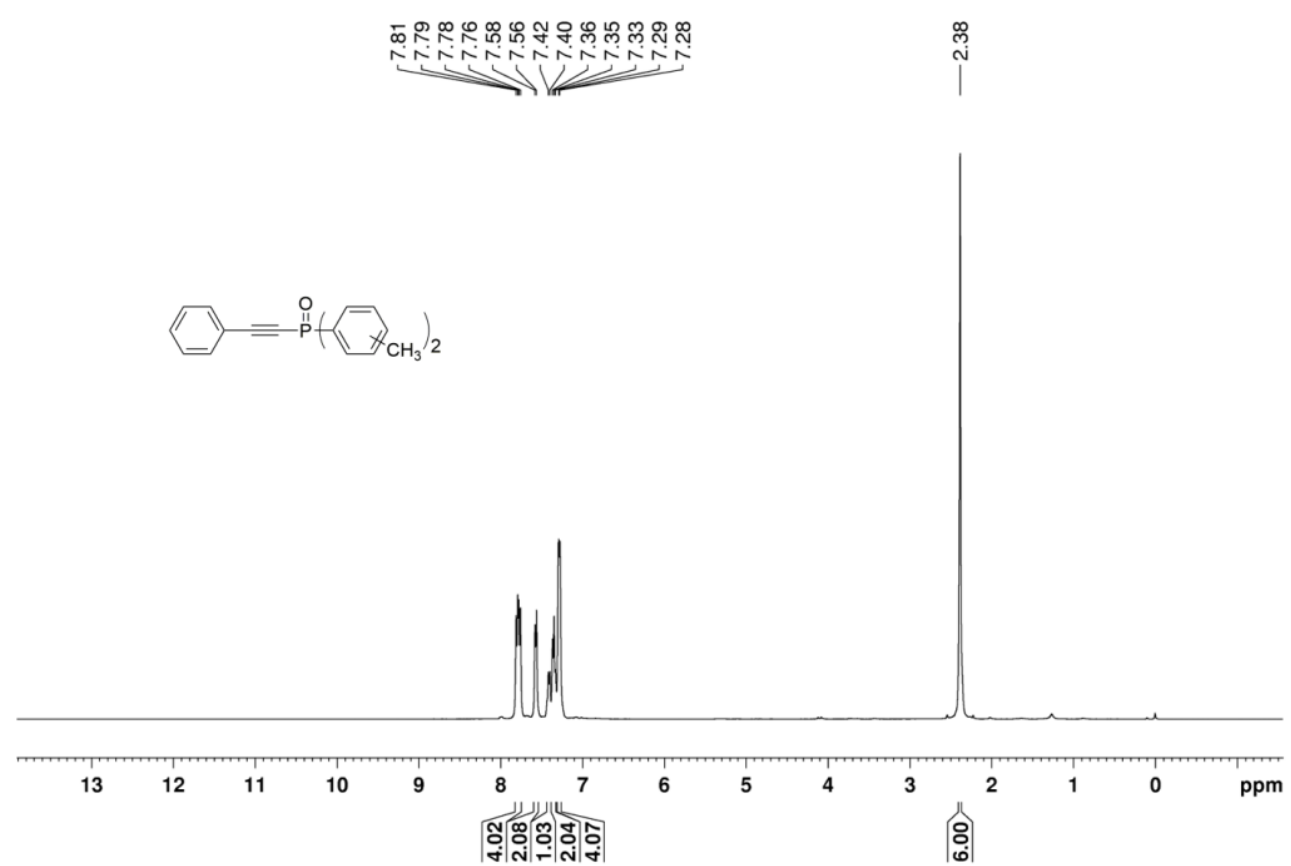

${ }^{1} \mathrm{H}$ NMR (400 MHz) spectrum of compound $\mathbf{1 k}$ in $\mathrm{CDCl}_{3}$ 


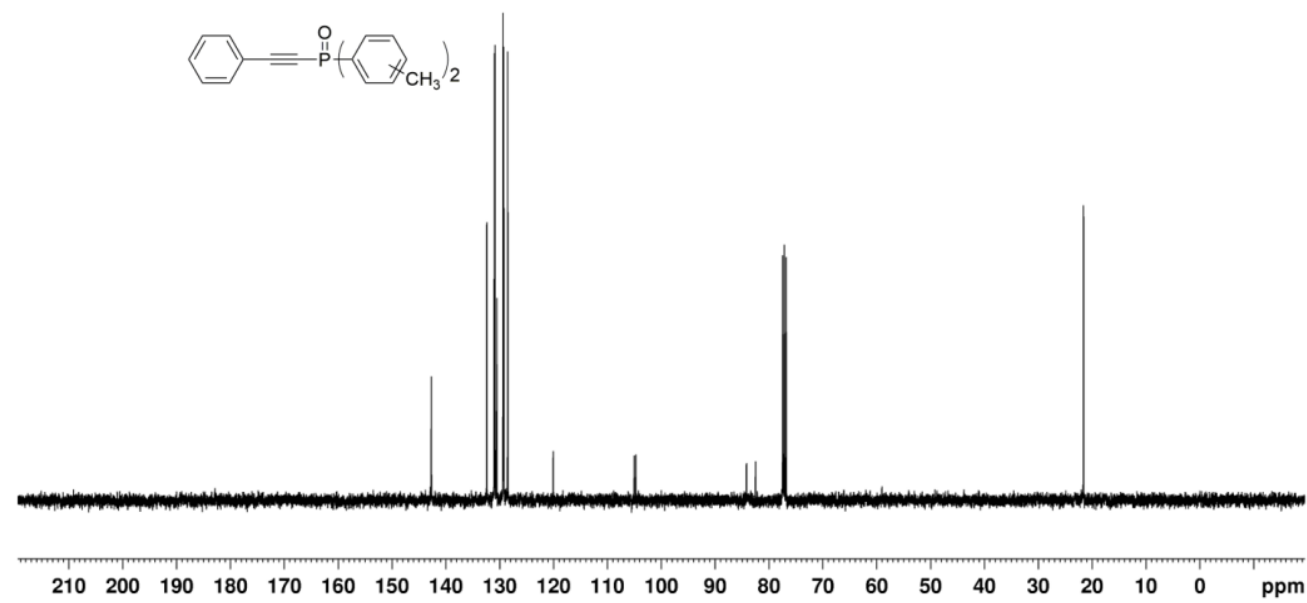

${ }^{13} \mathrm{C}$ NMR (400 MHz) spectrum of compound $\mathbf{1} \mathbf{k}$ in $\mathrm{CDCl}_{3}$

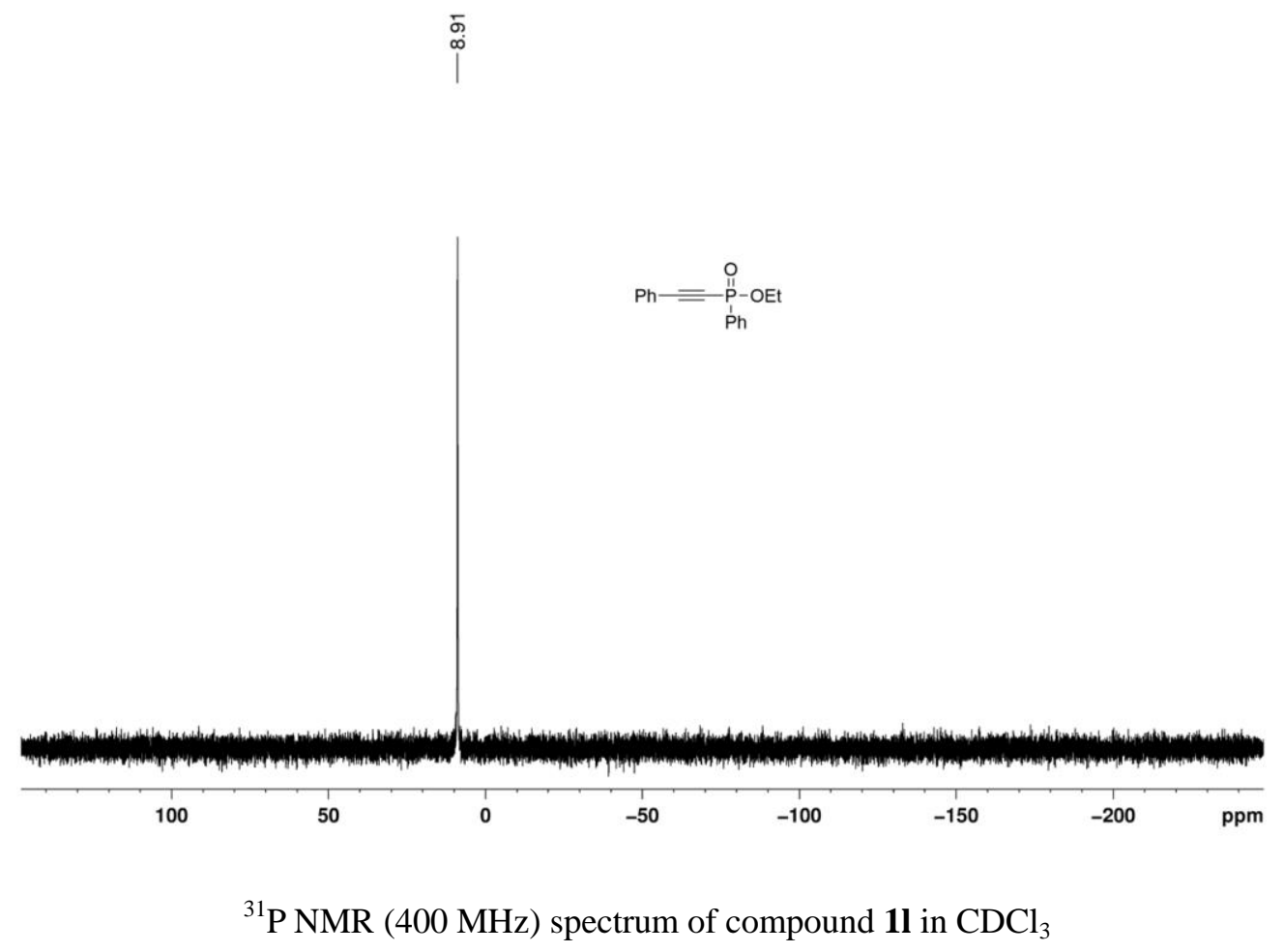




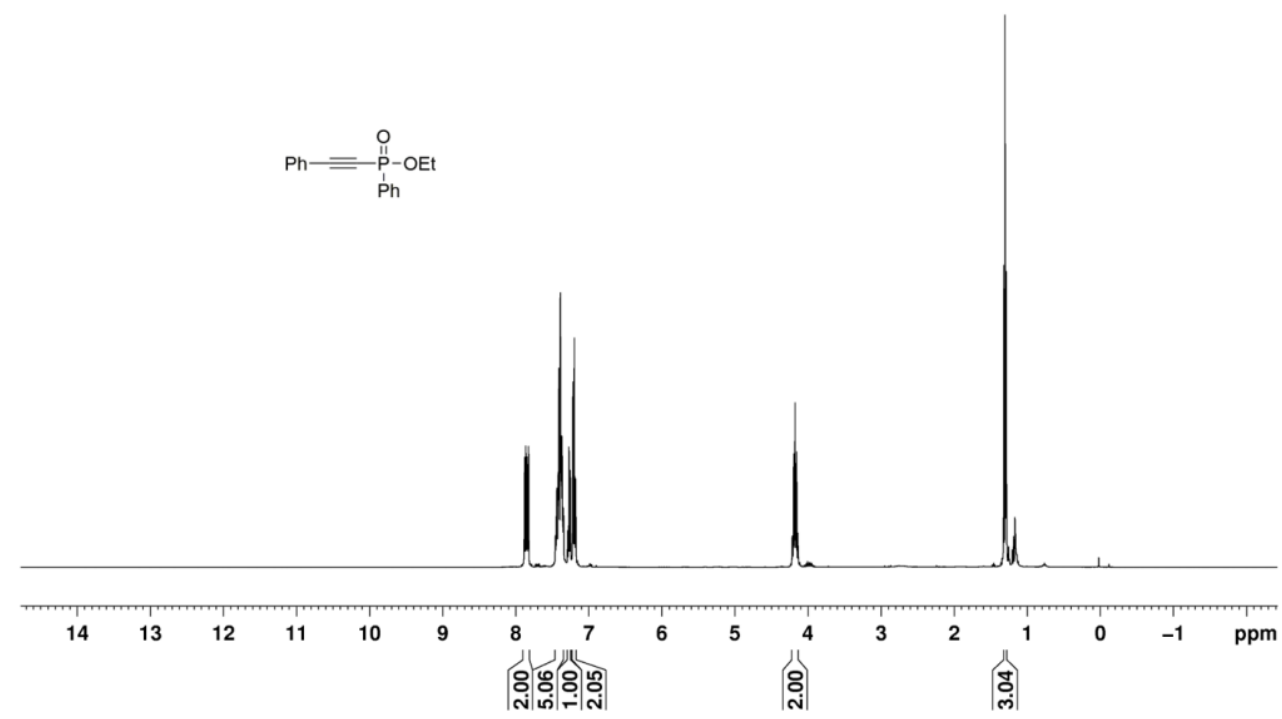

${ }^{1} \mathrm{H}$ NMR (400 MHz) spectrum of compound 11 in $\mathrm{CDCl}_{3}$

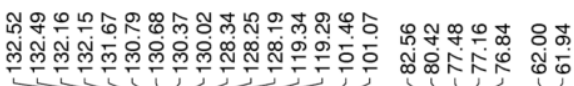

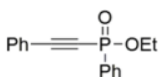

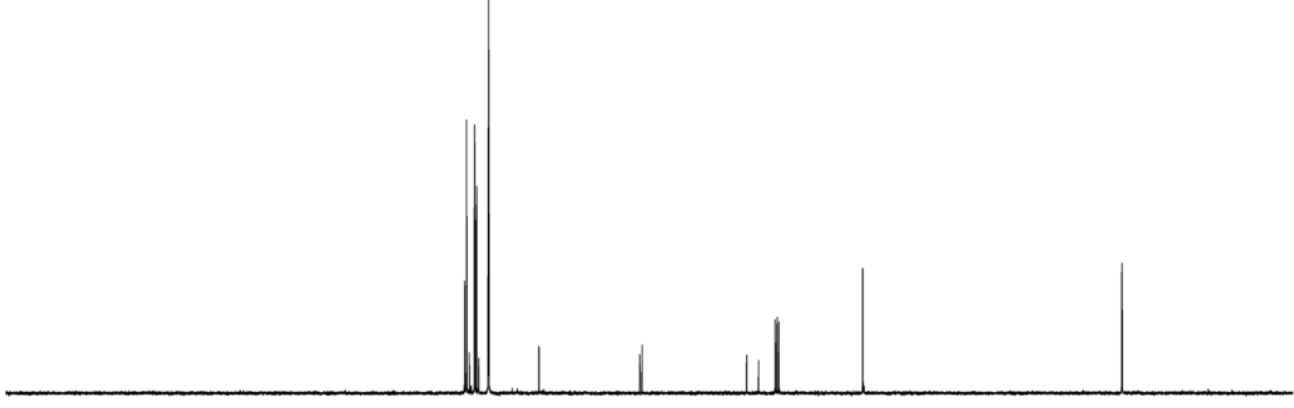

$\begin{array}{lllllllllllllllllllllll}210 & 200 & 190 & 180 & 170 & 160 & 150 & 140 & 130 & 120 & 110 & 100 & 90 & 80 & 70 & 60 & 50 & 40 & 30 & 20 & 10 & 0 & \mathrm{ppm}\end{array}$

${ }^{13} \mathrm{C}$ NMR (400 MHz) spectrum of compound 11 in $\mathrm{CDCl}_{3}$ 


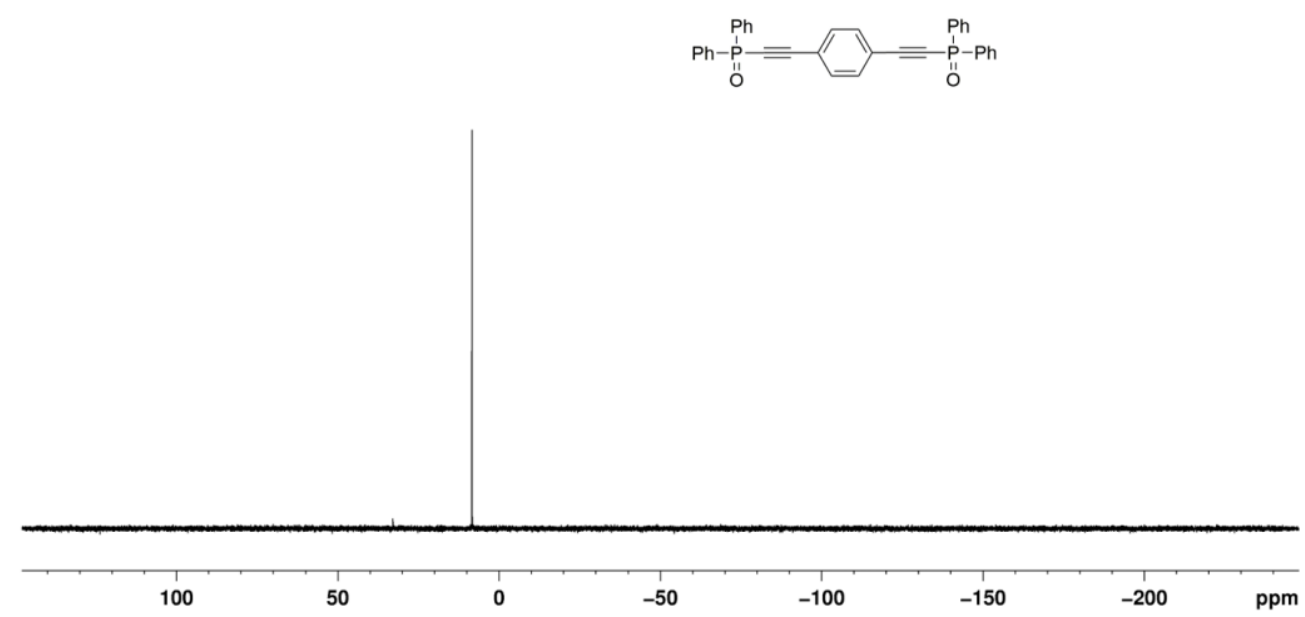

${ }^{31} \mathrm{P}$ NMR (400 MHz) spectrum of compound $\mathbf{1 m}$ in $\mathrm{CDCl}_{3}$

${ }^{1} \mathrm{H}$ NMR (400 MHz) spectrum of compound 11 in $\mathrm{CDCl}_{3}$

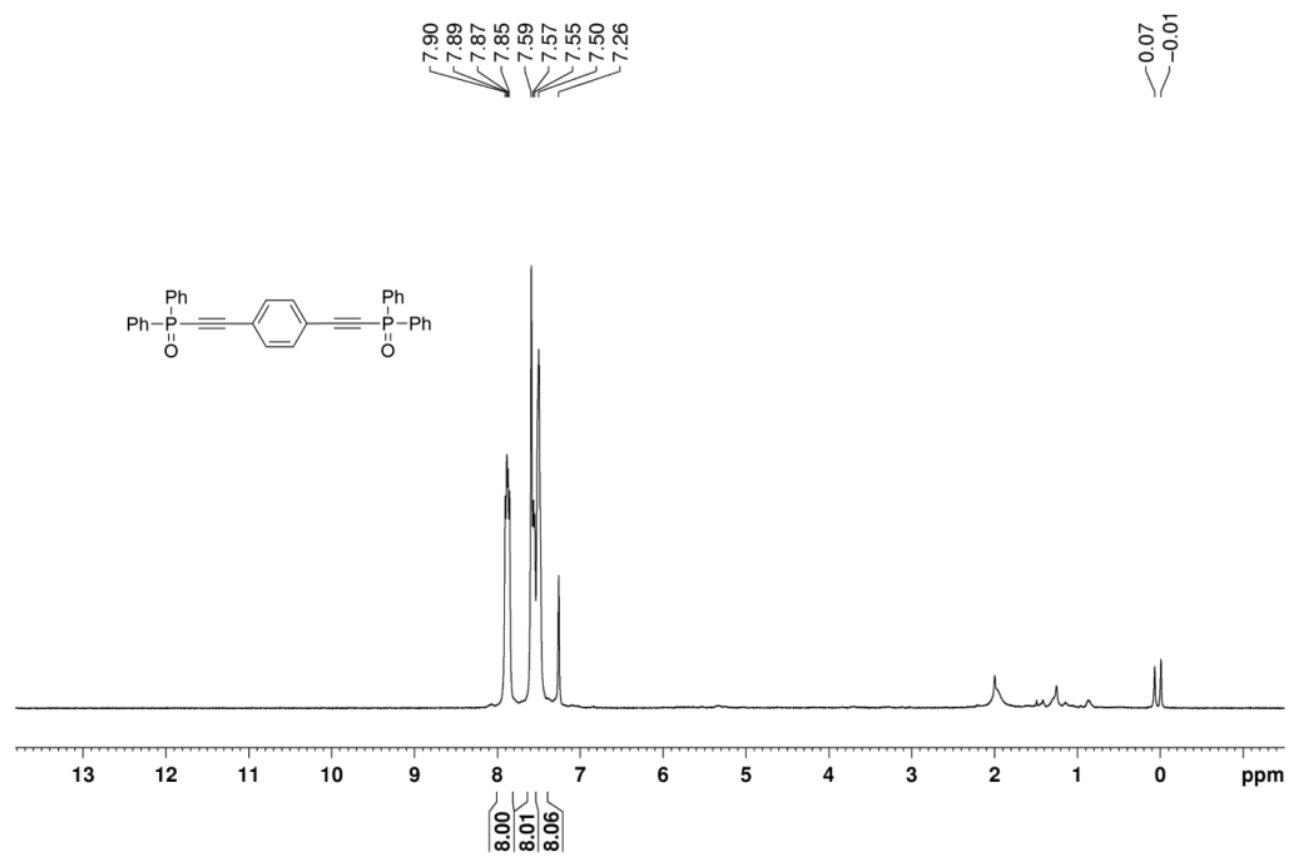

${ }^{1} \mathrm{H}$ NMR (400 MHz) spectrum of compound $\mathbf{1 m}$ in $\mathrm{CDCl}_{3}$ 


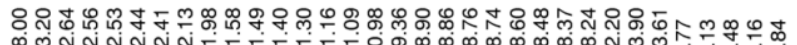

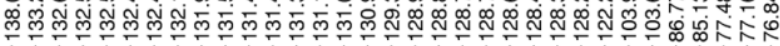

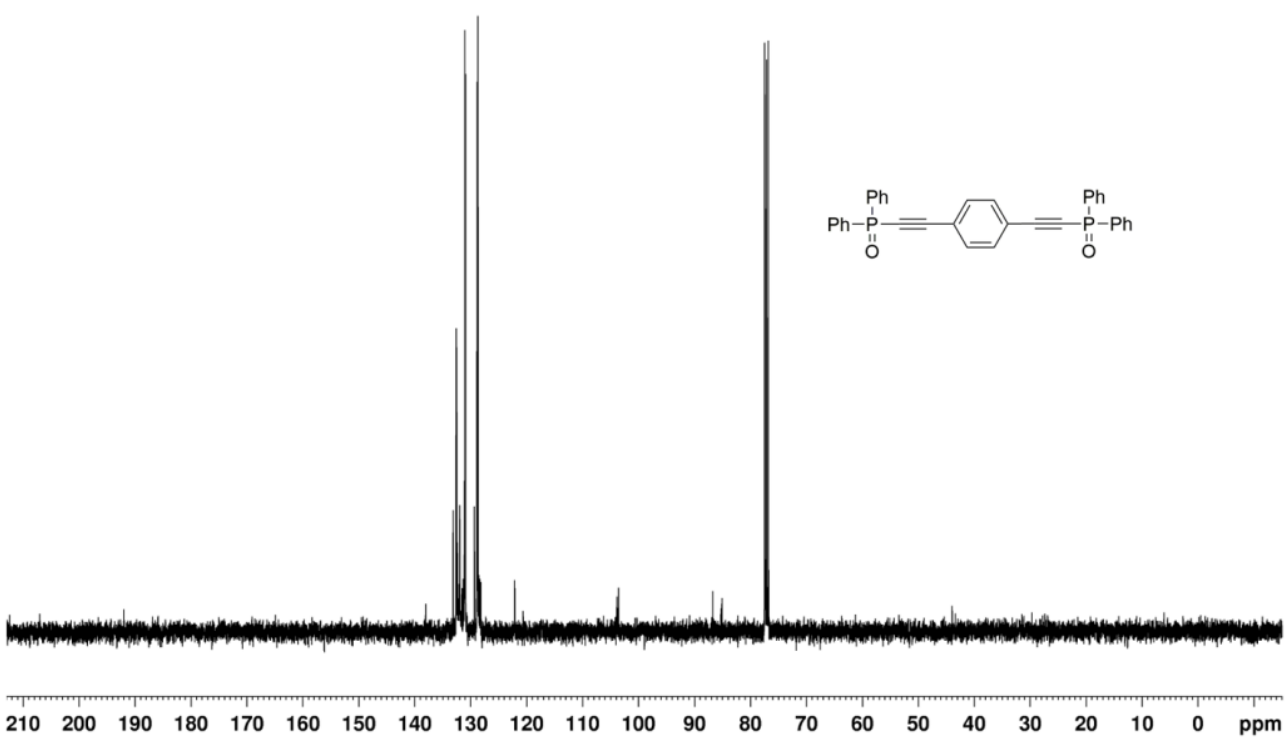

${ }^{13} \mathrm{C}$ NMR (400 MHz) spectrum of compound $\mathbf{1 m}$ in $\mathrm{CDCl}_{3}$ 
7. ${ }^{31} \mathrm{P}$ NMR, ${ }^{1} \mathrm{H}$ NMR, ${ }^{13} \mathrm{CNMR}$ Spectrum of Compounds 3a-3u, 4a-4k, 5a and $6 \mathrm{a}$

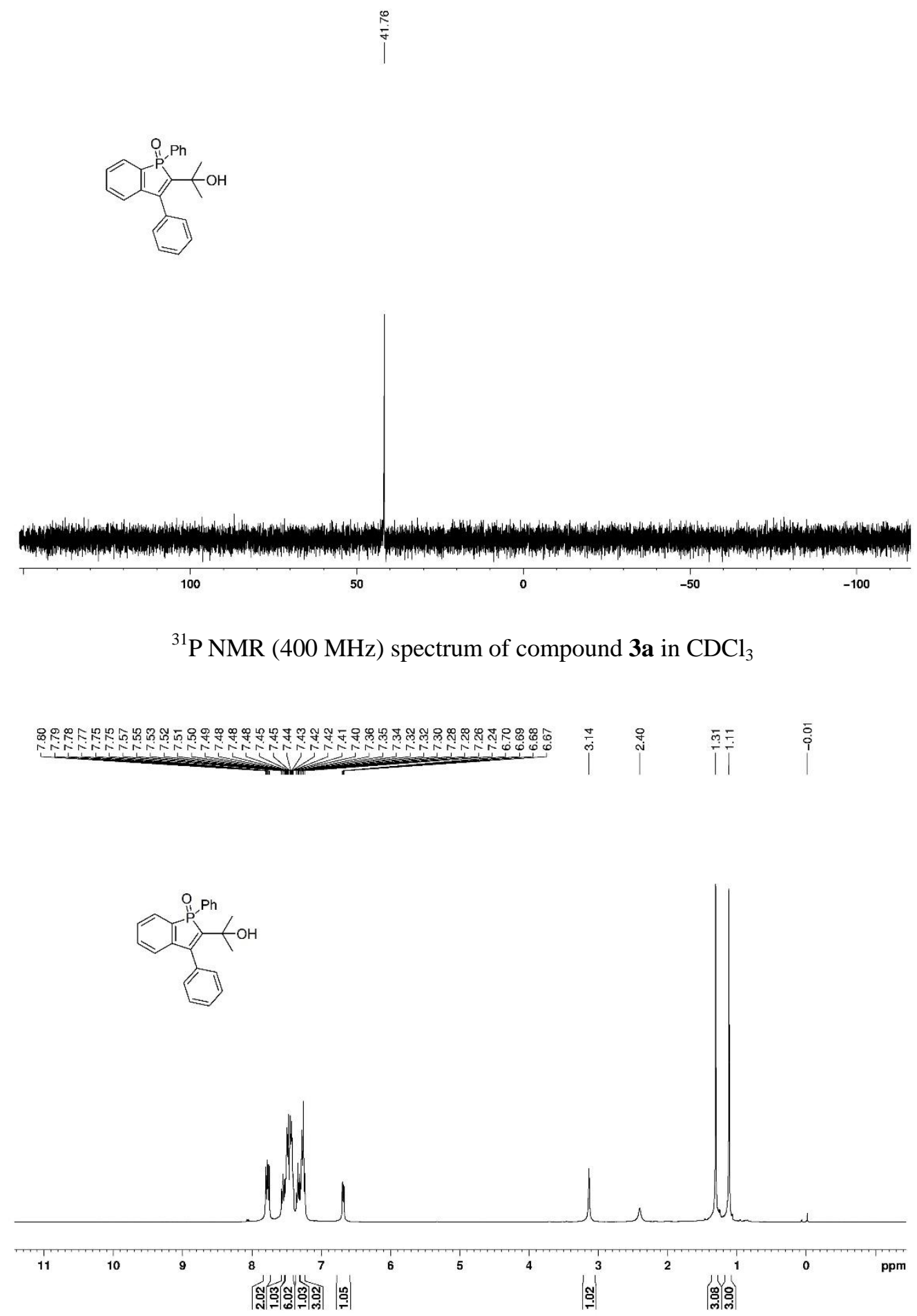

${ }^{1} \mathrm{H}$ NMR (400 MHz) spectrum of compound 3a in $\mathrm{CDCl}_{3}$ 


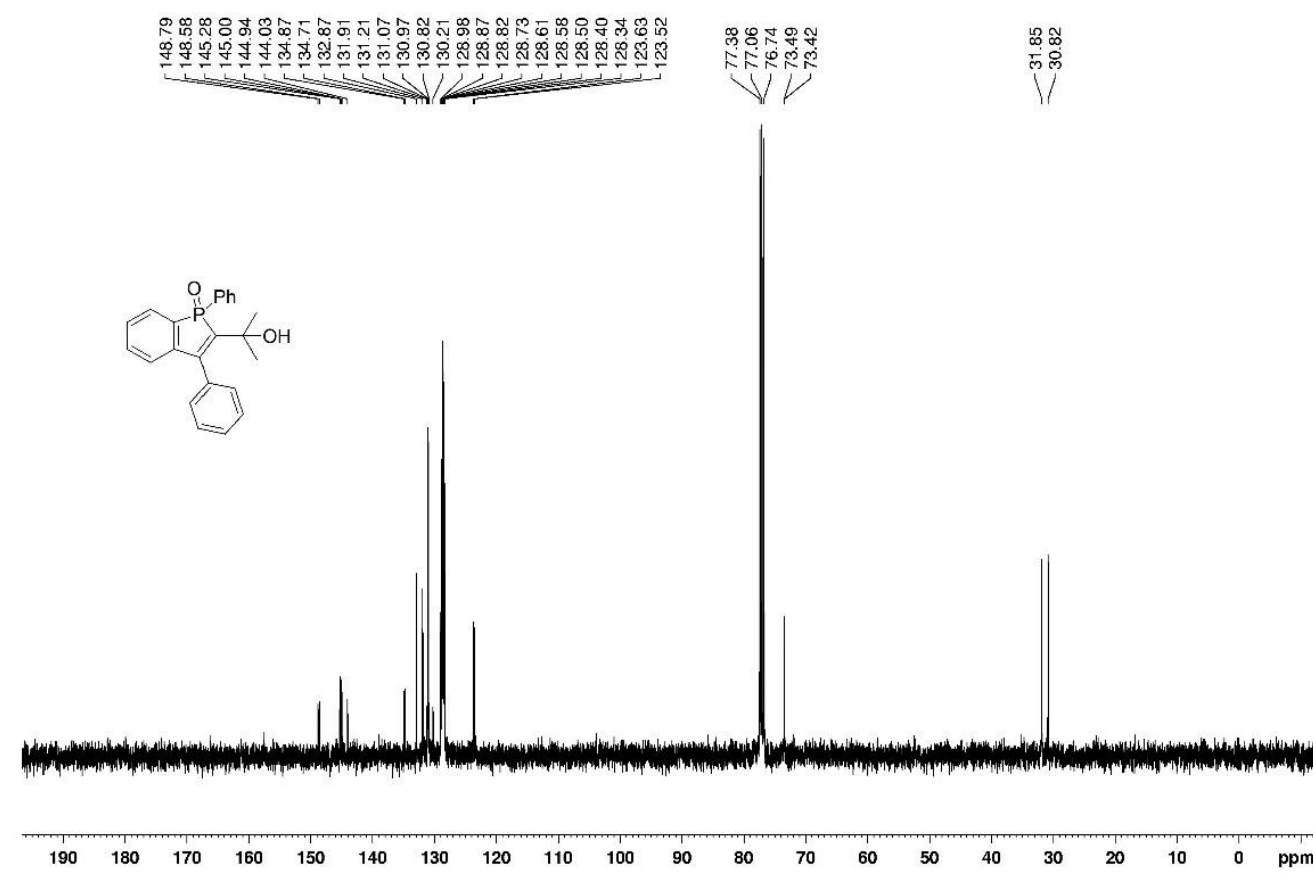

${ }^{13} \mathrm{C}$ NMR (400 MHz) spectrum of compound $\mathbf{3 a}$ in $\mathrm{CDCl}_{3}$
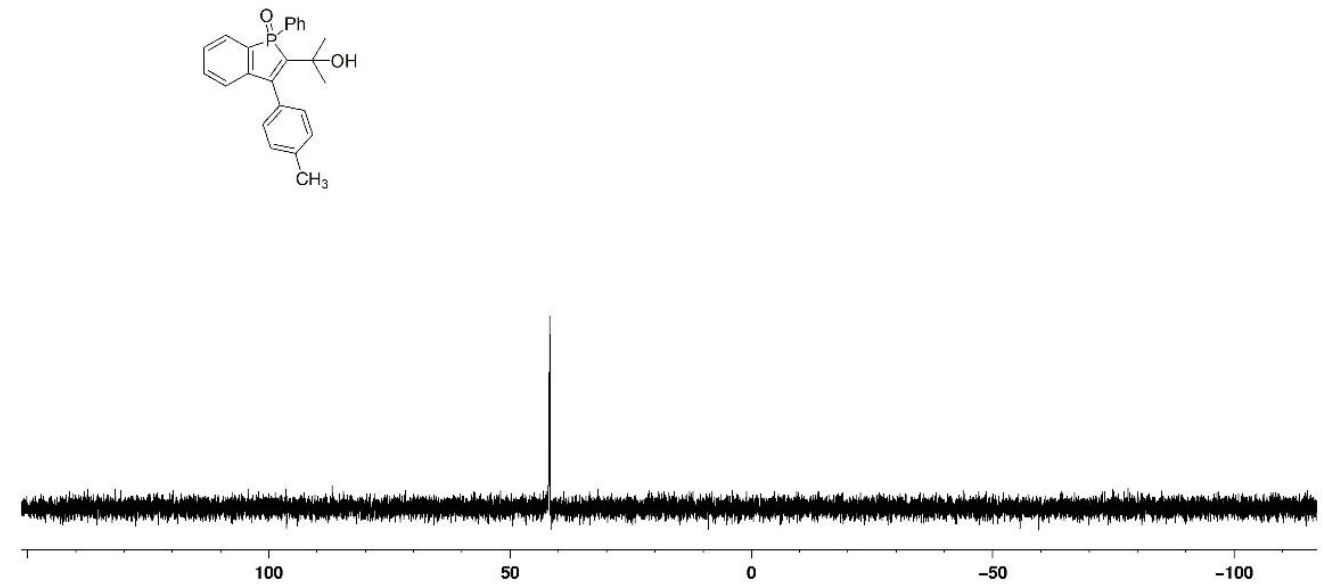

${ }^{31} \mathrm{P}$ NMR (500 MHz) spectrum of compound $\mathbf{3 b}$ in $\mathrm{CDCl}_{3}$ 


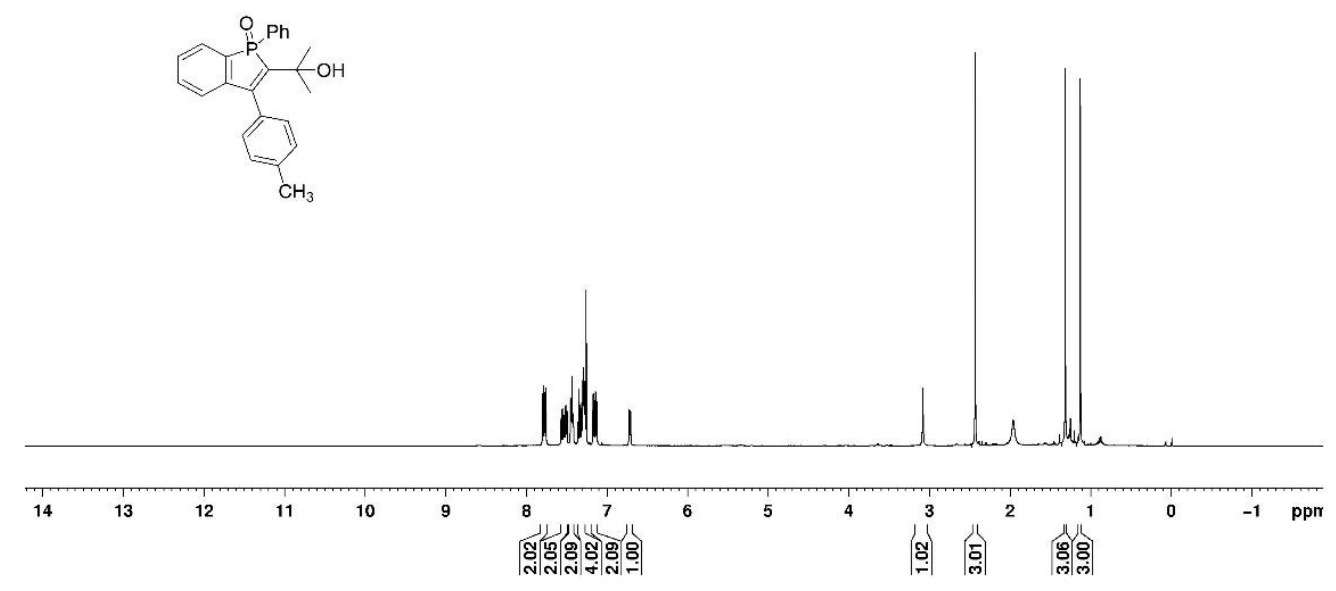

${ }^{1} \mathrm{H}$ NMR (500 MHz) spectrum of compound $\mathbf{3 b}$ in $\mathrm{CDCl}_{3}$

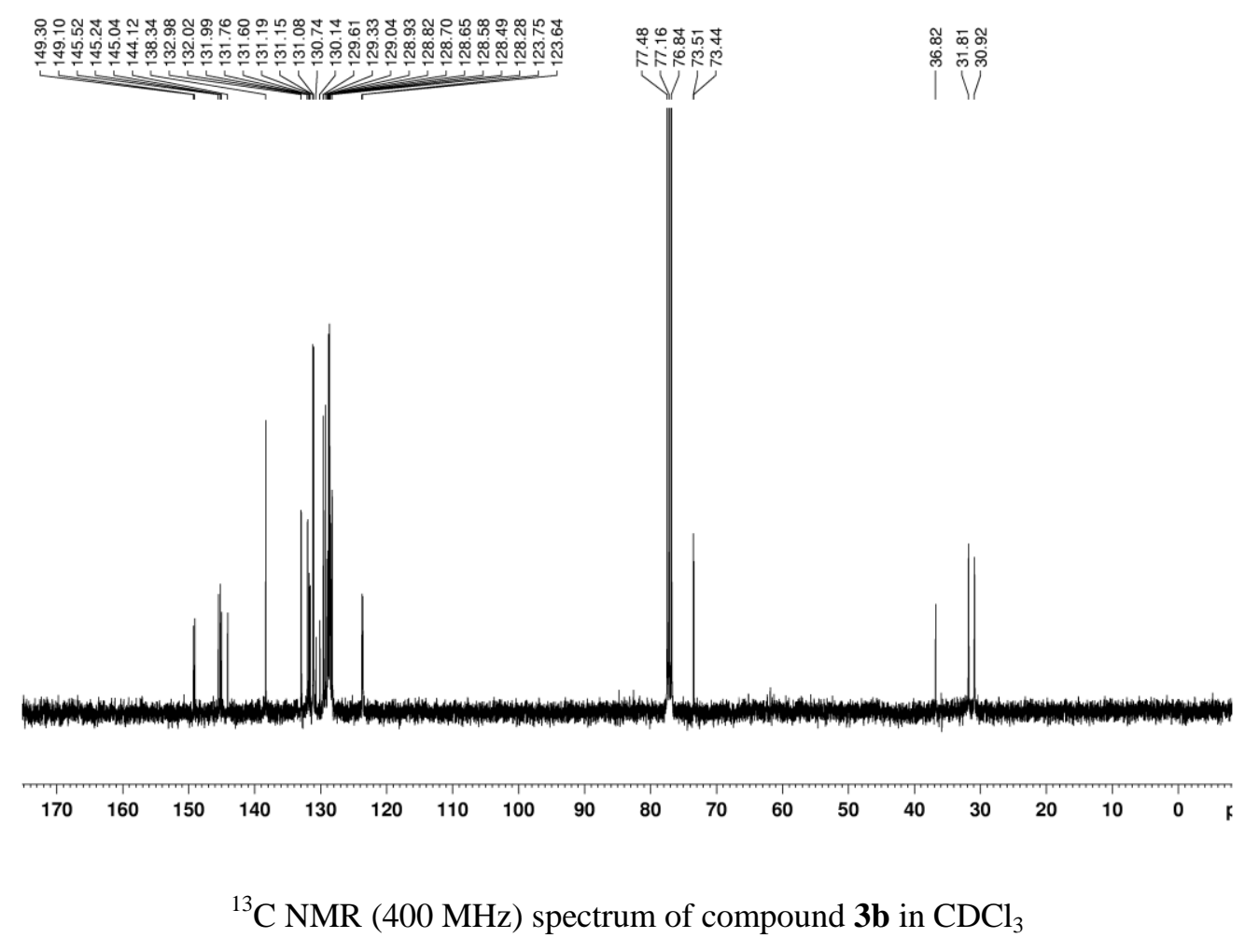




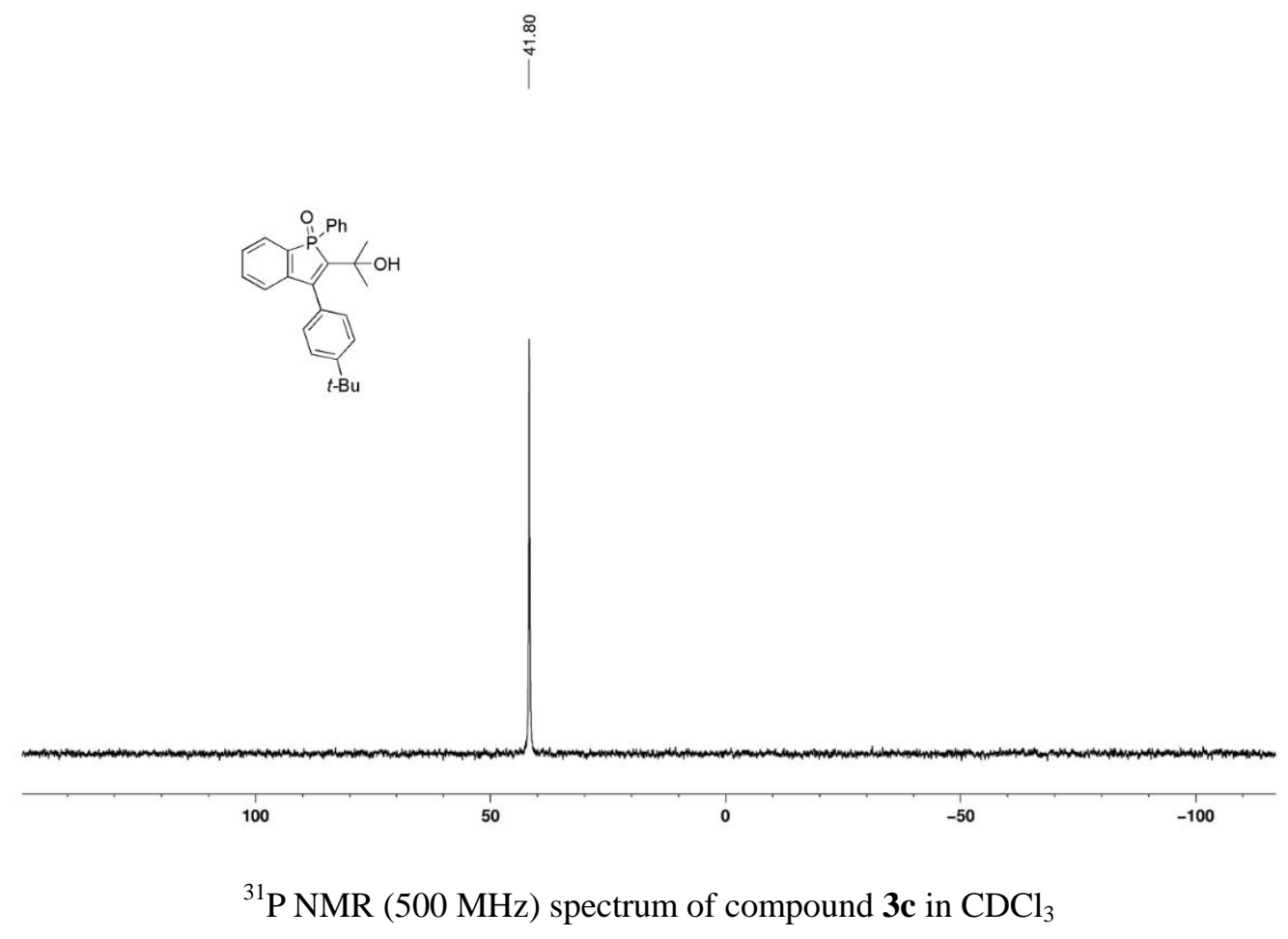

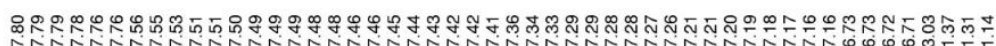

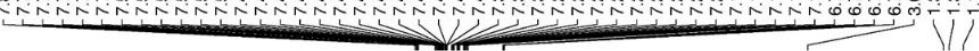<smiles>CC(C)OP(=O)(c1ccccc1)C(c1ccccc1)c1ccc(Br)cc1</smiles>
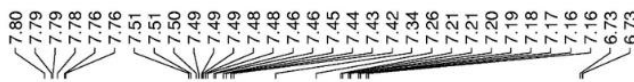

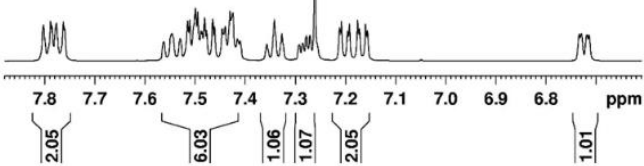

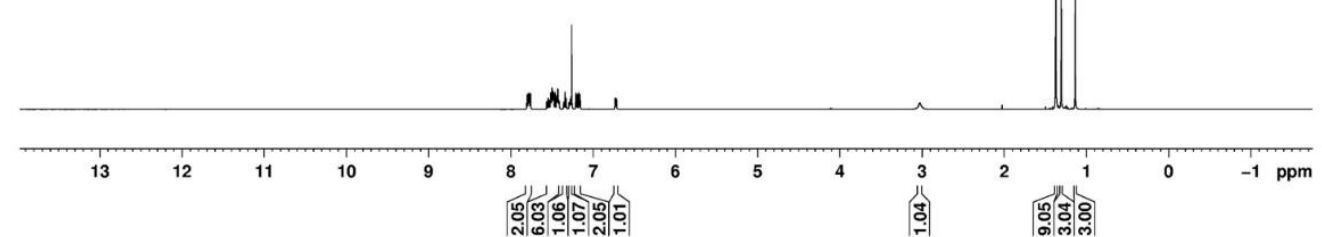

${ }^{1} \mathrm{H}$ NMR (500 MHz) spectrum of compound $\mathbf{3 c}$ in $\mathrm{CDCl}_{3}$ 


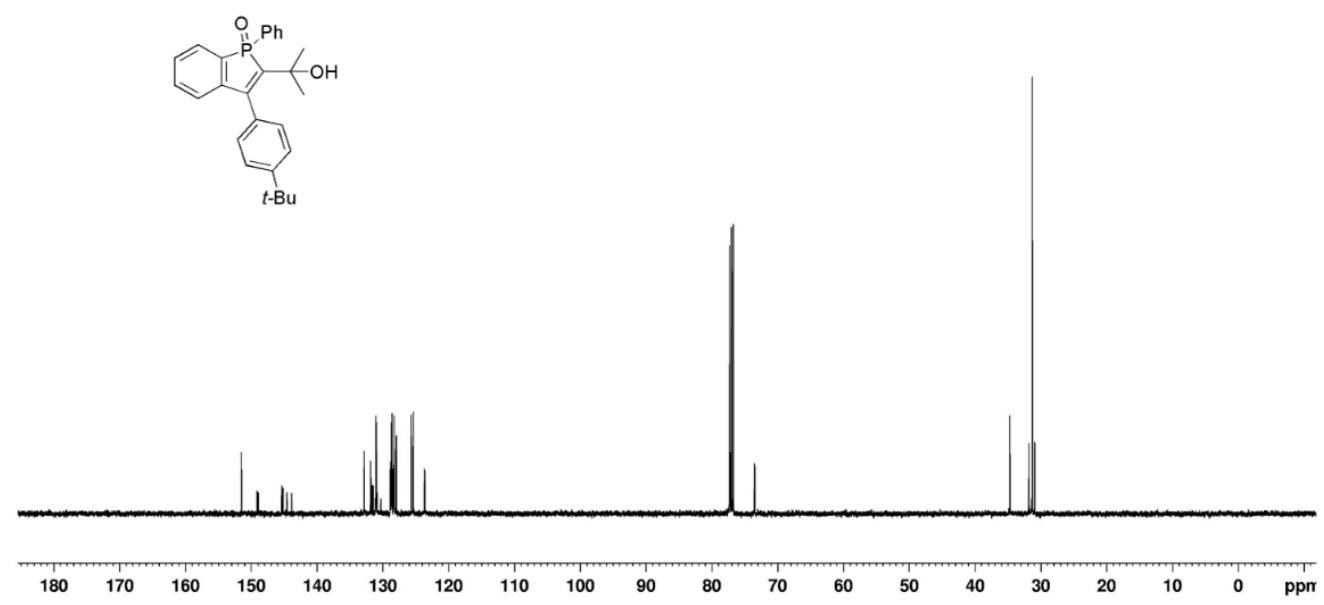

${ }^{13} \mathrm{C}$ NMR (500 MHz) spectrum of compound $\mathbf{3 c}$ in $\mathrm{CDCl}_{3}$

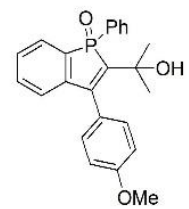

$$
\frac{\stackrel{R}{+}}{1}
$$

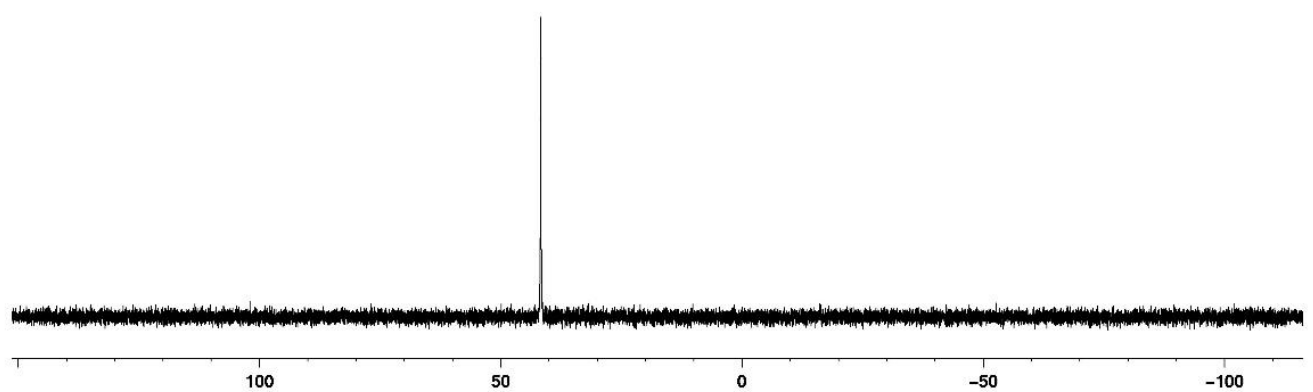

${ }^{31} \mathrm{P}$ NMR (500 MHz) spectrum of compound $\mathbf{3 d}$ in $\mathrm{CDCl}_{3}$ 


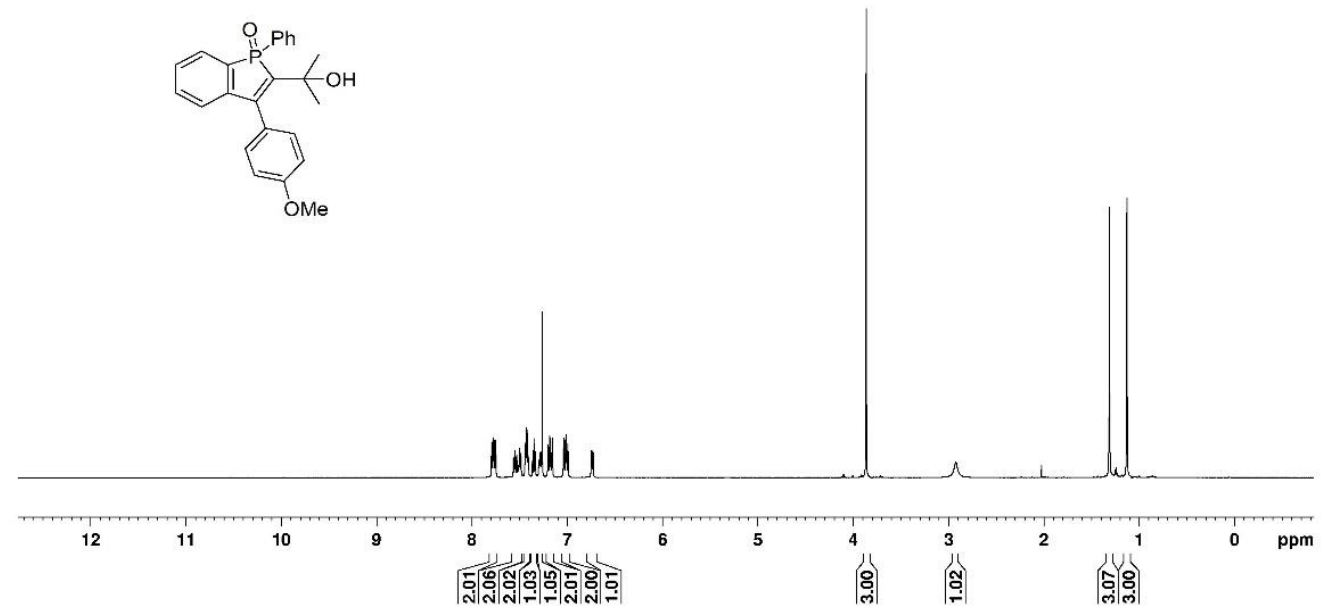

${ }^{1} \mathrm{H}$ NMR (500 MHz) spectrum of compound $\mathbf{3 d}$ in $\mathrm{CDCl}_{3}$

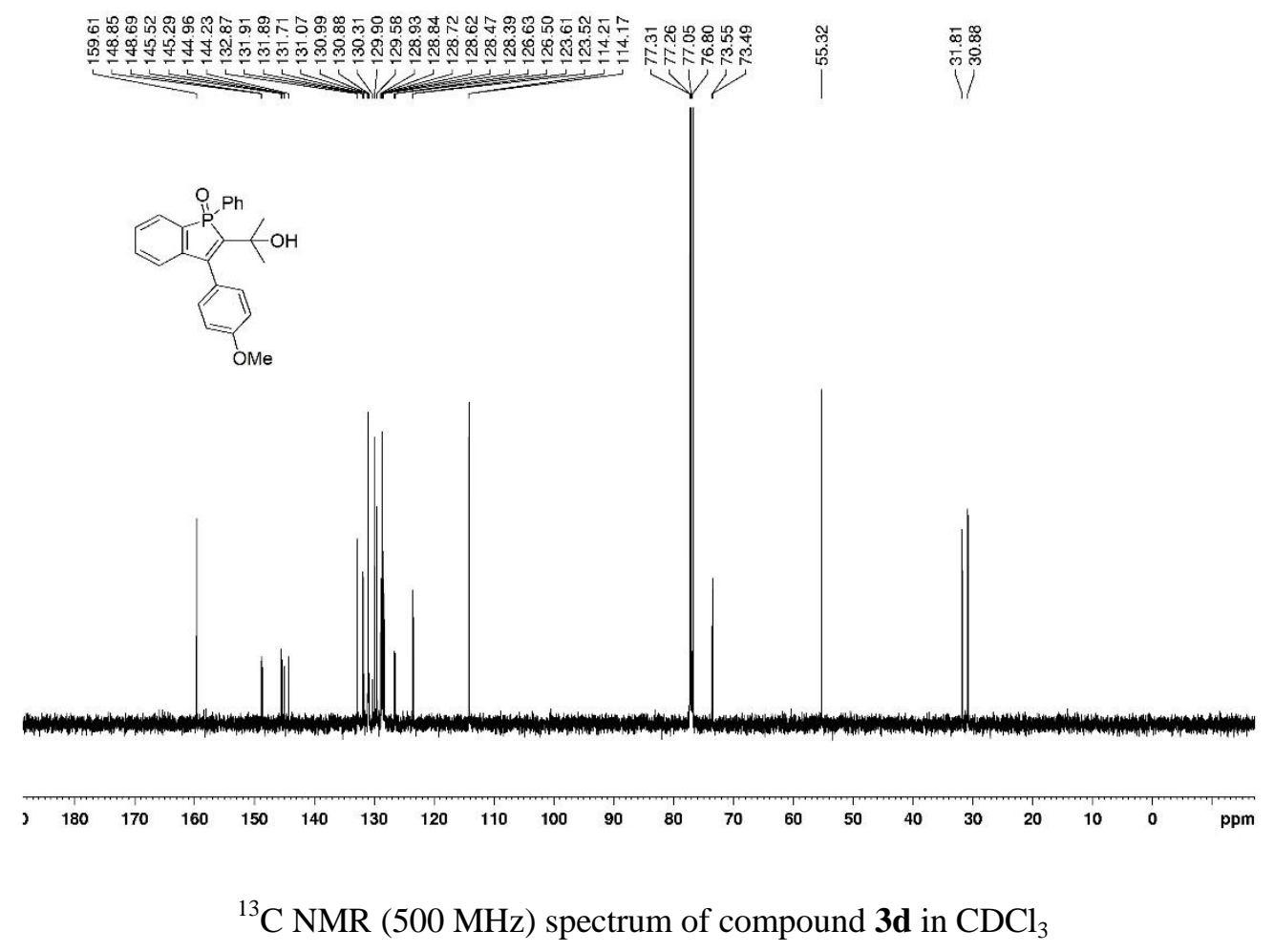




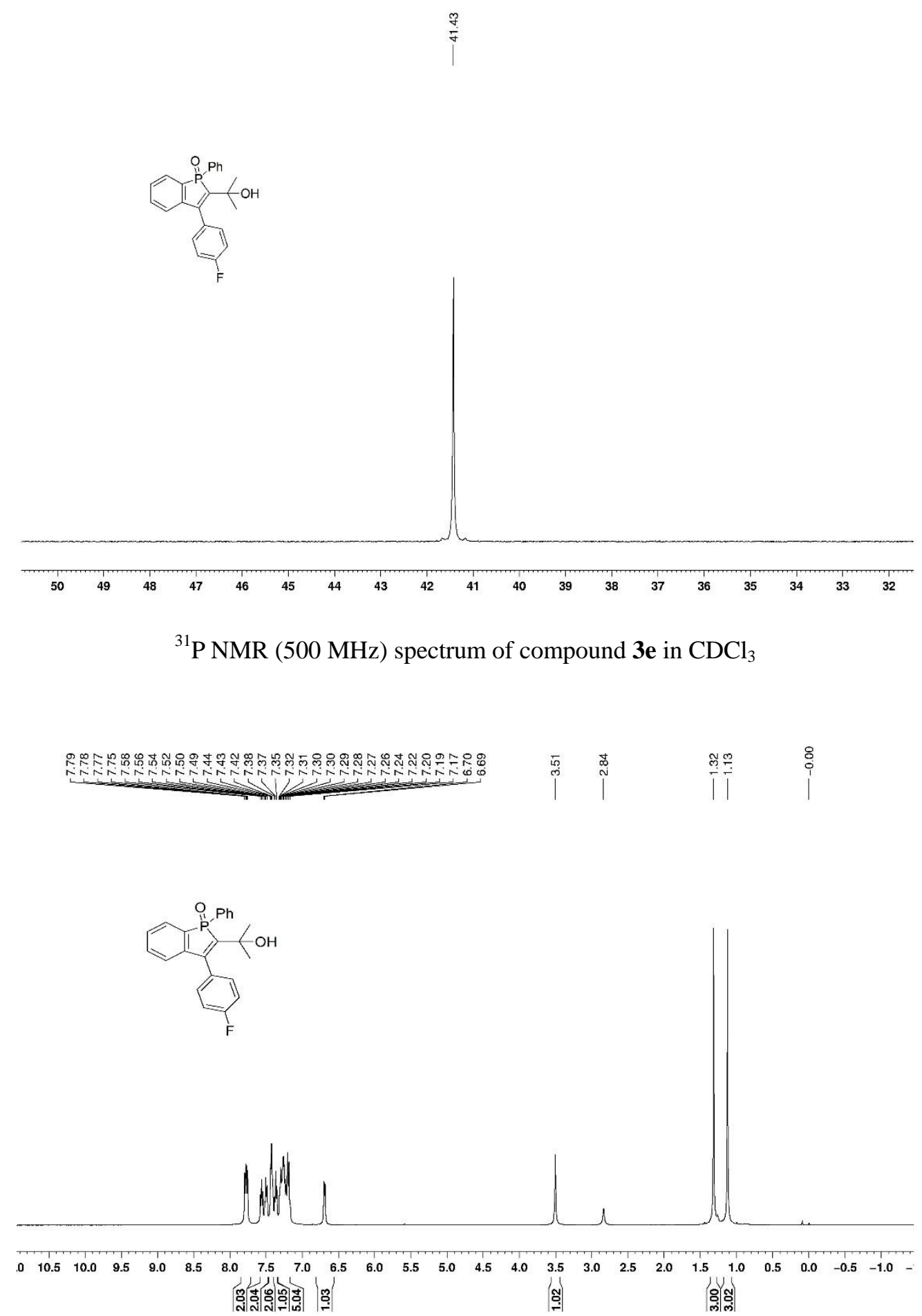

${ }^{1} \mathrm{H}$ NMR (500 MHz) spectrum of compound $\mathbf{3 e}$ in $\mathrm{CDCl}_{3}$ 


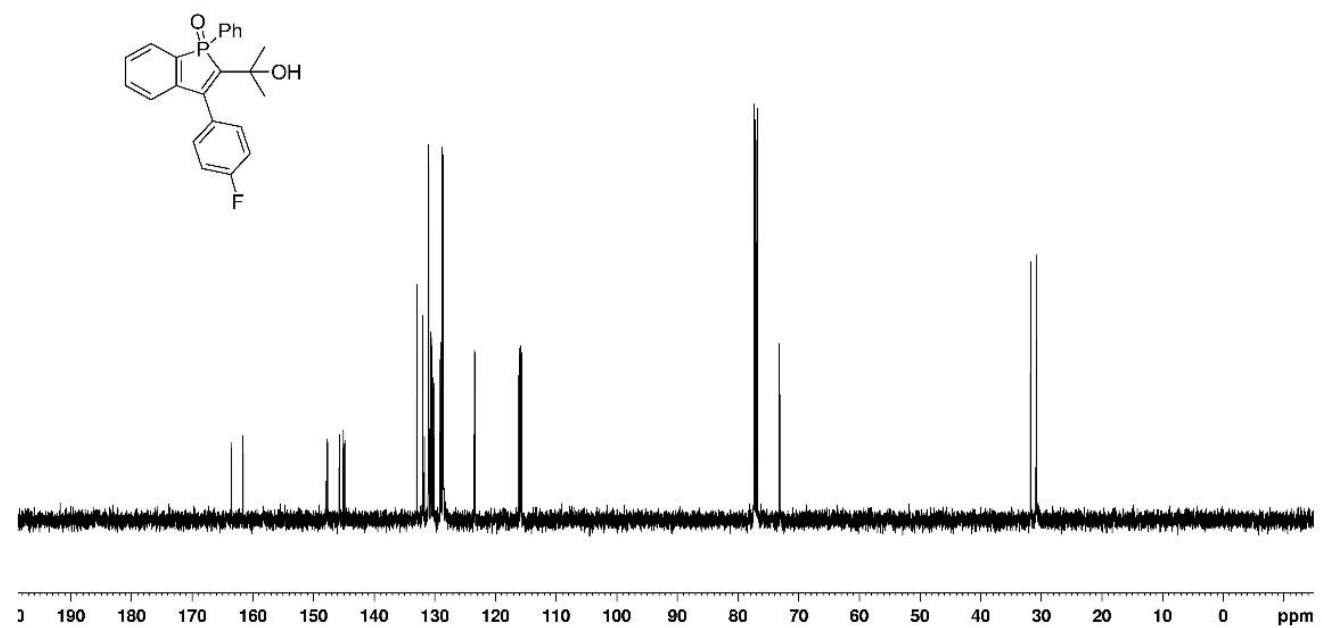

${ }^{13} \mathrm{C}$ NMR (500 MHz) spectrum of compound $\mathbf{3 e}$ in $\mathrm{CDCl}_{3}$

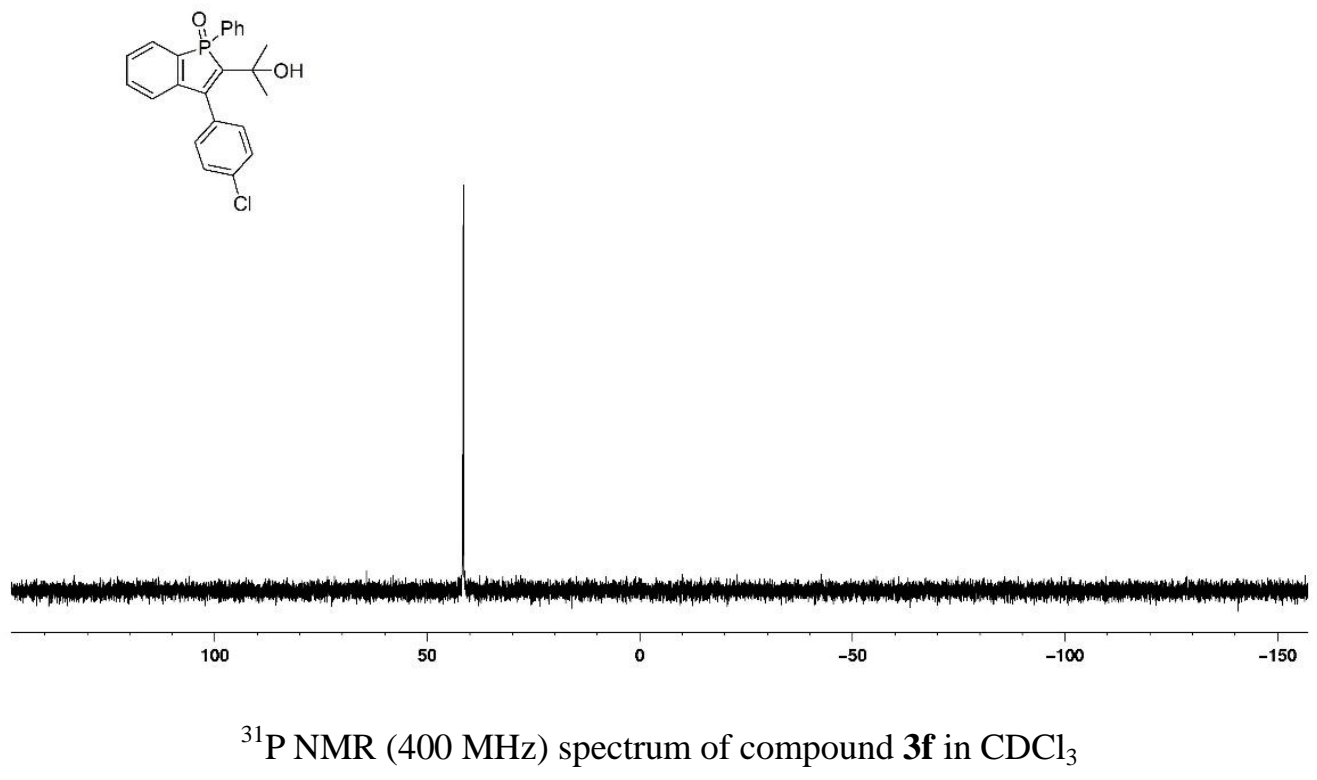




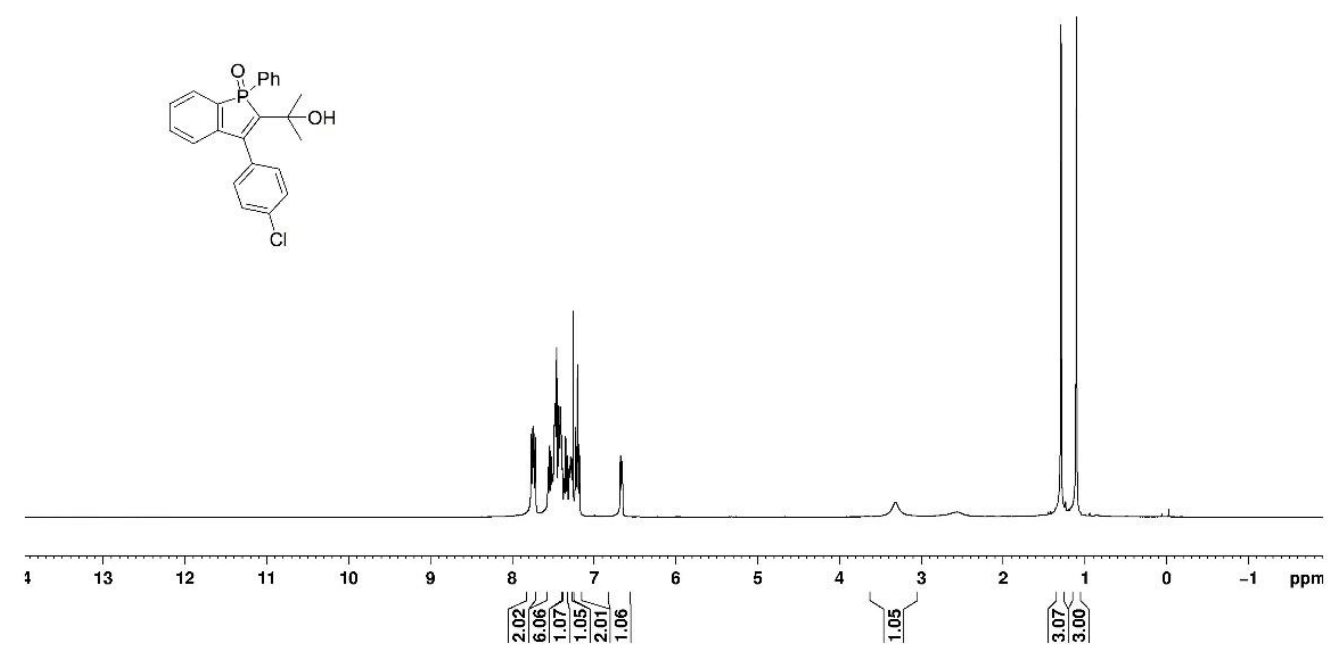

${ }^{1} \mathrm{H}$ NMR (400 MHz) spectrum of compound $\mathbf{3 f}$ in $\mathrm{CDCl}_{3}$

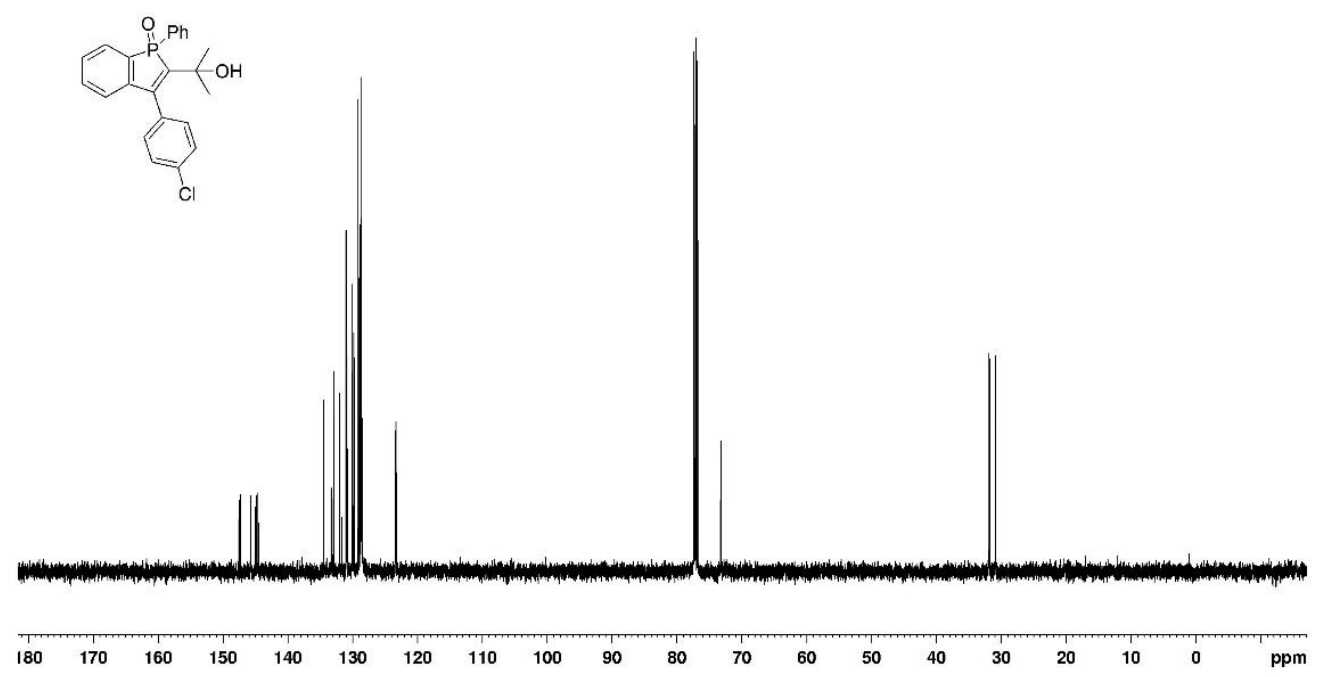

${ }^{13} \mathrm{C}$ NMR (500 MHz) spectrum of compound $\mathbf{3 f}$ in $\mathrm{CDCl}_{3}$ 

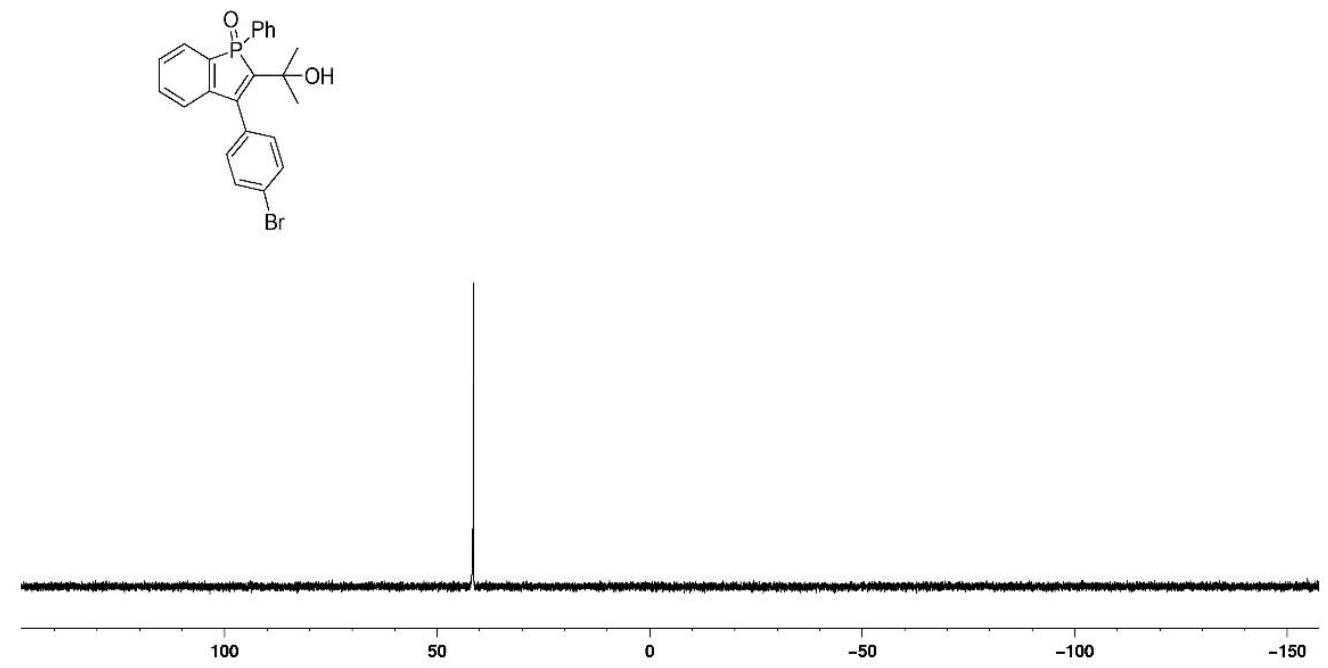

${ }^{31} \mathrm{P}$ NMR $\left(500 \mathrm{MHz}\right.$ ) spectrum of compound $\mathbf{3 g}$ in $\mathrm{CDCl}_{3}$
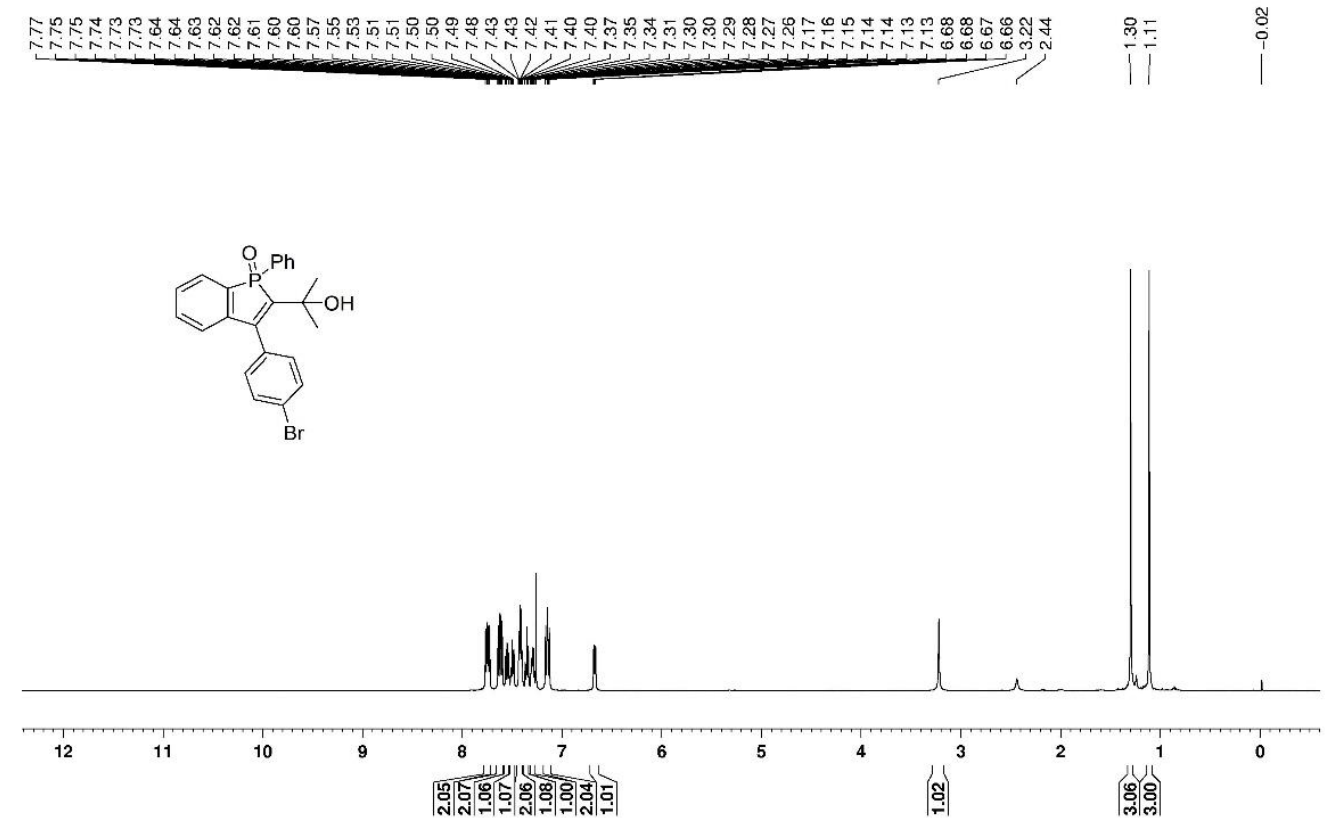

${ }^{1} \mathrm{H}$ NMR (500 MHz) spectrum of compound $\mathbf{3 g}$ in $\mathrm{CDCl}_{3}$ 

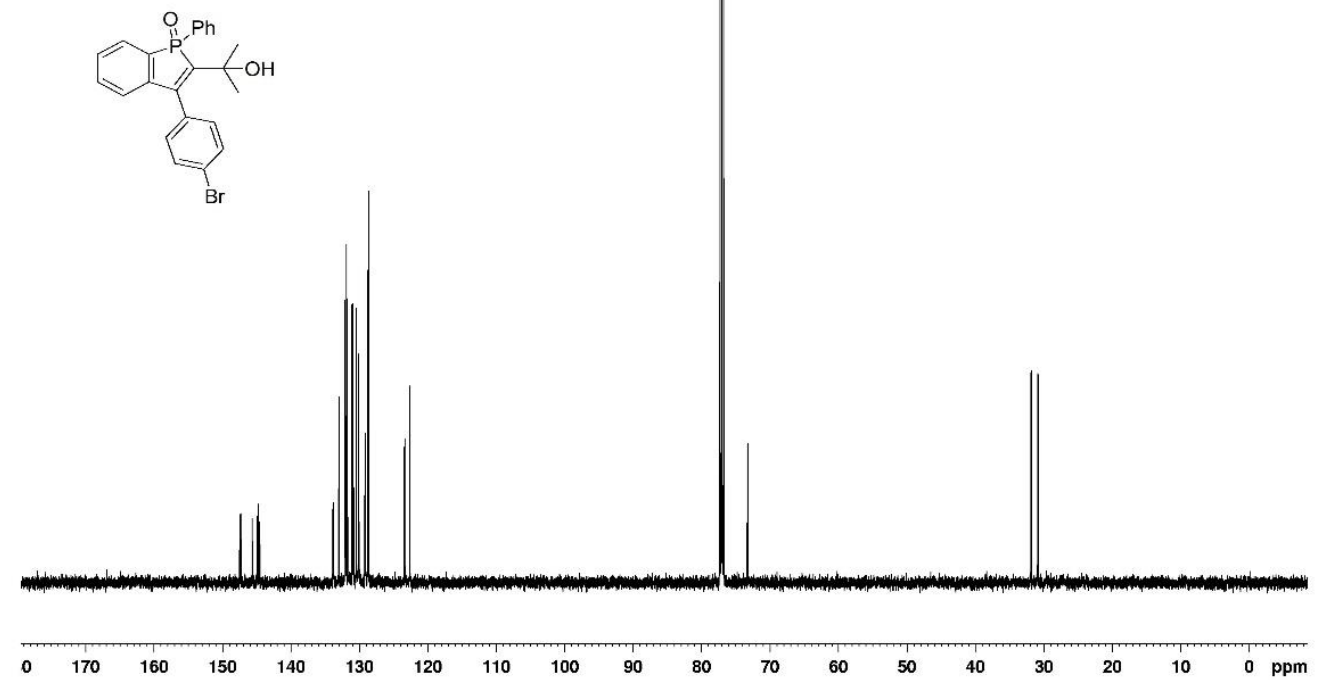

${ }^{13} \mathrm{C}$ NMR (500 MHz) spectrum of compound $\mathbf{3 g}$ in $\mathrm{CDCl}_{3}$

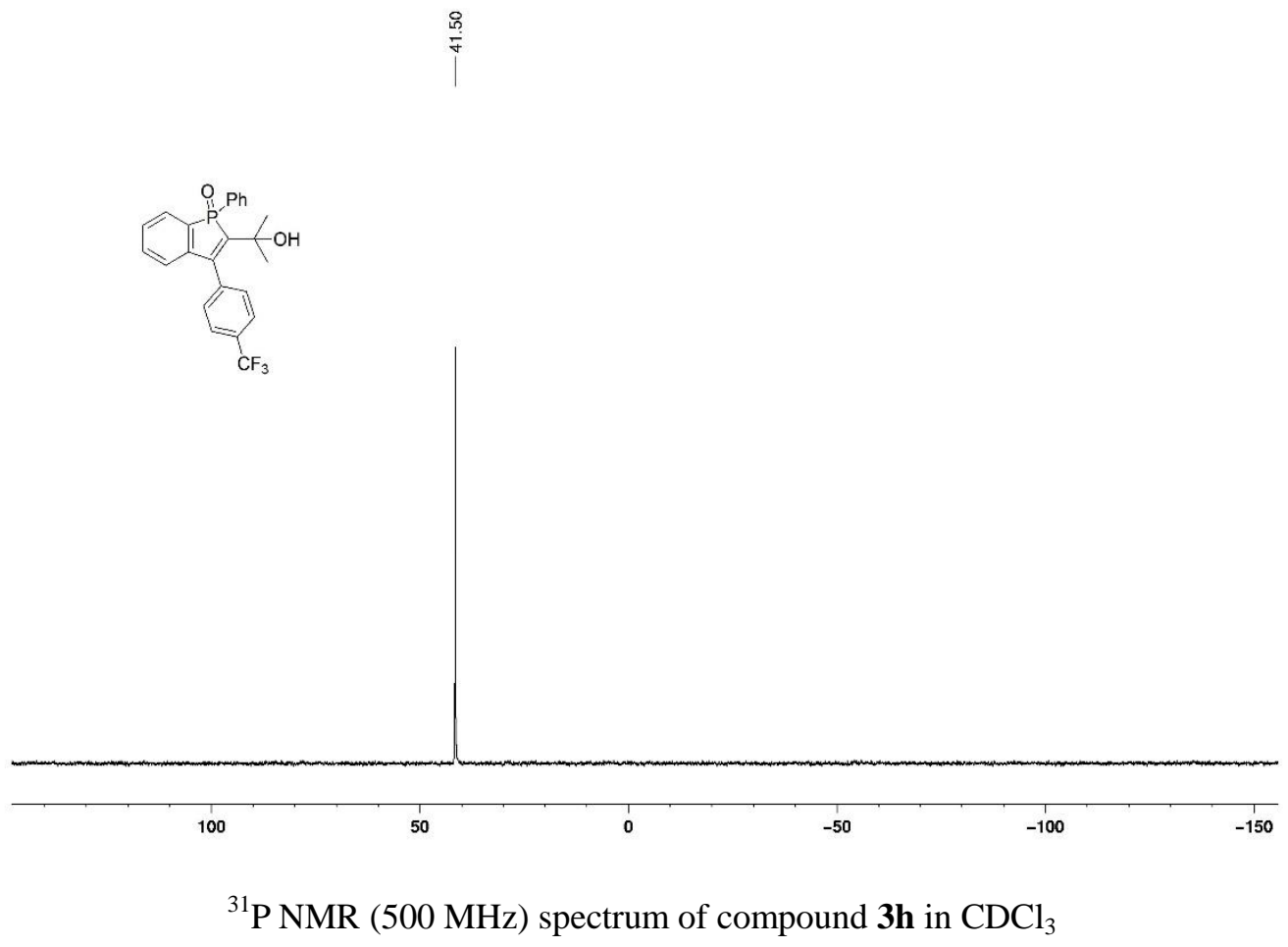




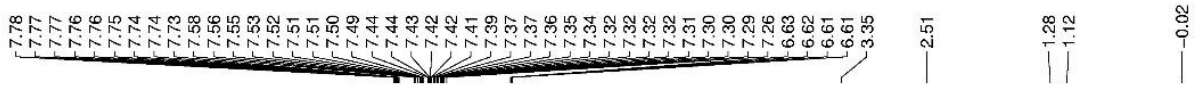

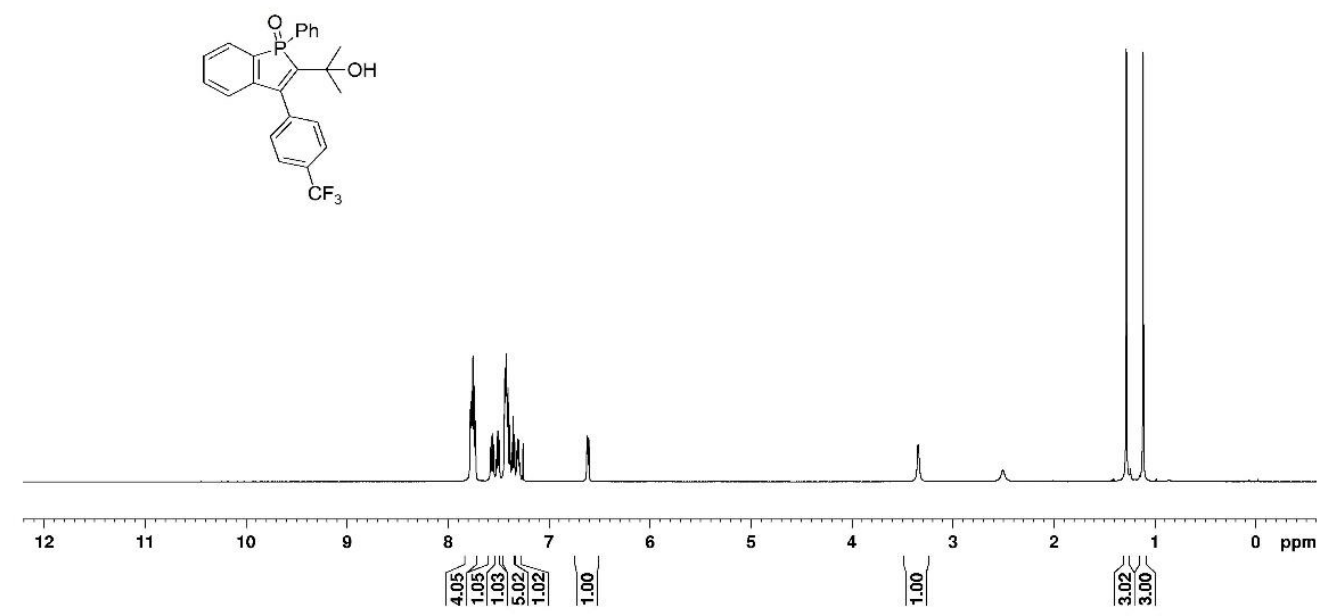

${ }^{1} \mathrm{H}$ NMR (500 MHz) spectrum of compound $\mathbf{3 h}$ in $\mathrm{CDCl}_{3}$ 


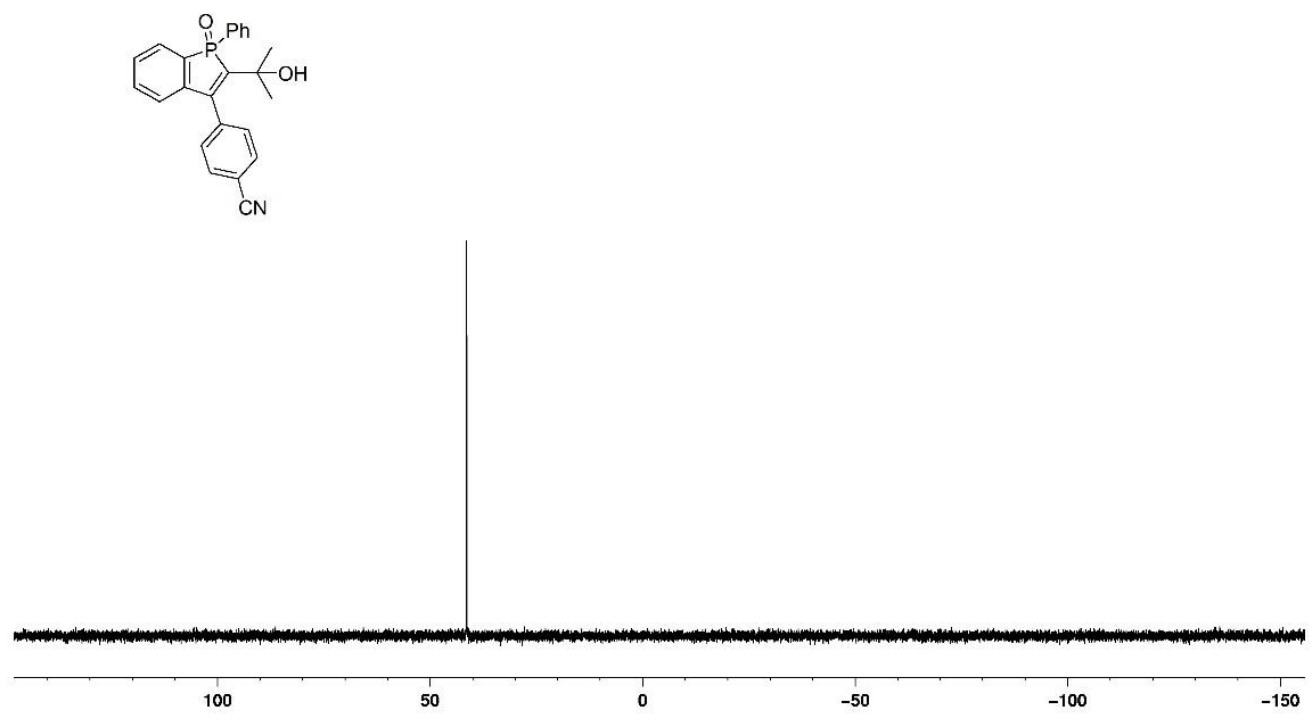

${ }^{31} \mathrm{P} \mathrm{NMR}\left(400 \mathrm{MHz}\right.$ ) spectrum of compound $3 \mathbf{i}$ in $\mathrm{CDCl}_{3}$

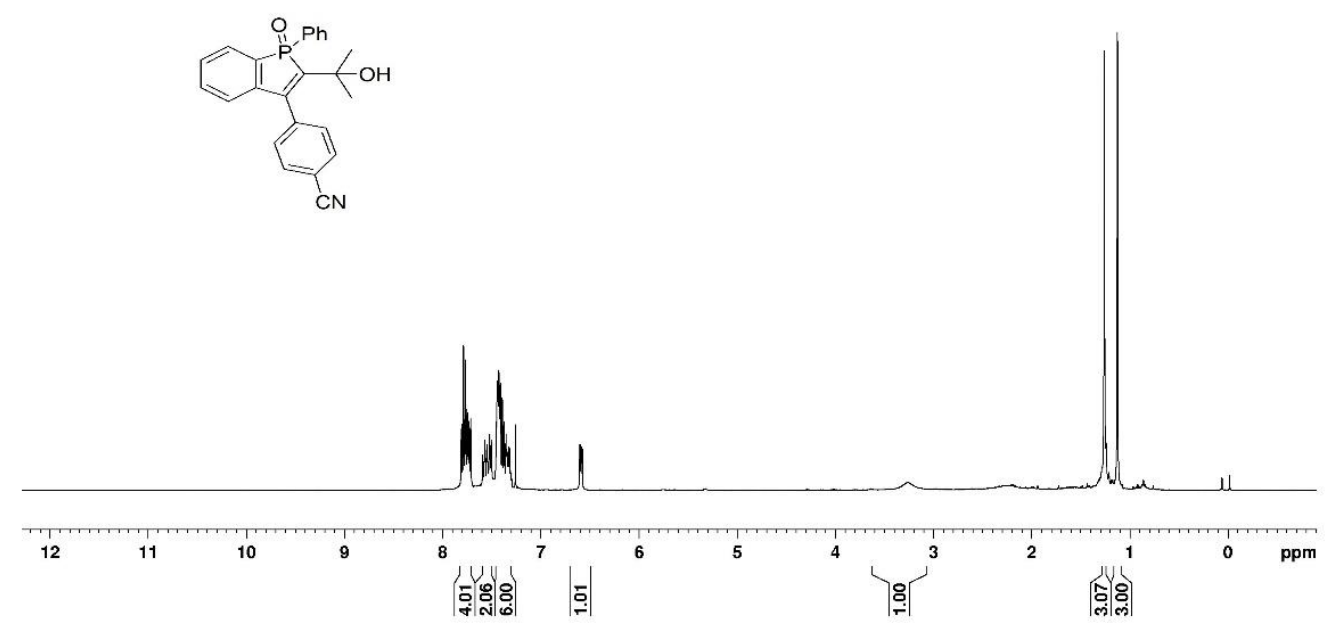

${ }^{1} \mathrm{H}$ NMR (500 MHz) spectrum of compound 3i in $\mathrm{CDCl}_{3}$ 


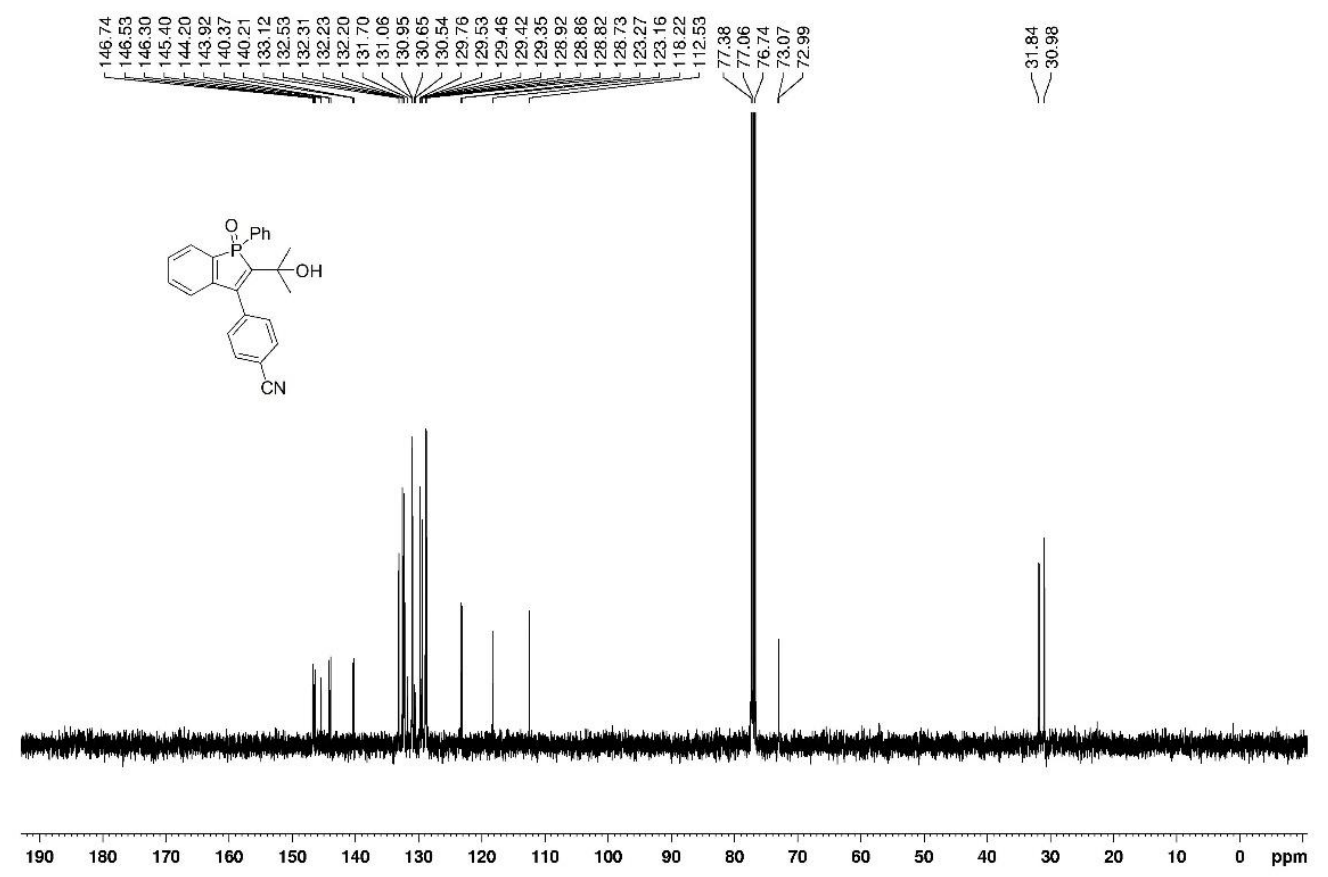

${ }^{13} \mathrm{C}$ NMR (500 MHz) spectrum of compound $3 \mathbf{i}$ in $\mathrm{CDCl}_{3}$<smiles></smiles>

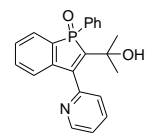

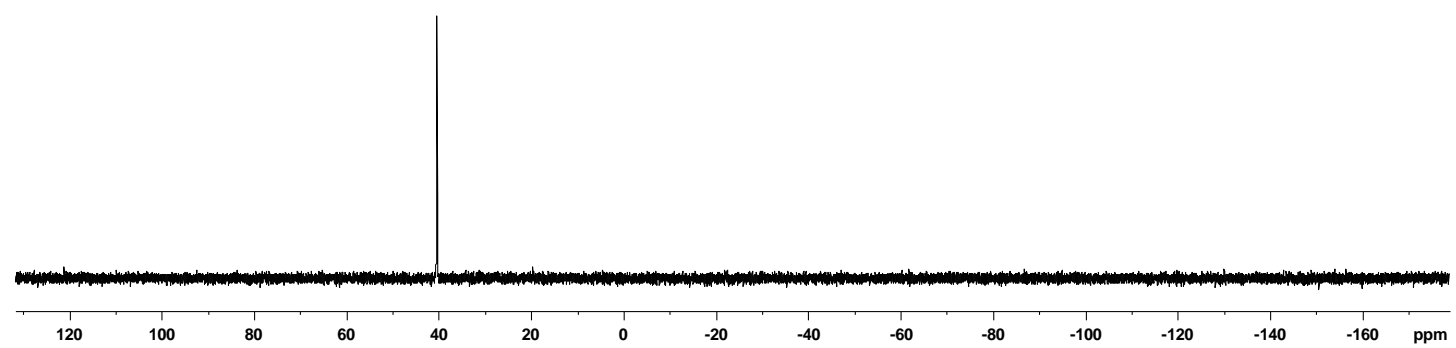

${ }^{31} \mathrm{P}$ NMR (500 MHz) spectrum of compound $\mathbf{3} \mathbf{j}$ in $\mathrm{CDCl}_{3}$ 


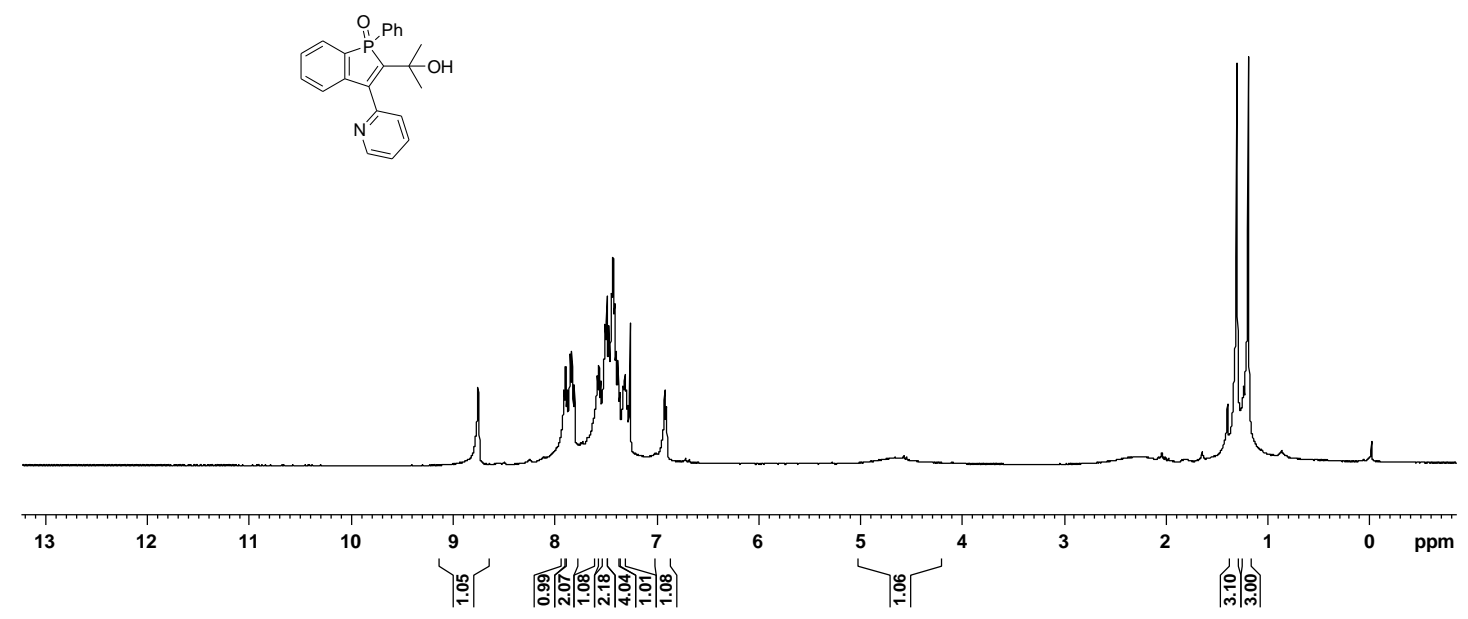

${ }^{1} \mathrm{H}$ NMR (500 MHz) spectrum of compound $\mathbf{3} \mathbf{j}$ in $\mathrm{CDCl}_{3}$

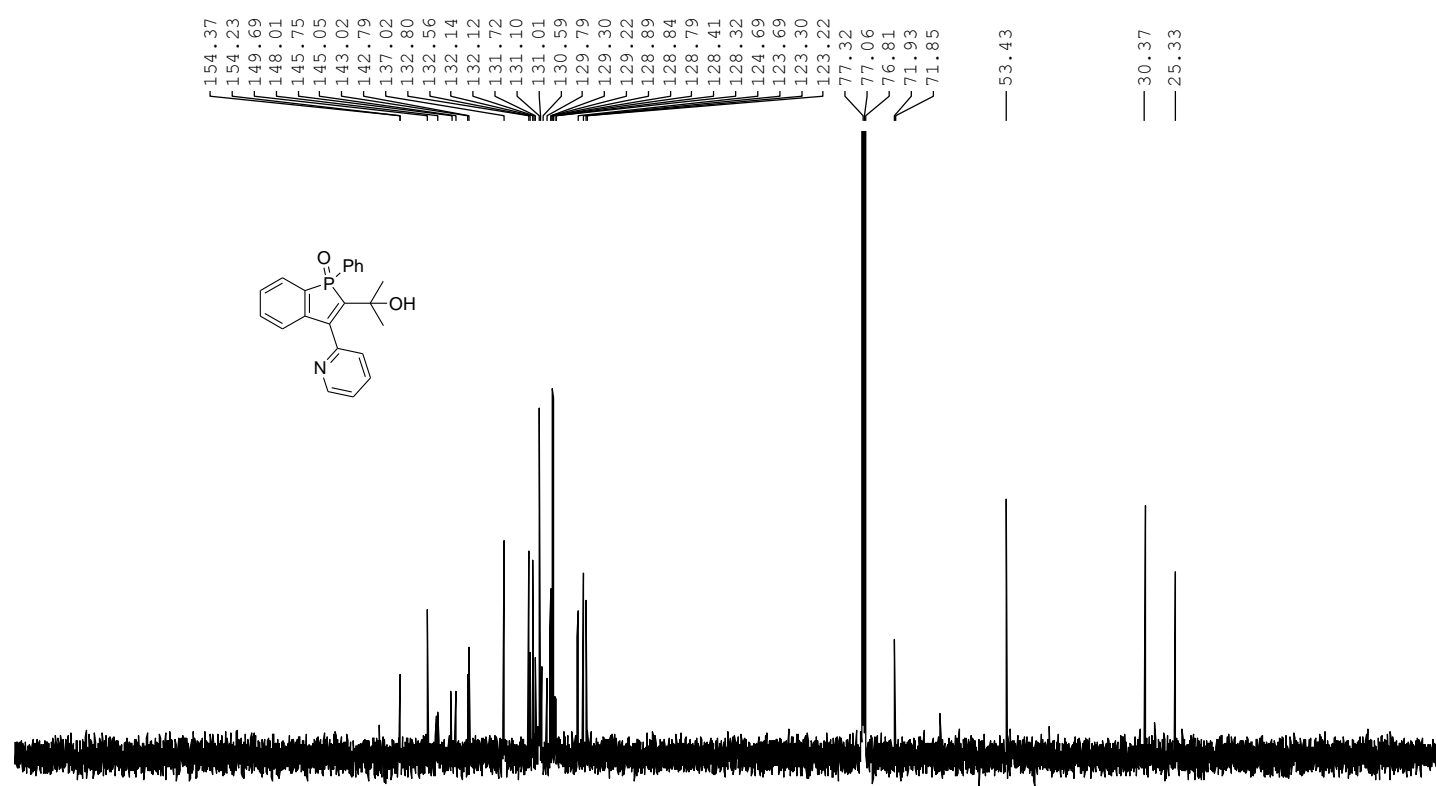

$\begin{array}{lllllllllllllllllllllll}210 & 200 & 190 & 180 & 170 & 160 & 150 & 140 & 130 & 120 & 110 & 100 & 90 & 80 & 70 & 60 & 50 & 40 & 30 & 20 & 10 & 0 & \mathrm{ppm}\end{array}$

${ }^{13} \mathrm{C}$ NMR (400 MHz) spectrum of compound $\mathbf{3 j}$ in $\mathrm{CDCl}_{3}$ 

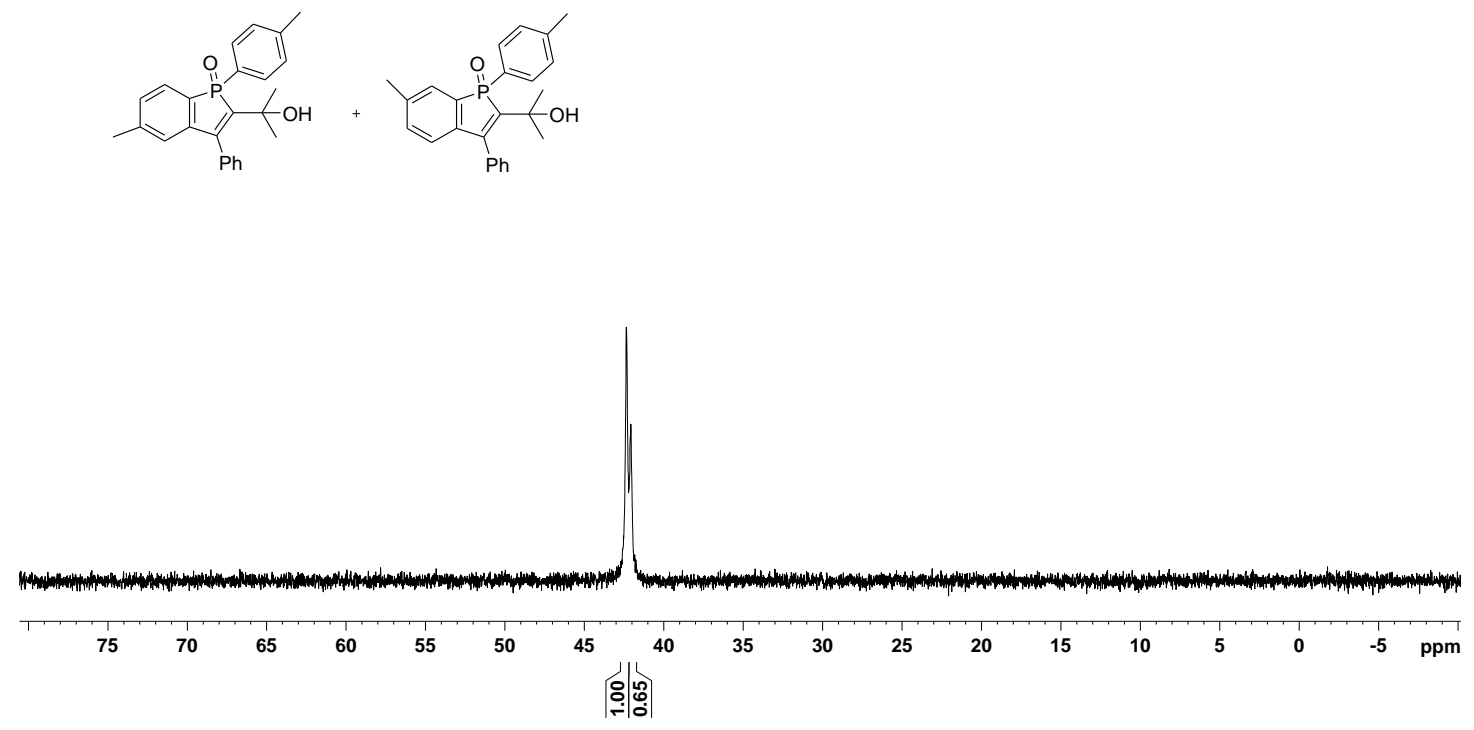

${ }^{31} \mathrm{P}$ NMR $(500 \mathrm{MHz})$ spectrum of compound $\mathbf{3 k}$ in $\mathrm{CDCl}_{3}$

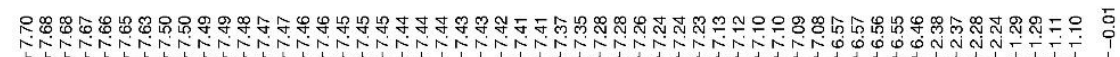

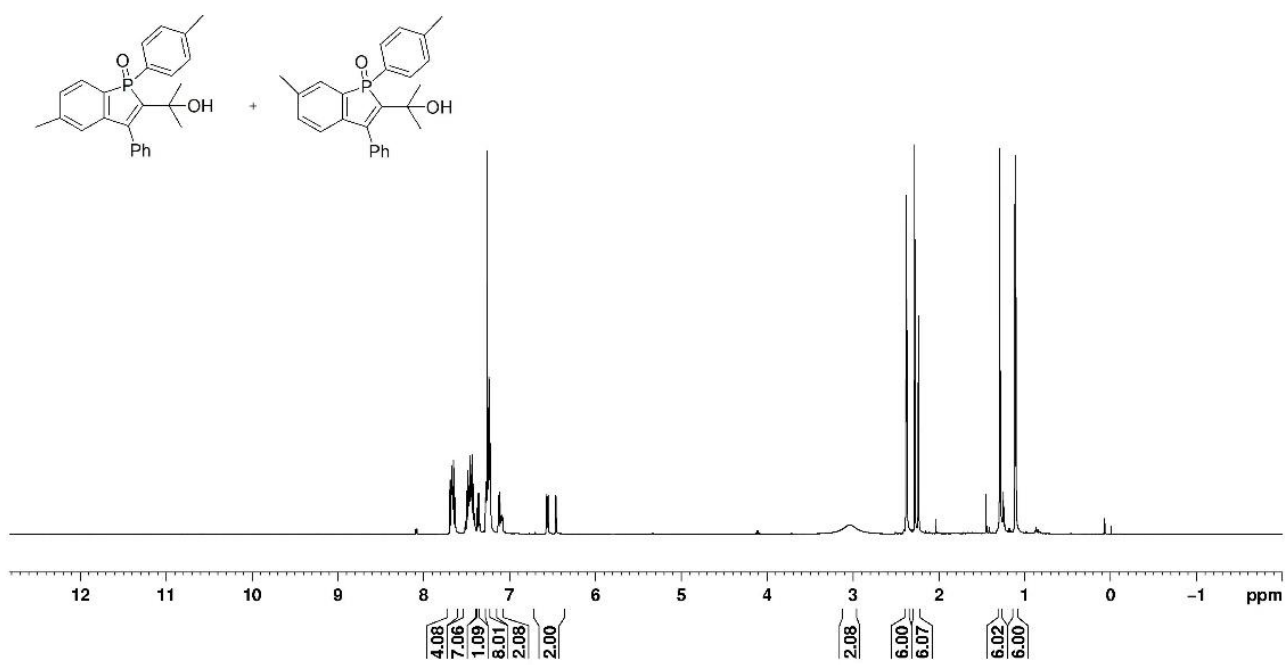

${ }^{1} \mathrm{H}$ NMR (500 MHz) spectrum of compound $\mathbf{3 k}$ in $\mathrm{CDCl}_{3}$ 


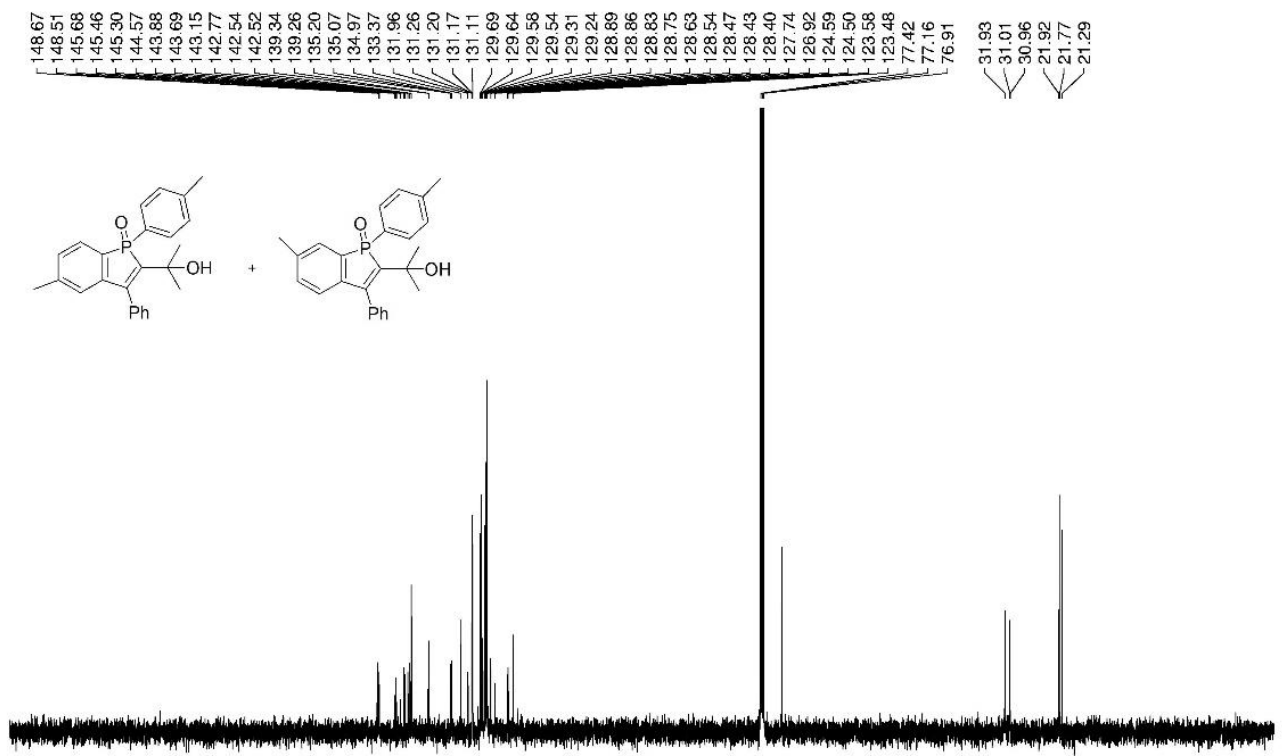

$\begin{array}{llllllllllllllllllllllll}210 & 200 & 190 & 180 & 170 & 160 & 150 & 140 & 130 & 120 & 110 & 100 & 90 & 80 & 70 & 60 & 50 & 40 & 30 & 20 & 10 & 0 & \mathrm{ppm}\end{array}$

${ }^{13} \mathrm{C}$ NMR (400 MHz) spectrum of compound $\mathbf{3 k}$ in $\mathrm{CDCl}_{3}$
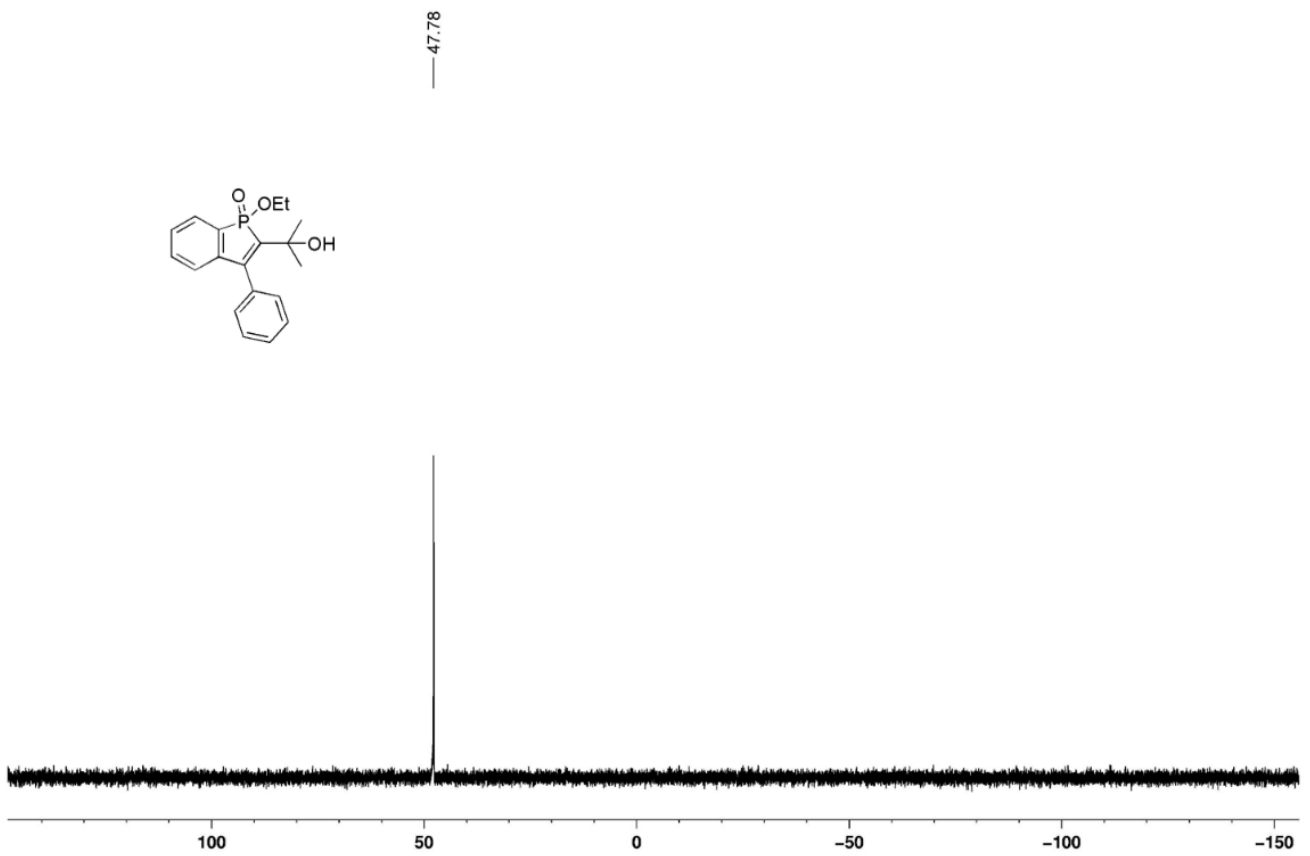

${ }^{31} \mathrm{P}$ NMR (500 MHz) spectrum of compound $3 \mathrm{l}$ in $\mathrm{CDCl}_{3}$ 

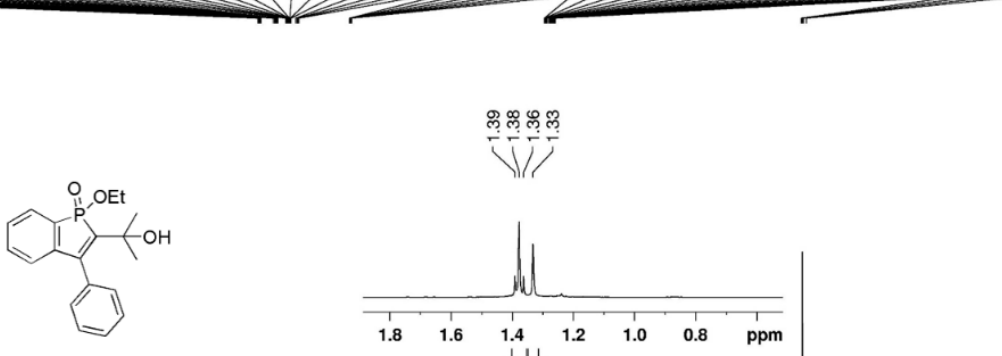

这

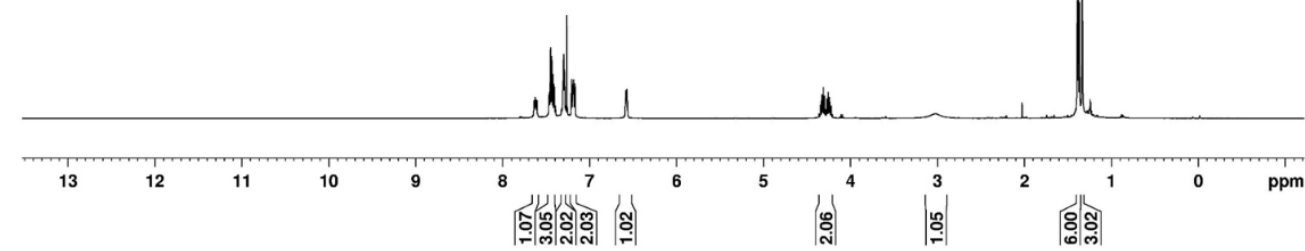

${ }^{1} \mathrm{H}$ NMR (500 MHz) spectrum of compound $3 \mathbf{l}$ in $\mathrm{CDCl}_{3}$

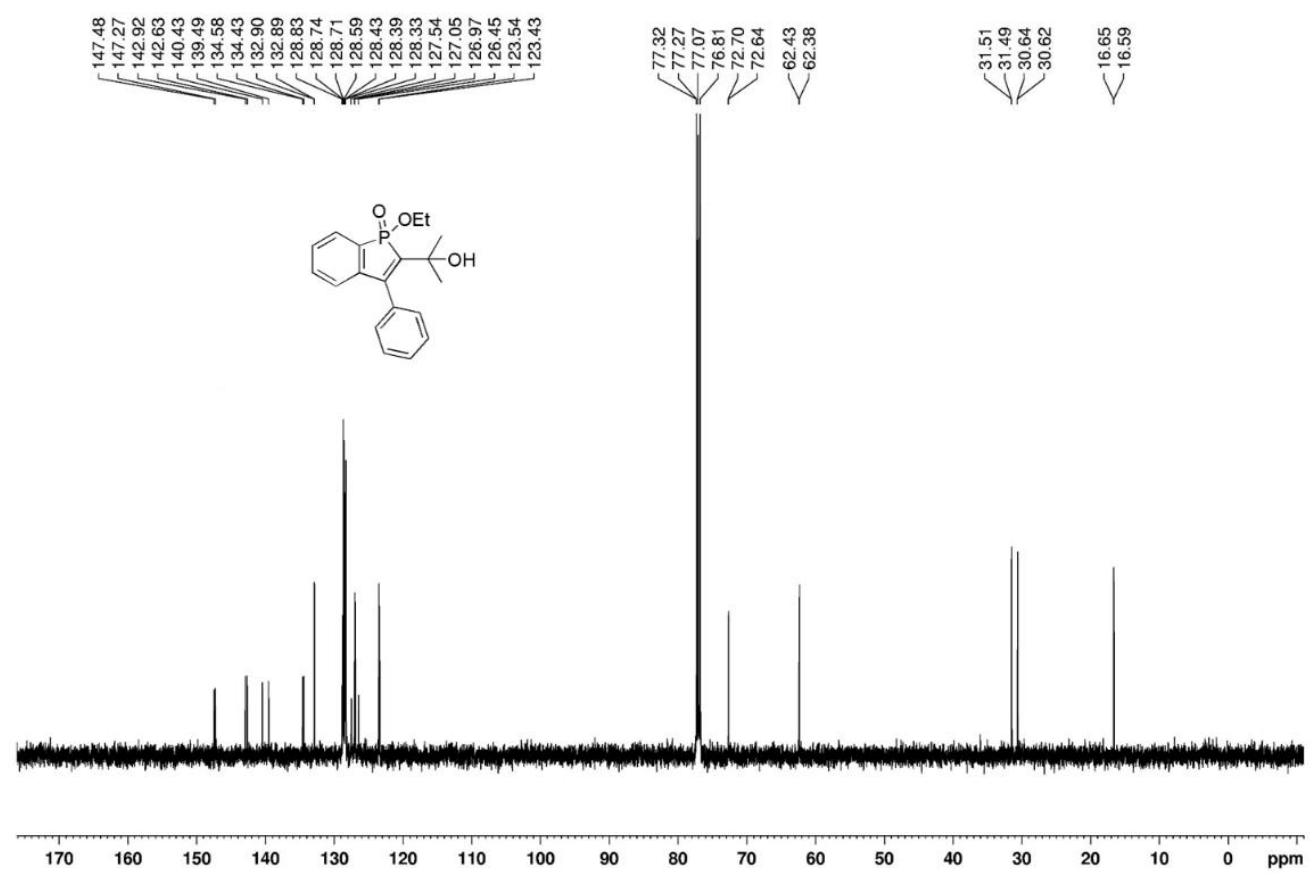

${ }^{13} \mathrm{CNMR}\left(500 \mathrm{MHz}\right.$ ) spectrum of compound $3 \mathbf{l}$ in $\mathrm{CDCl}_{3}$ 


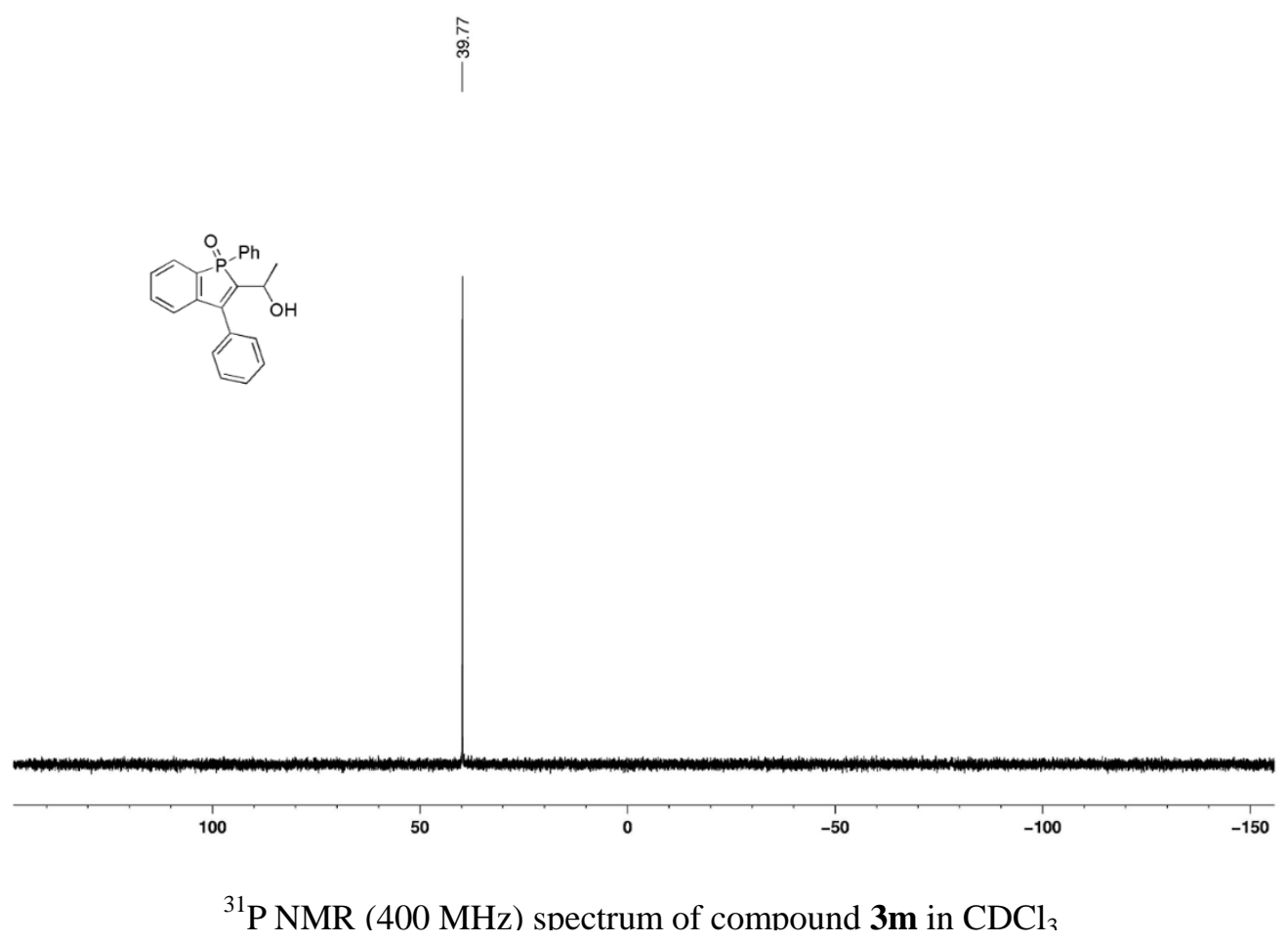

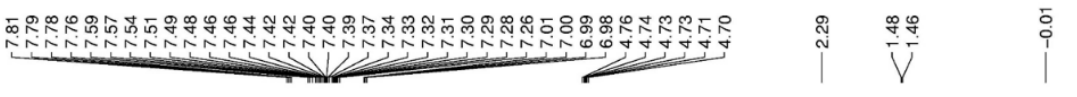

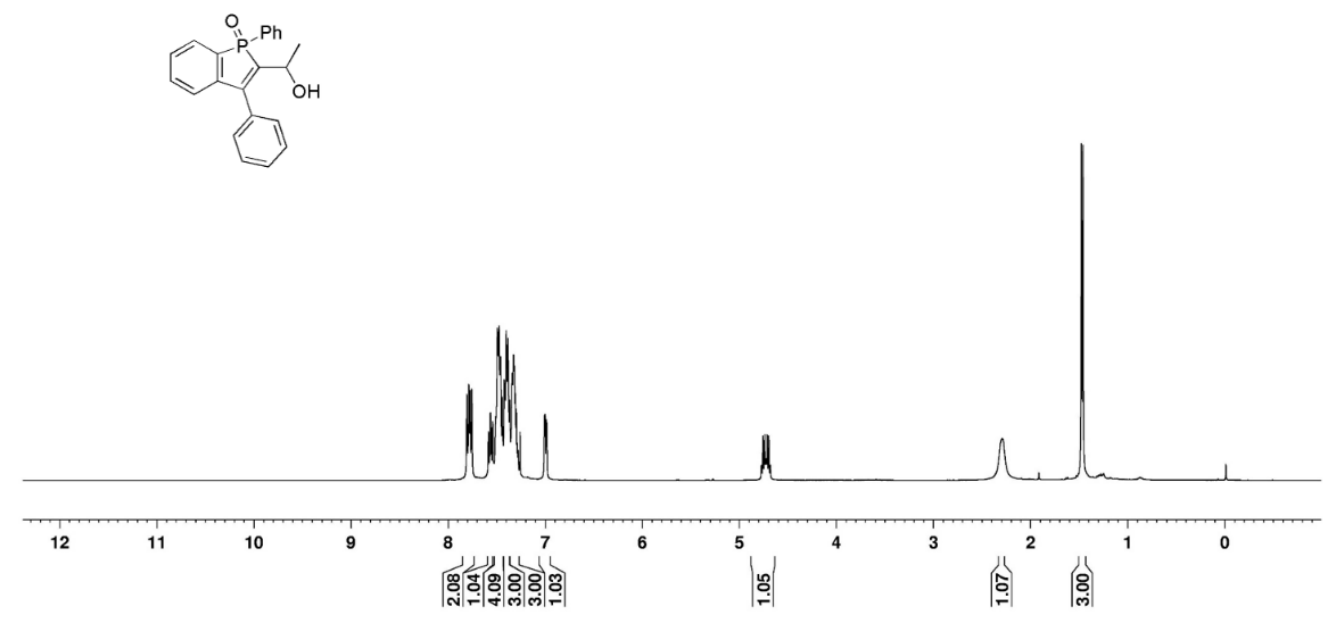

${ }^{1} \mathrm{H}$ NMR (400 MHz) spectrum of compound $\mathbf{3 m}$ in $\mathrm{CDCl}_{3}$ 


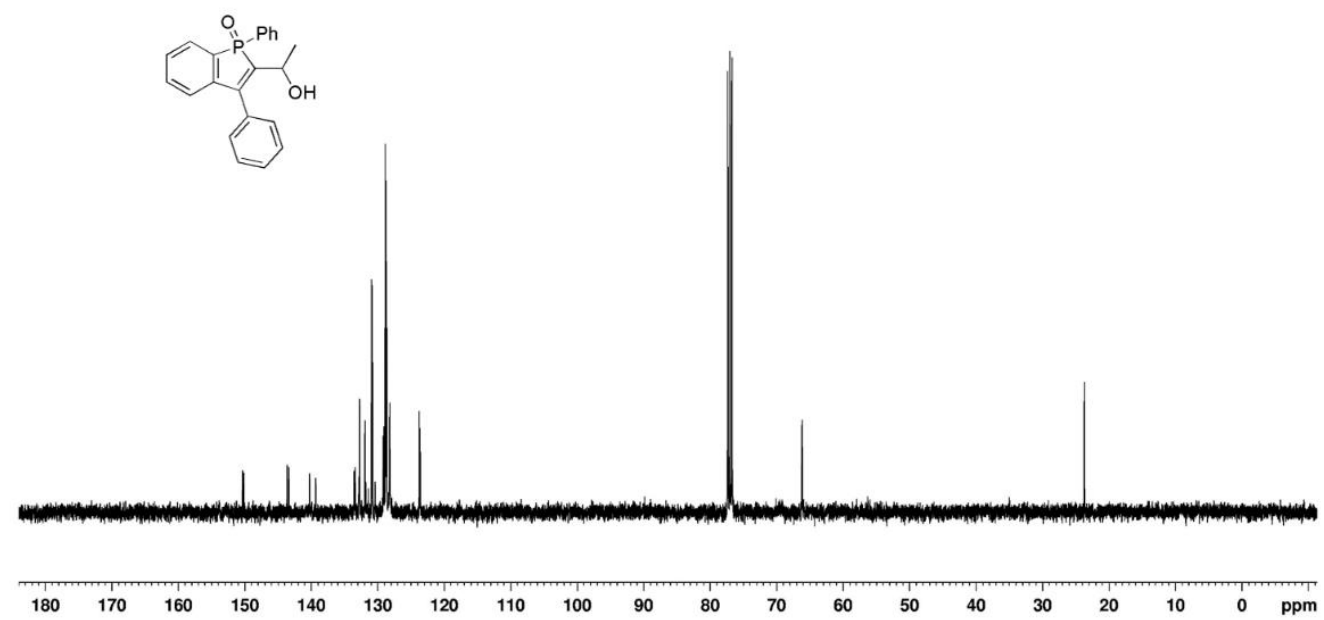

${ }^{13} \mathrm{C} \mathrm{NMR}\left(400 \mathrm{MHz}\right.$ ) spectrum of compound $\mathbf{3 m}$ in $\mathrm{CDCl}_{3}$

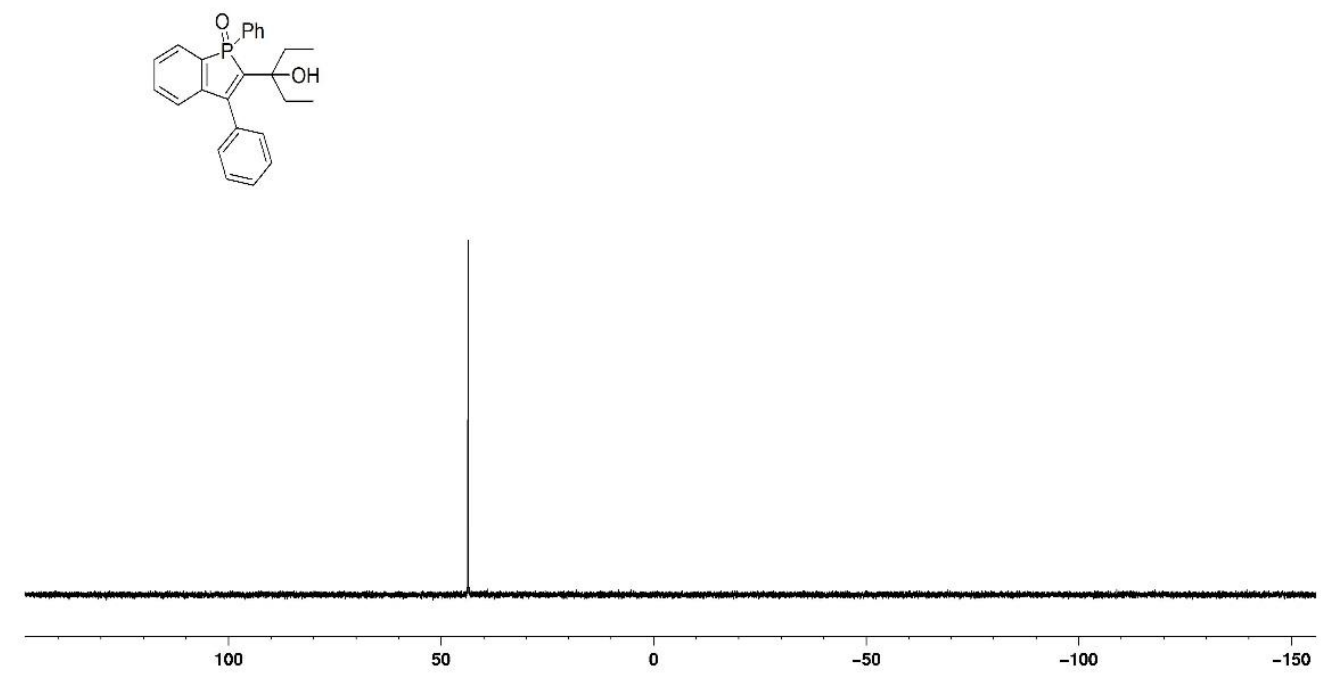

${ }^{31} \mathrm{P}$ NMR (400 MHz) spectrum of compound $\mathbf{3 n}$ in $\mathrm{CDCl}_{3}$ 


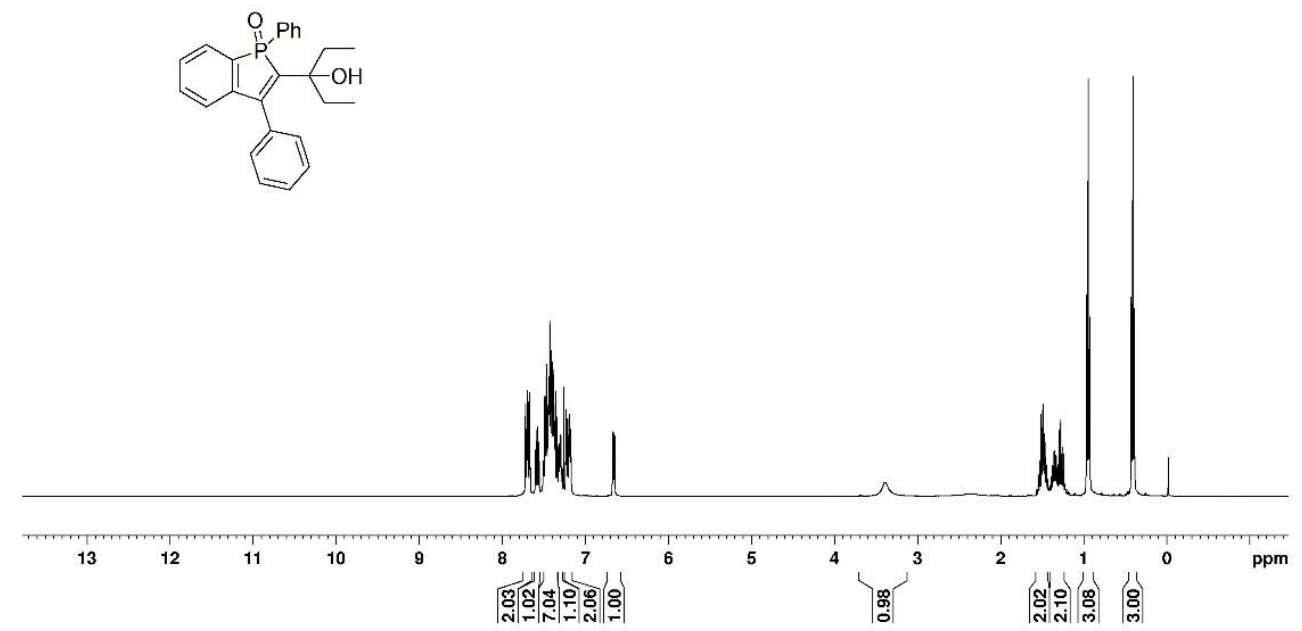

${ }^{1} \mathrm{H}$ NMR (400 MHz) spectrum of compound $\mathbf{3 n}$ in $\mathrm{CDCl}_{3}$

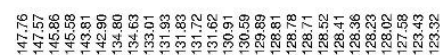

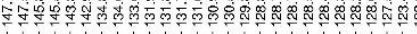

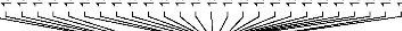

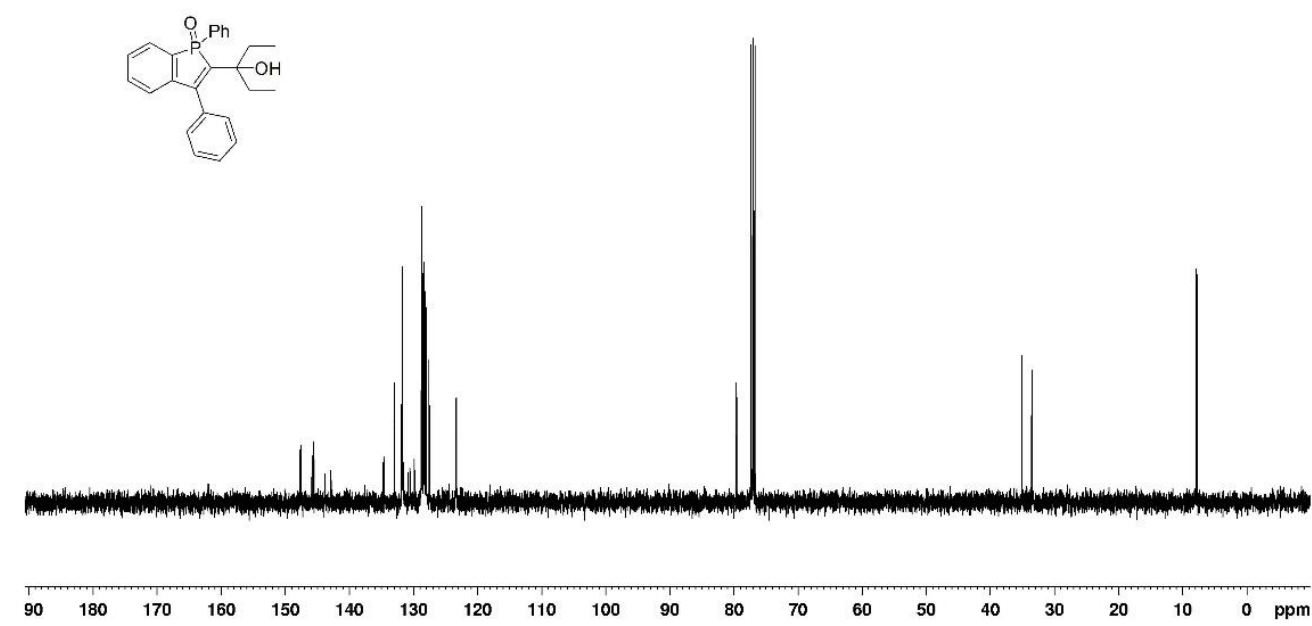

${ }^{13} \mathrm{C}$ NMR (400 MHz) spectrum of compound $\mathbf{3 n}$ in $\mathrm{CDCl}_{3}$ 


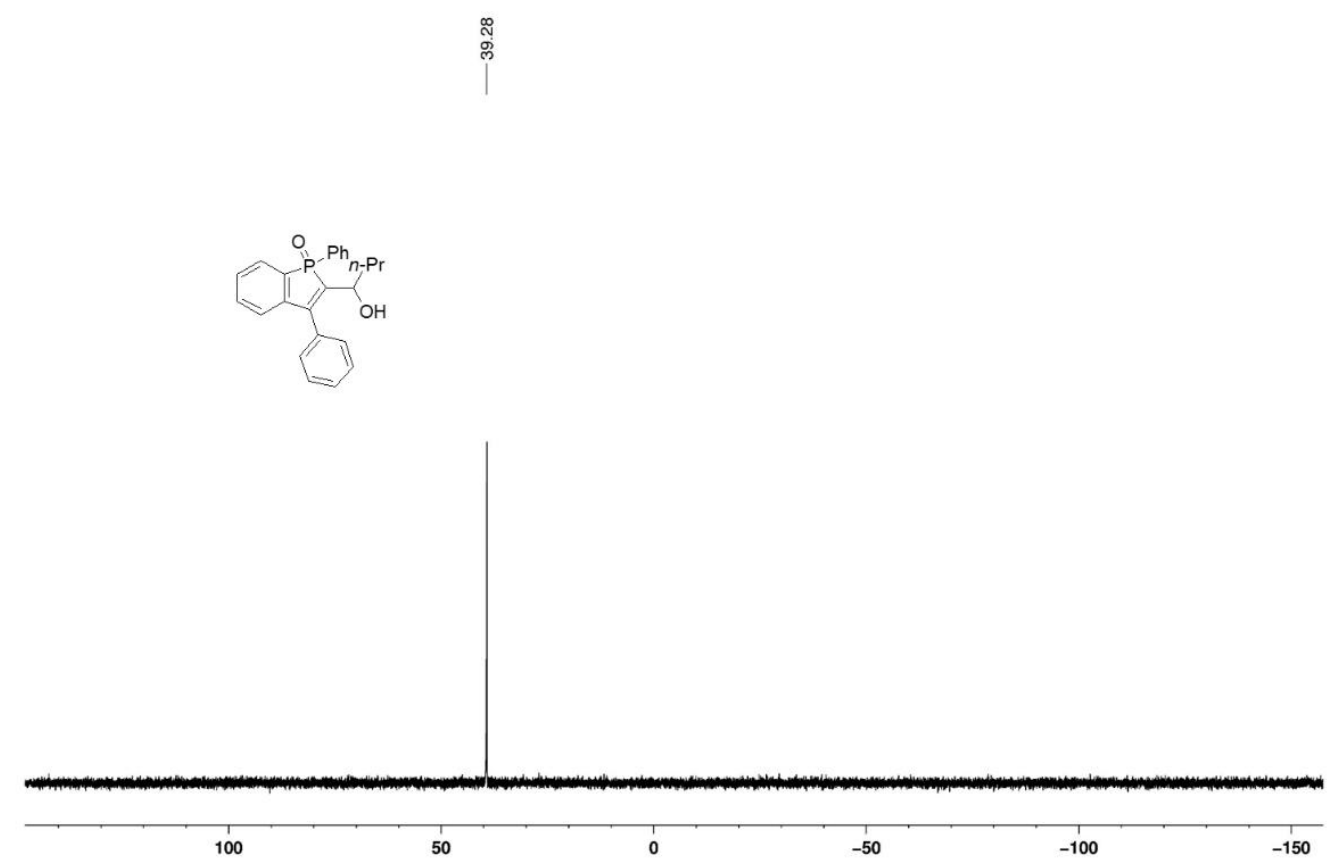

${ }^{31} \mathrm{P}$ NMR (400 MHz) spectrum of compound 30 in $\mathrm{CDCl}_{3}$

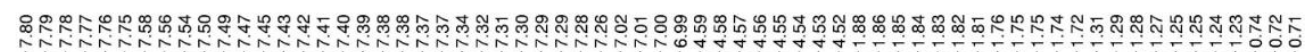

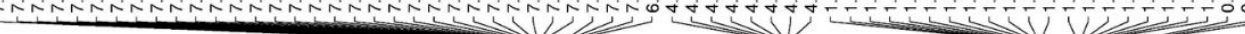

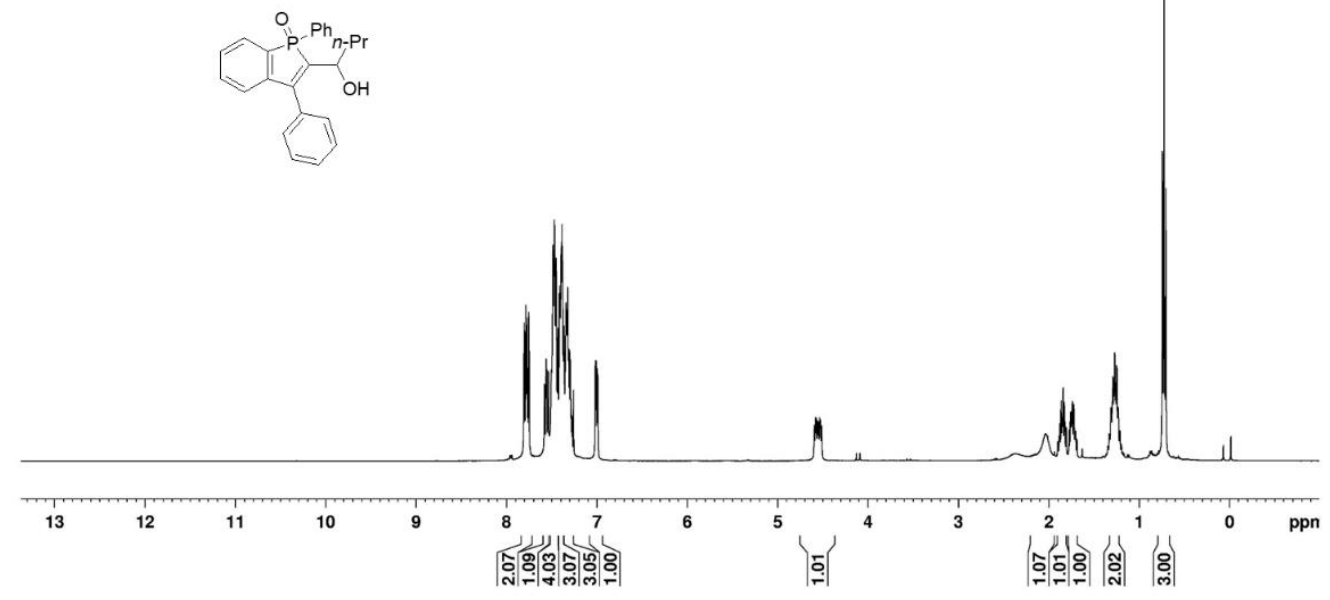

${ }^{1} \mathrm{H}$ NMR (400 MHz) spectrum of compound 3o in $\mathrm{CDCl}_{3}$ 

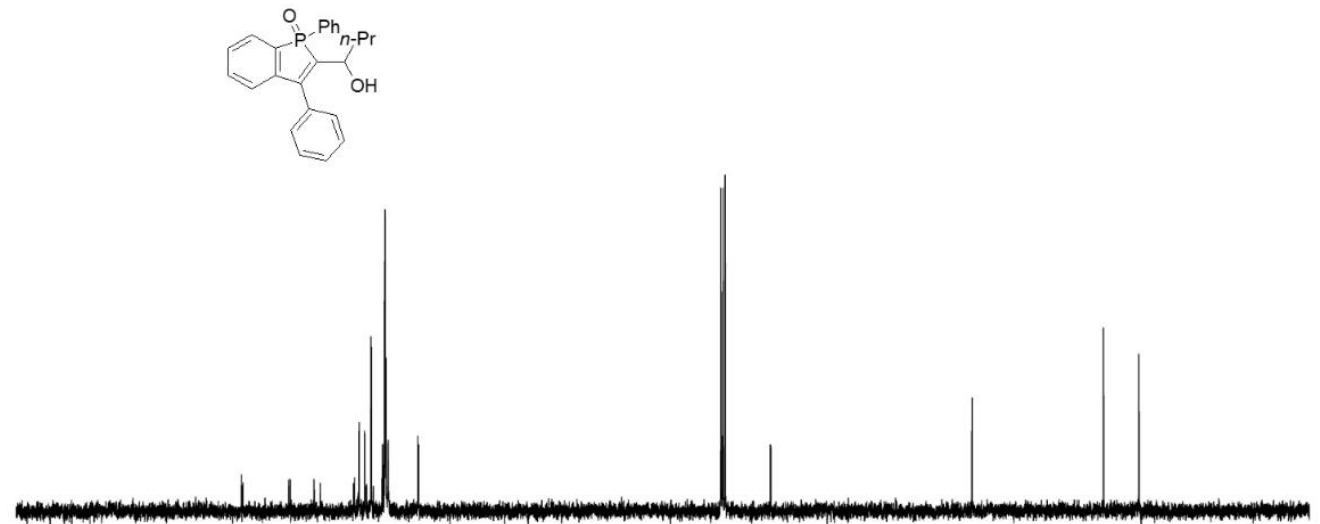

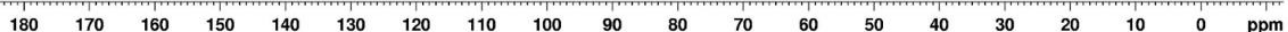

${ }^{13} \mathrm{C}$ NMR (400 MHz) spectrum of compound 30 in $\mathrm{CDCl}_{3}$

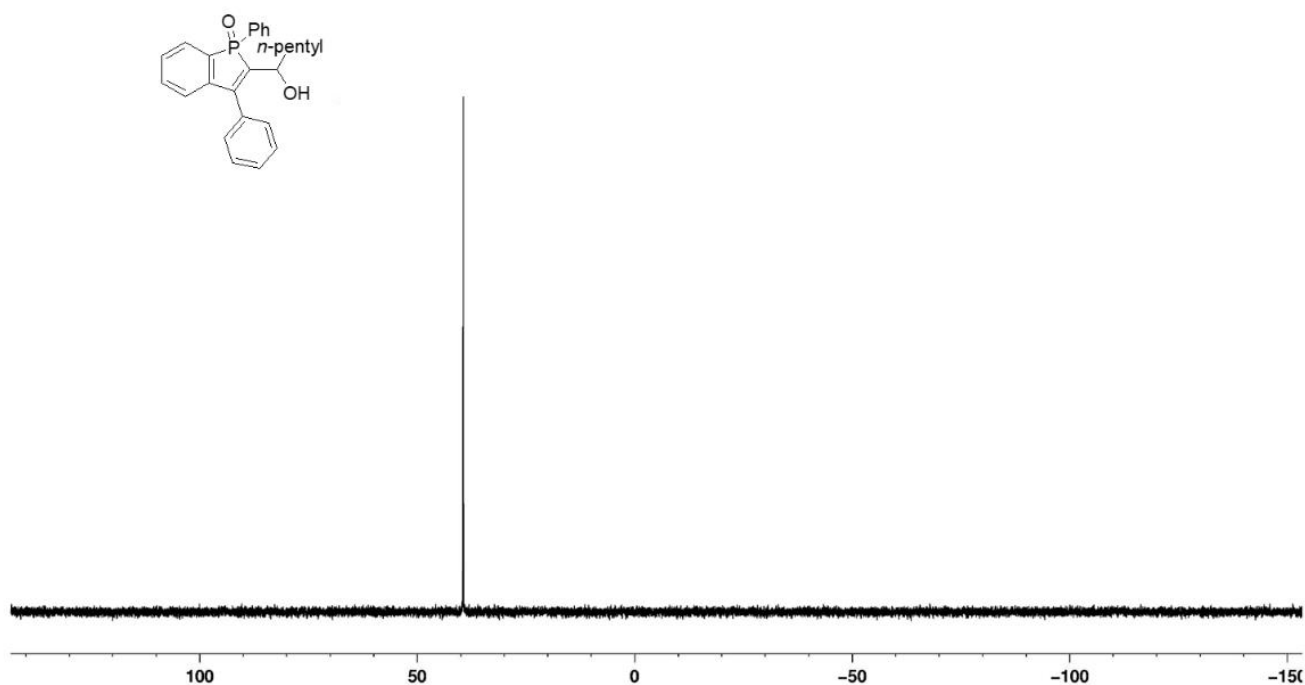

${ }^{31} \mathrm{P}$ NMR (400 MHz) spectrum of compound $3 \mathbf{p}$ in $\mathrm{CDCl}_{3}$ 


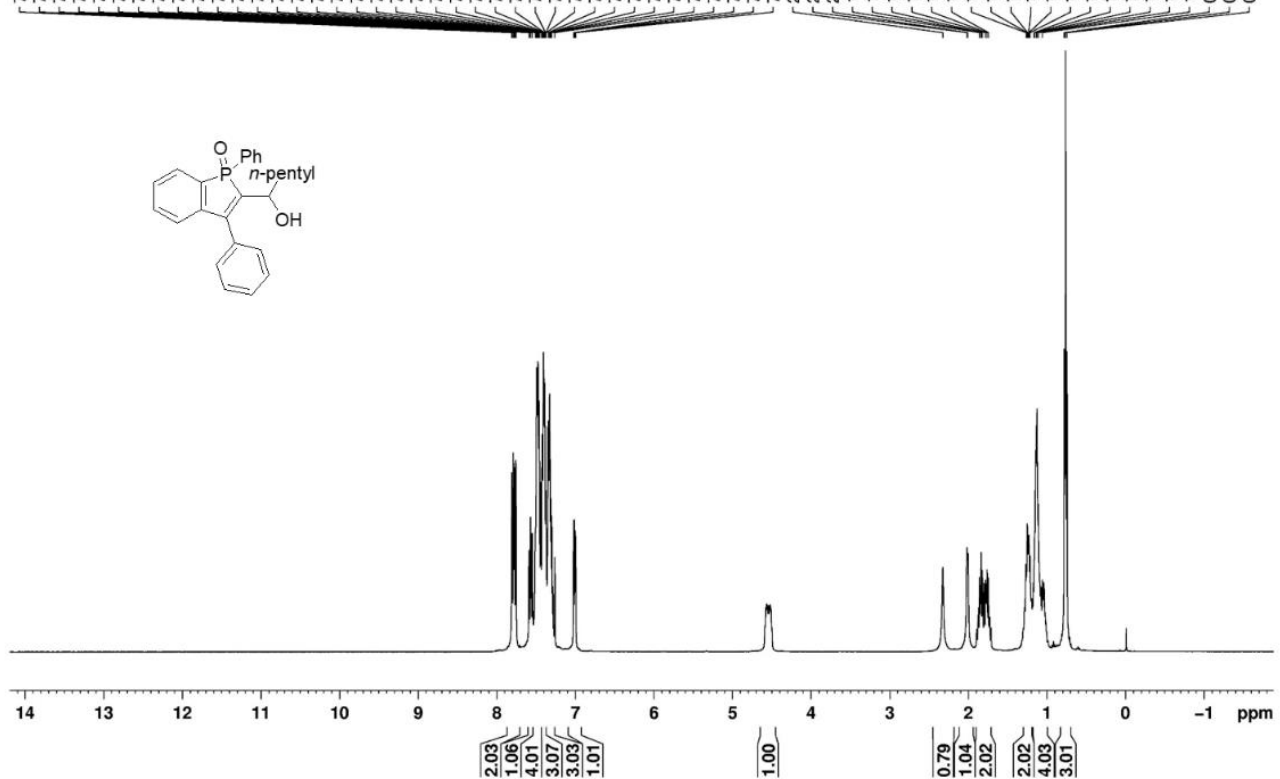

${ }^{1} \mathrm{H}$ NMR (400 MHz) spectrum of compound $\mathbf{3 p}$ in $\mathrm{CDCl}_{3}$

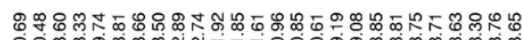

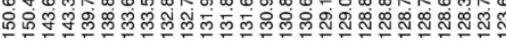

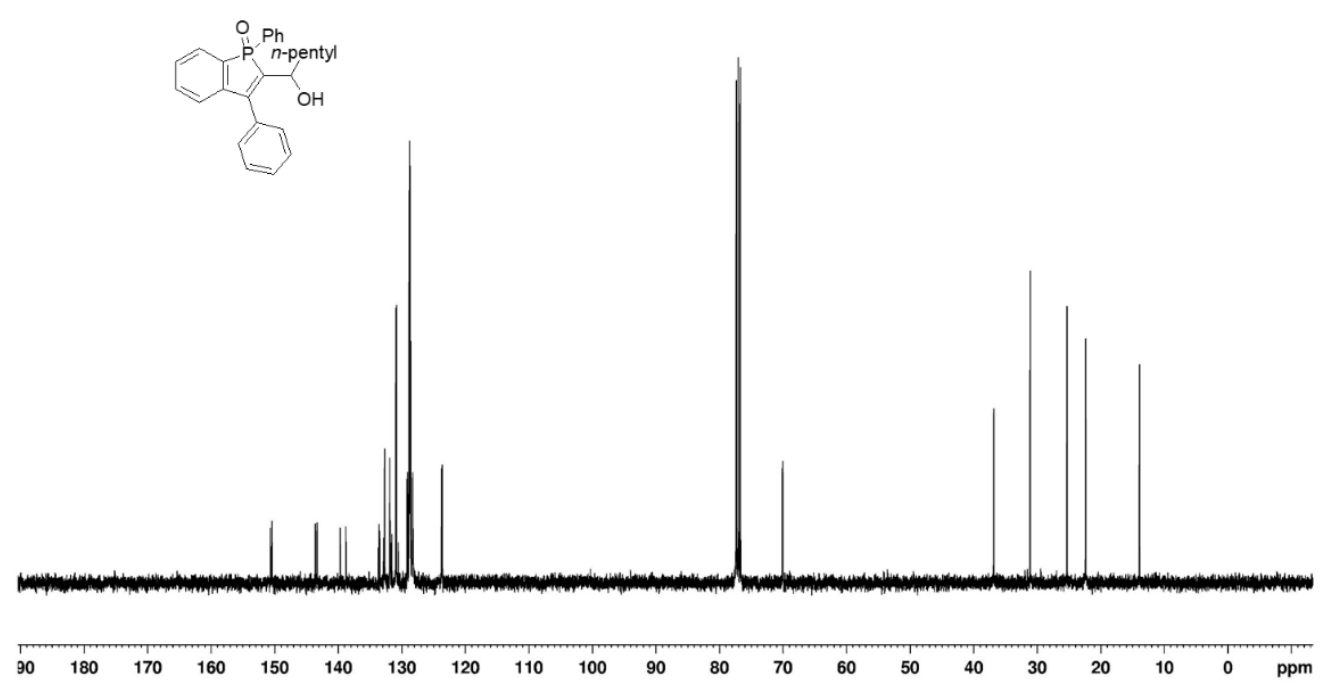

${ }^{13} \mathrm{C}$ NMR (400 MHz) spectrum of compound $\mathbf{3 p}$ in $\mathrm{CDCl}_{3}$ 


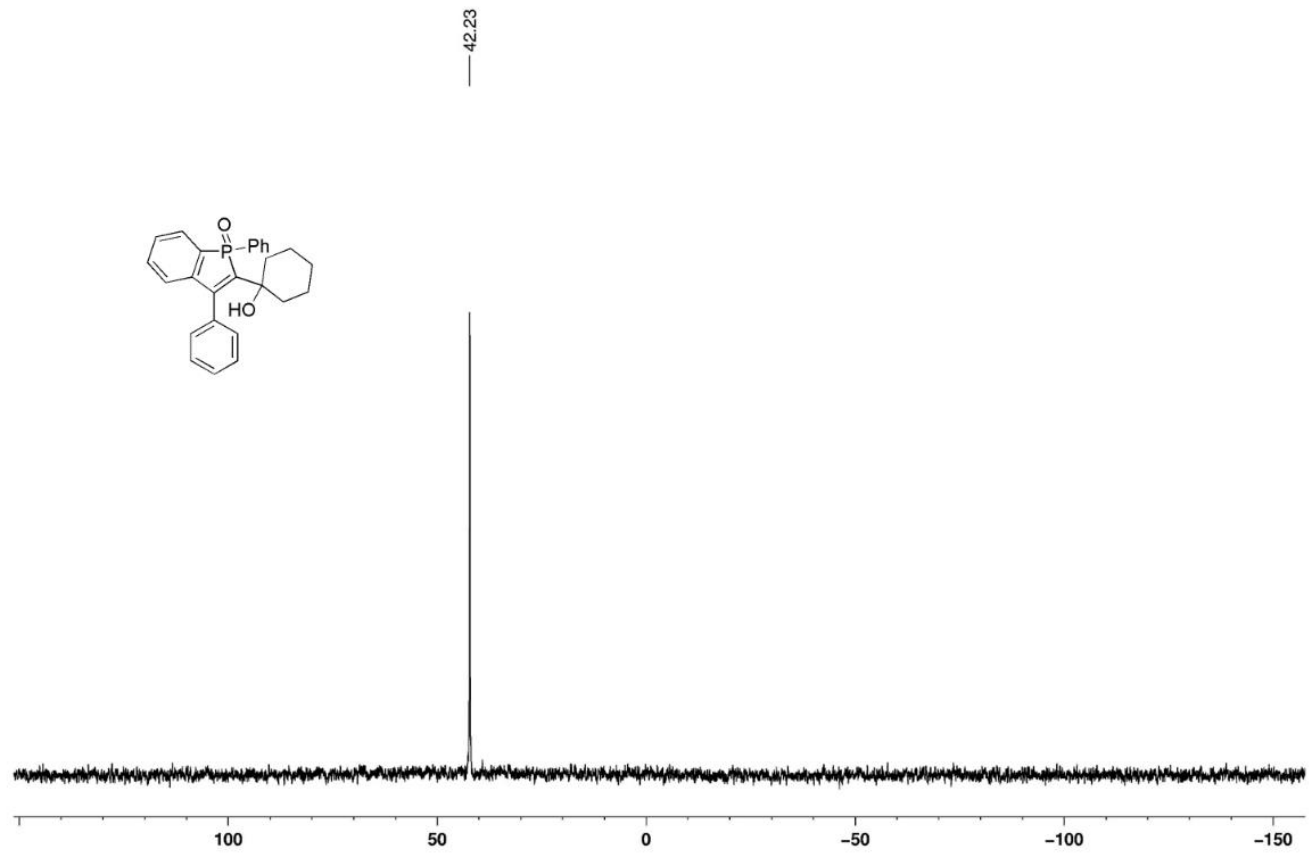

${ }^{31} \mathrm{P}$ NMR (500 MHz) spectrum of compound $\mathbf{3 q}$ in $\mathrm{CDCl}_{3}$

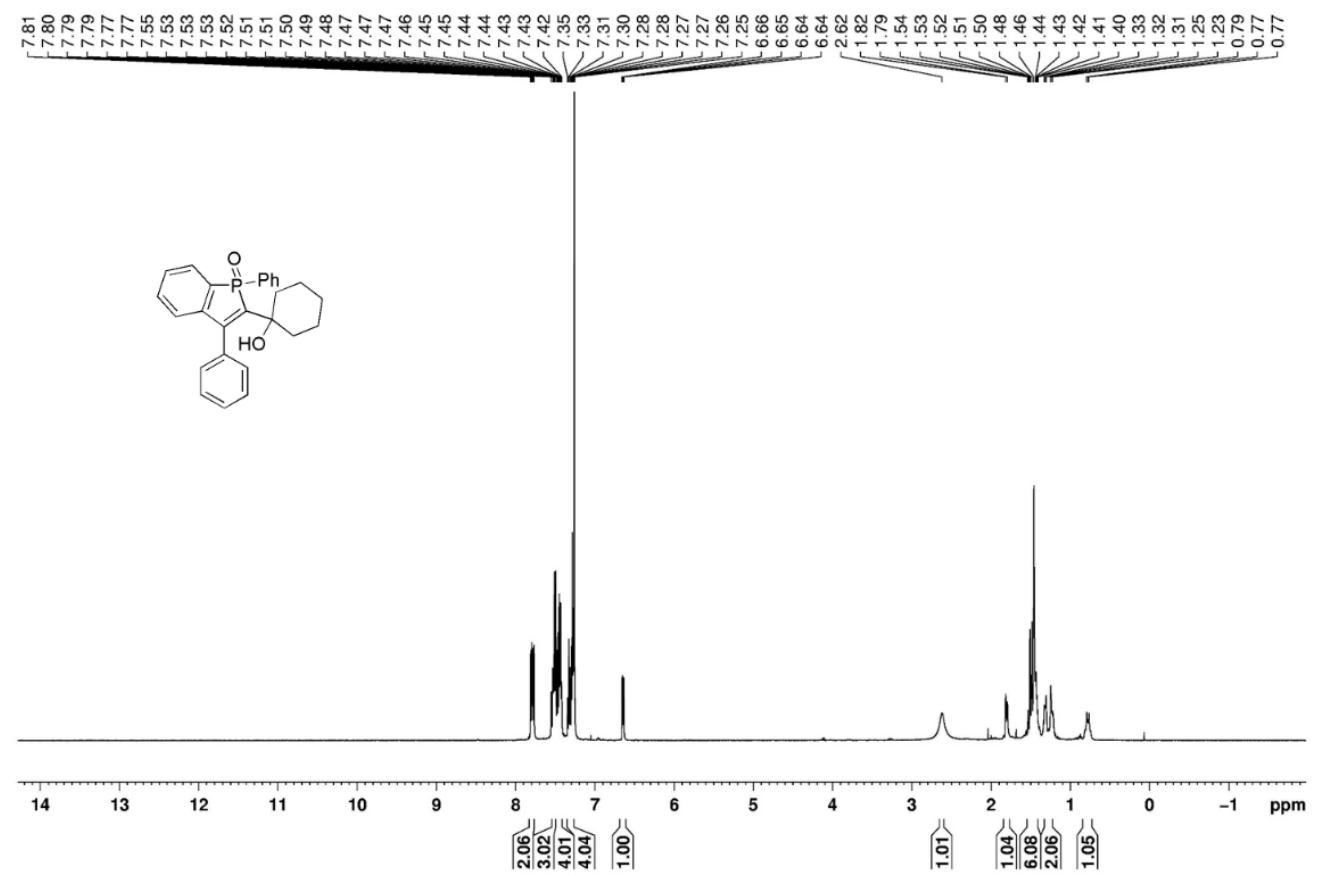

${ }^{1} \mathrm{H}$ NMR (500 MHz) spectrum of compound $\mathbf{3 q}$ in $\mathrm{CDCl}_{3}$ 


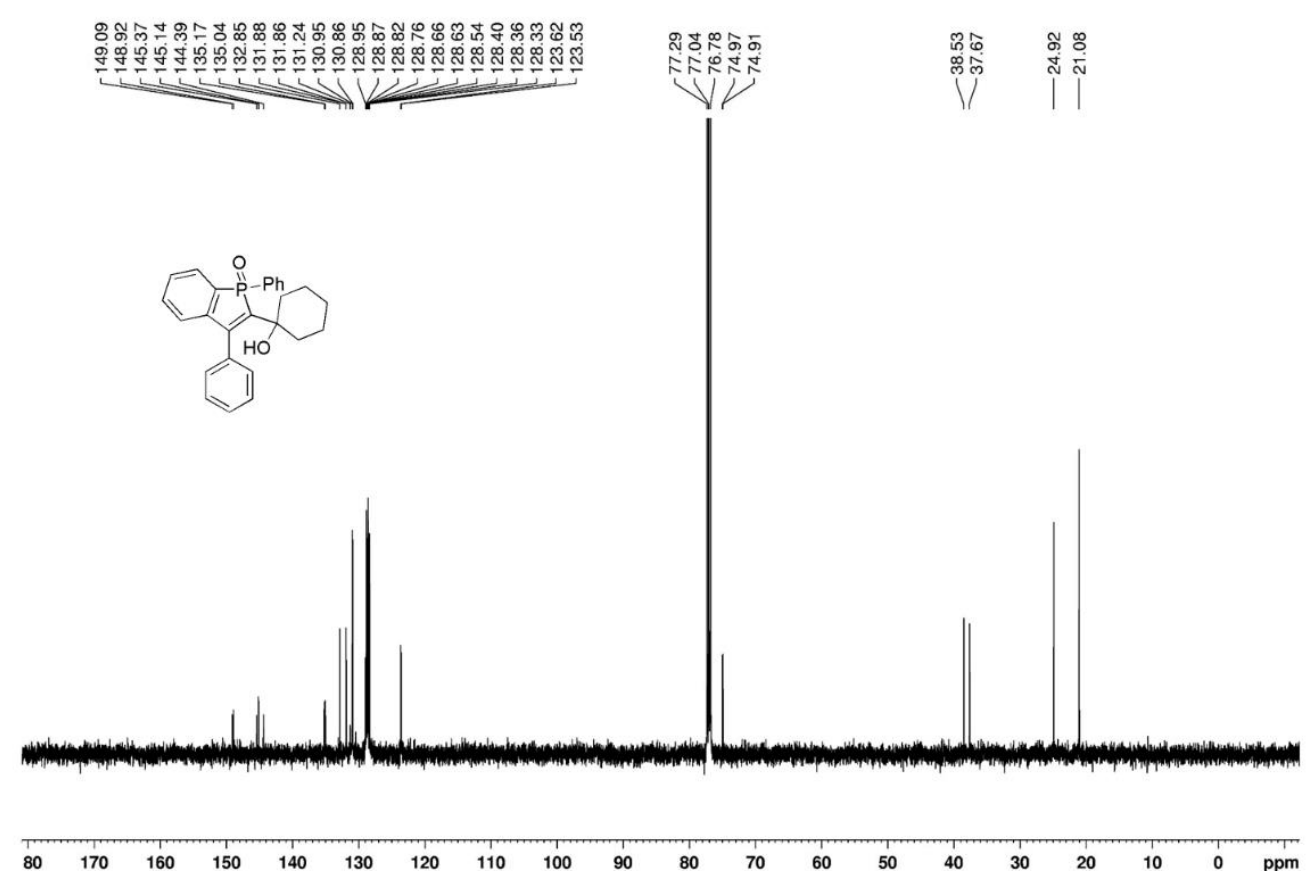

${ }^{13} \mathrm{C}$ NMR (500 MHz) spectrum of compound $\mathbf{3 q}$ in $\mathrm{CDCl}_{3}$

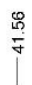

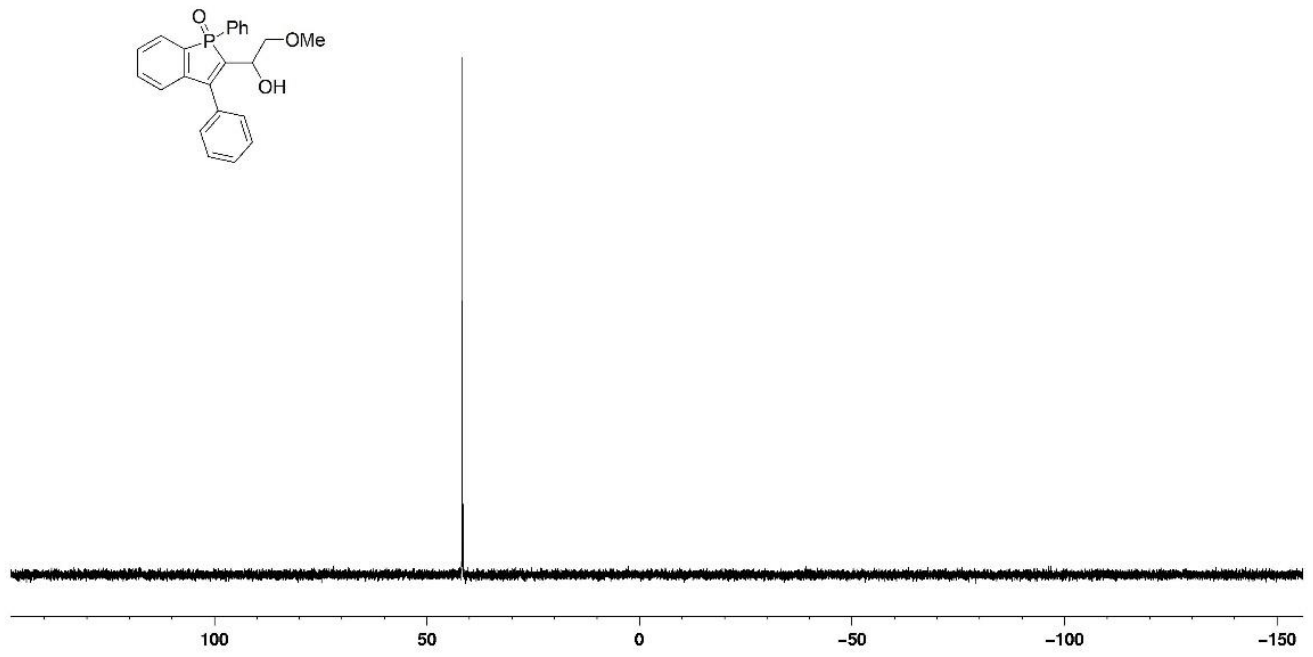

${ }^{31} \mathrm{P}$ NMR (500 MHz) spectrum of compound $\mathbf{3 r}$ in $\mathrm{CDCl}_{3}$ 


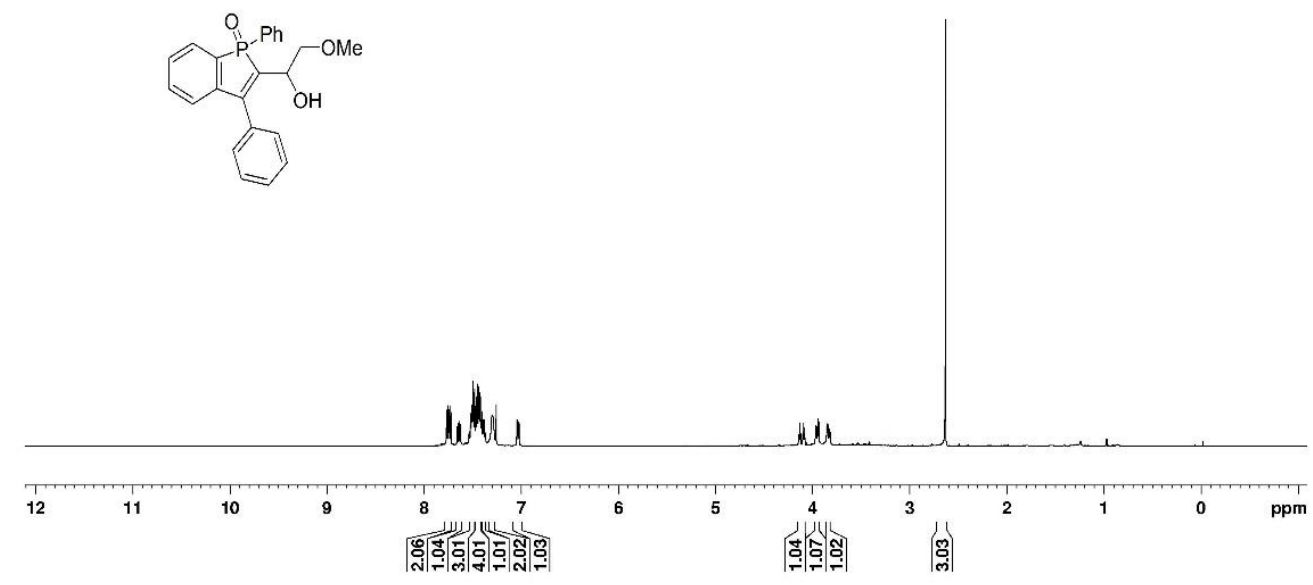

${ }^{1} \mathrm{H}$ NMR (500 MHz) spectrum of compound $3 \mathbf{r}$ in $\mathrm{CDCl}_{3}$

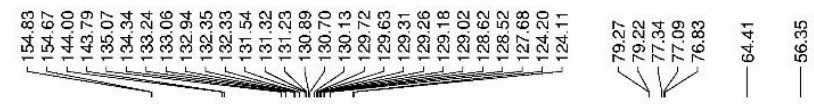

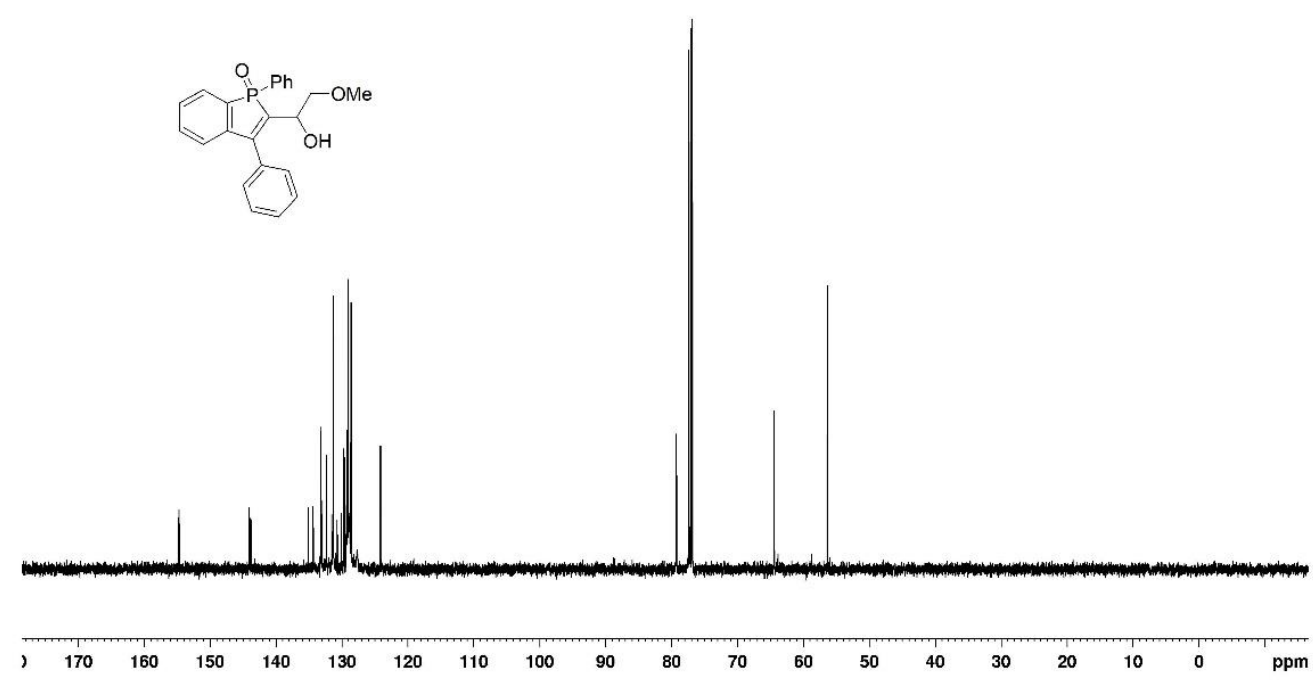

${ }^{13} \mathrm{C}$ NMR $(500 \mathrm{MHz})$ spectrum of compound $\mathbf{3 r}$ in $\mathrm{CDCl}_{3}$ 


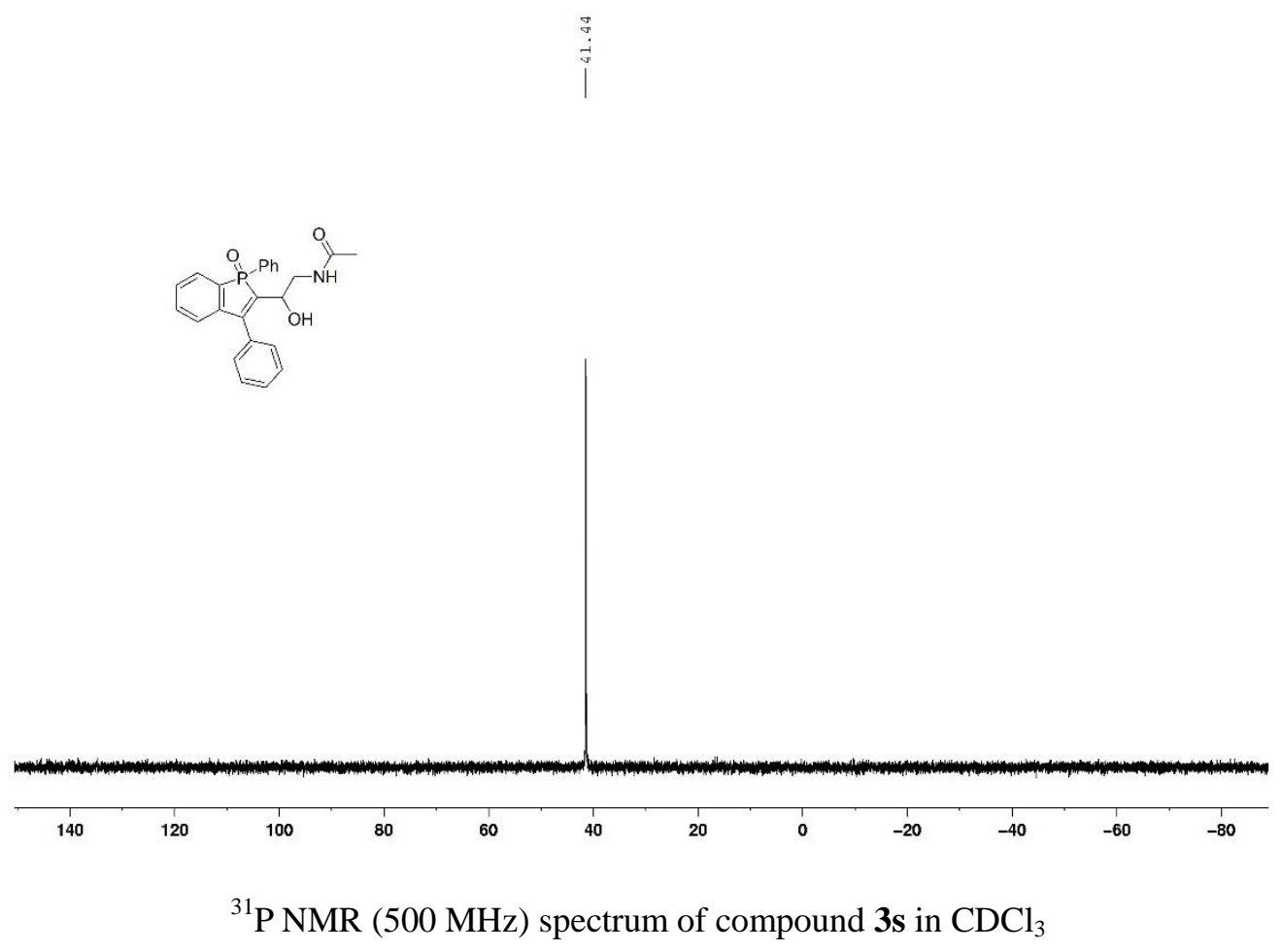

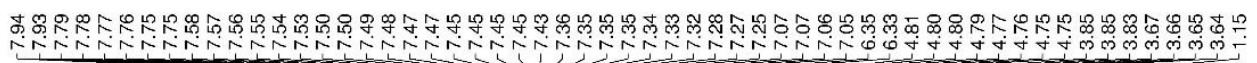

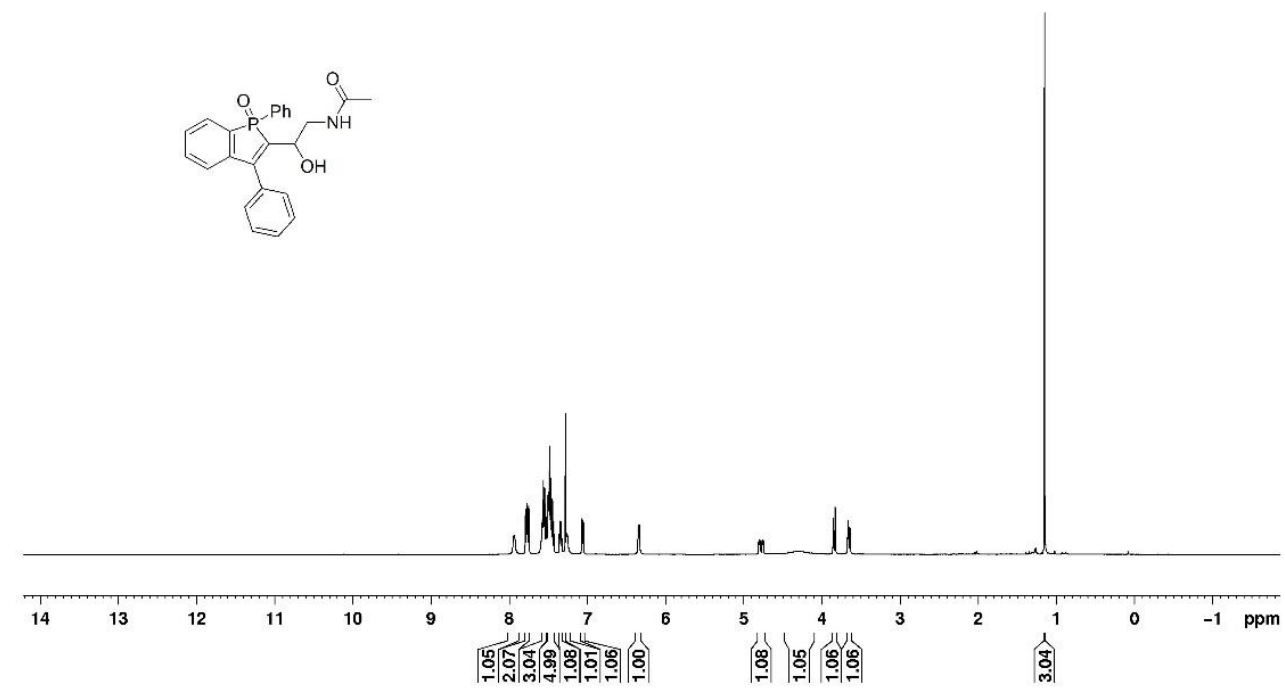

${ }^{1} \mathrm{H}$ NMR (500 MHz) spectrum of compound $3 \mathrm{~s}$ in $\mathrm{CDCl}_{3}$ 


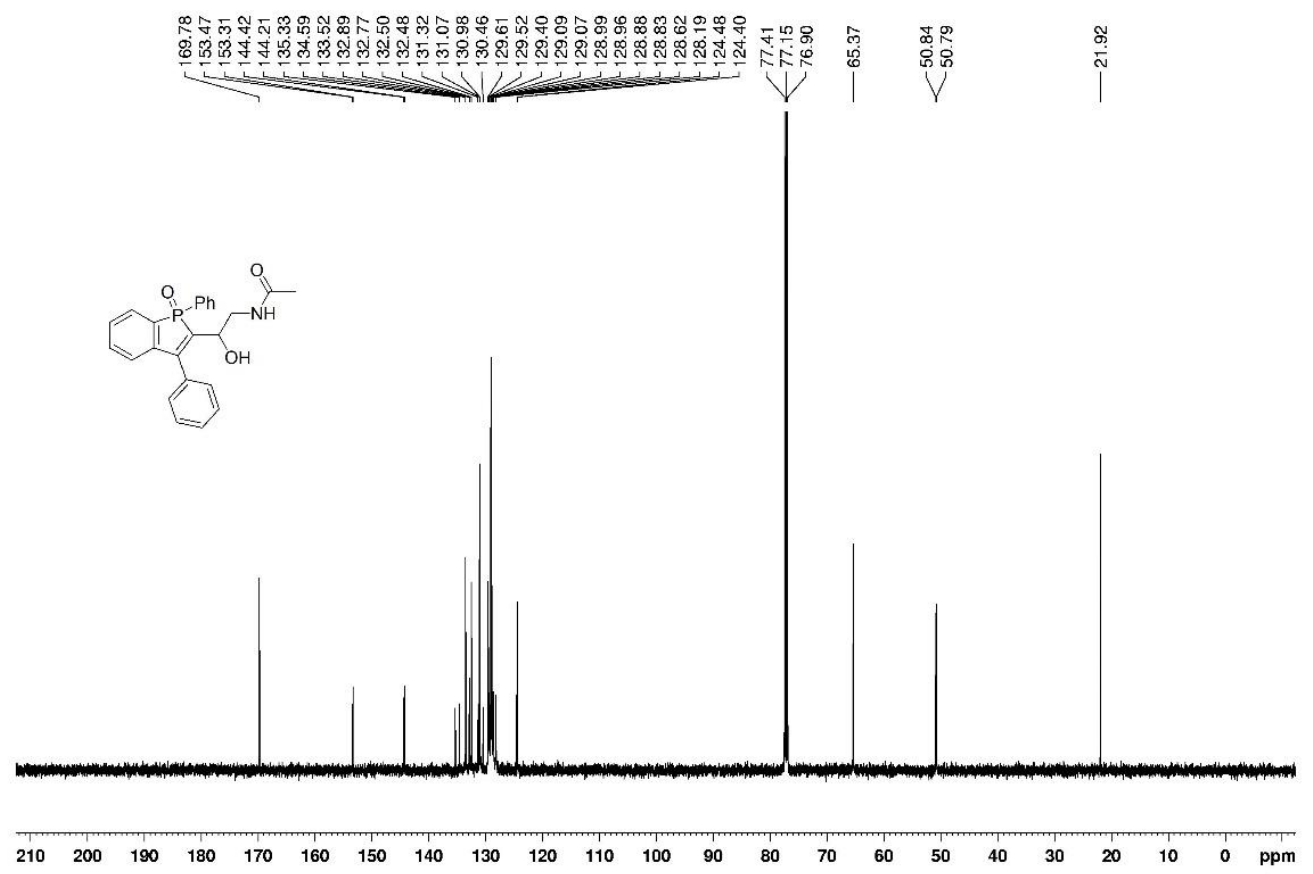

${ }^{13} \mathrm{C}$ NMR (500 MHz) spectrum of compound $3 \mathrm{~s}$ in $\mathrm{CDCl}_{3}$
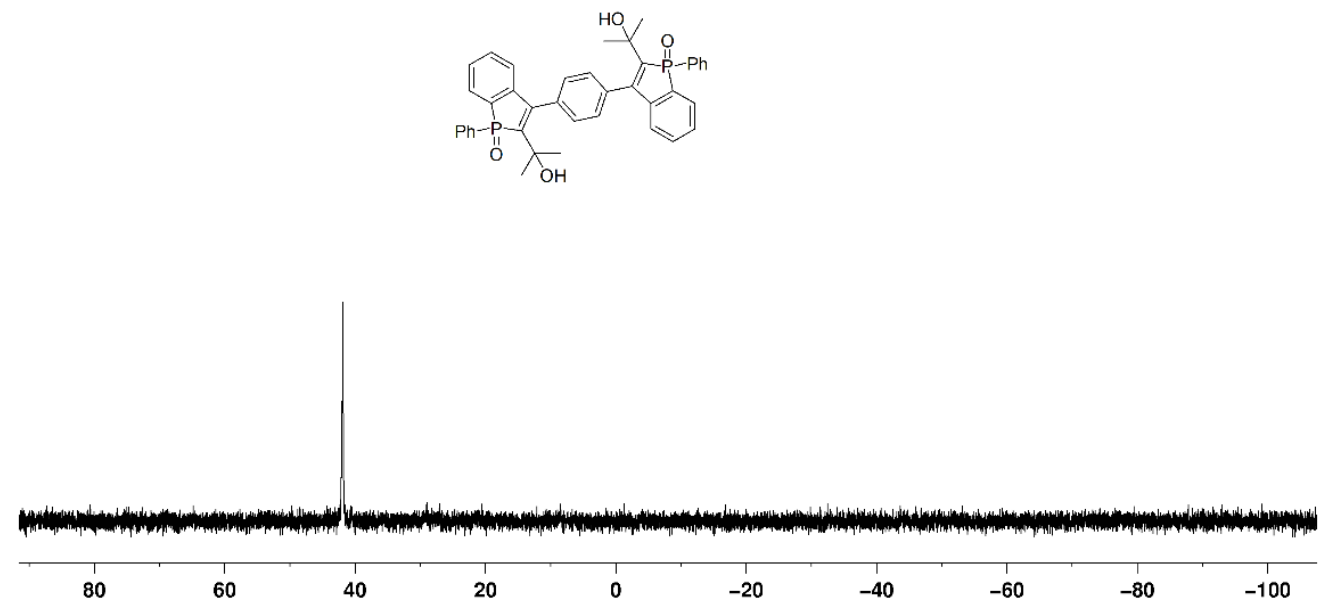

${ }^{31} \mathrm{P}$ NMR (500 MHz) spectrum of compound $3 \mathbf{u}$ in $\mathrm{CDCl}_{3}$ 


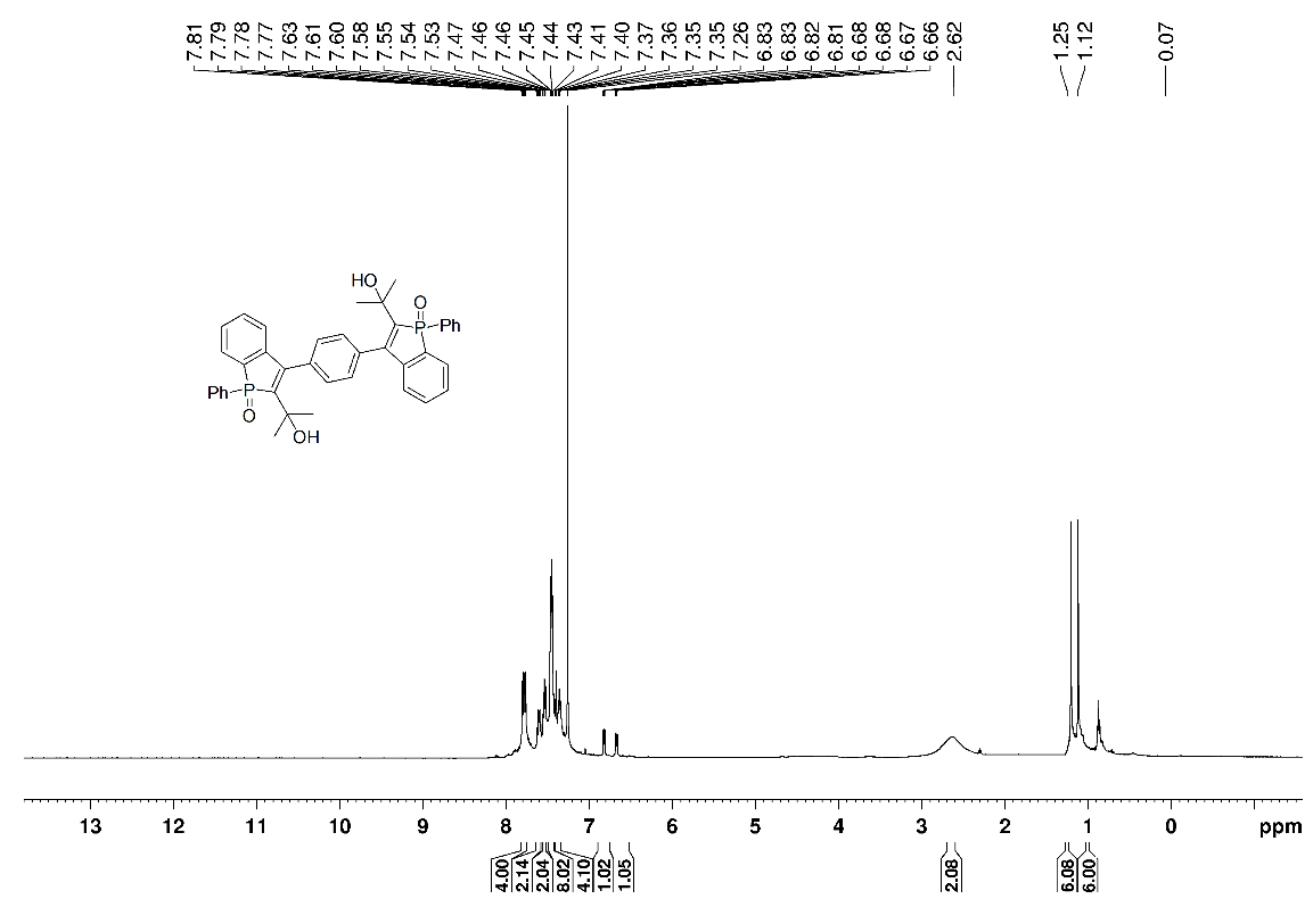

${ }^{1} \mathrm{H}$ NMR $(500 \mathrm{MHz})$ spectrum of compound $3 \mathbf{u}$ in $\mathrm{CDCl}_{3}$
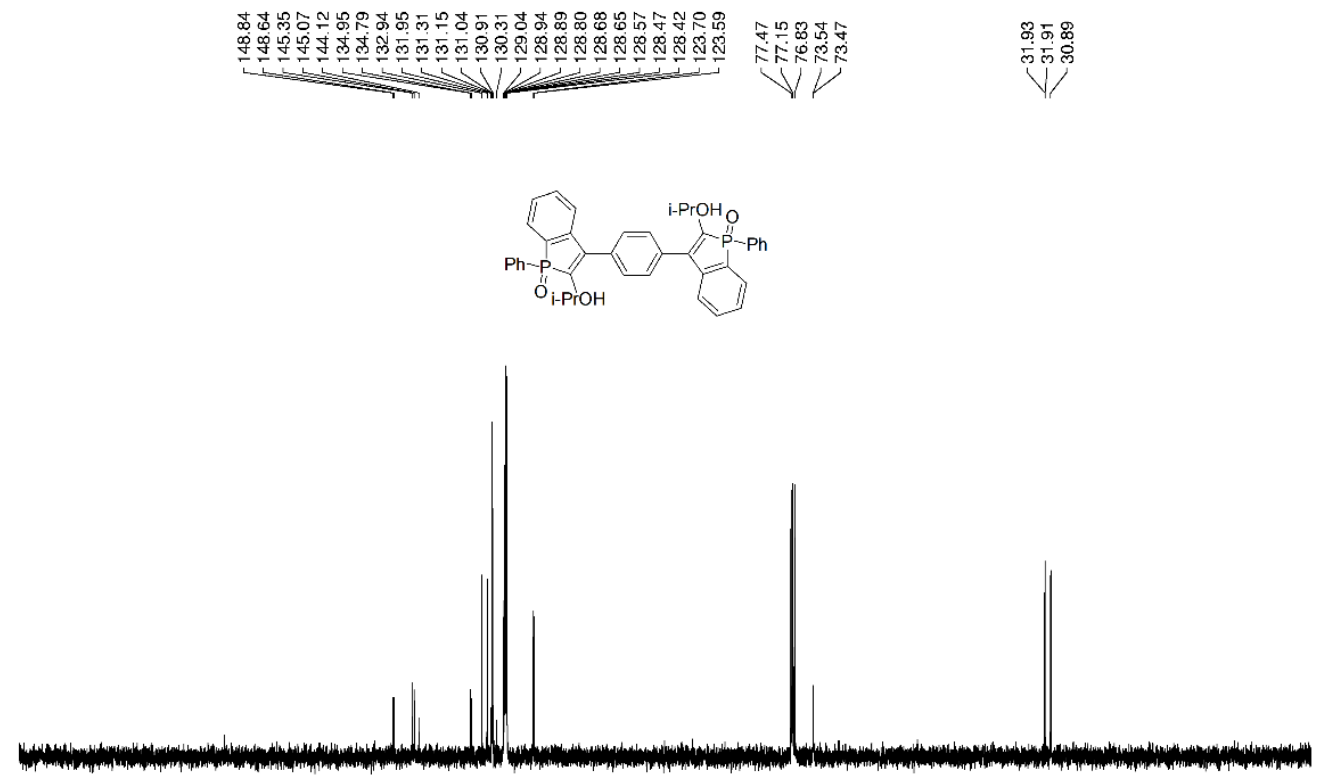

$\begin{array}{lllllllllllllllllllllll}210 & 200 & 190 & 180 & 170 & 160 & 150 & 140 & 130 & 120 & 110 & 100 & 90 & 80 & 70 & 60 & 50 & 40 & 30 & 20 & 10 & 0 & \mathrm{ppm}\end{array}$

${ }^{13} \mathrm{C}$ NMR (500 MHz) spectrum of compound $3 \mathbf{u}$ in $\mathrm{CDCl}_{3}$ 


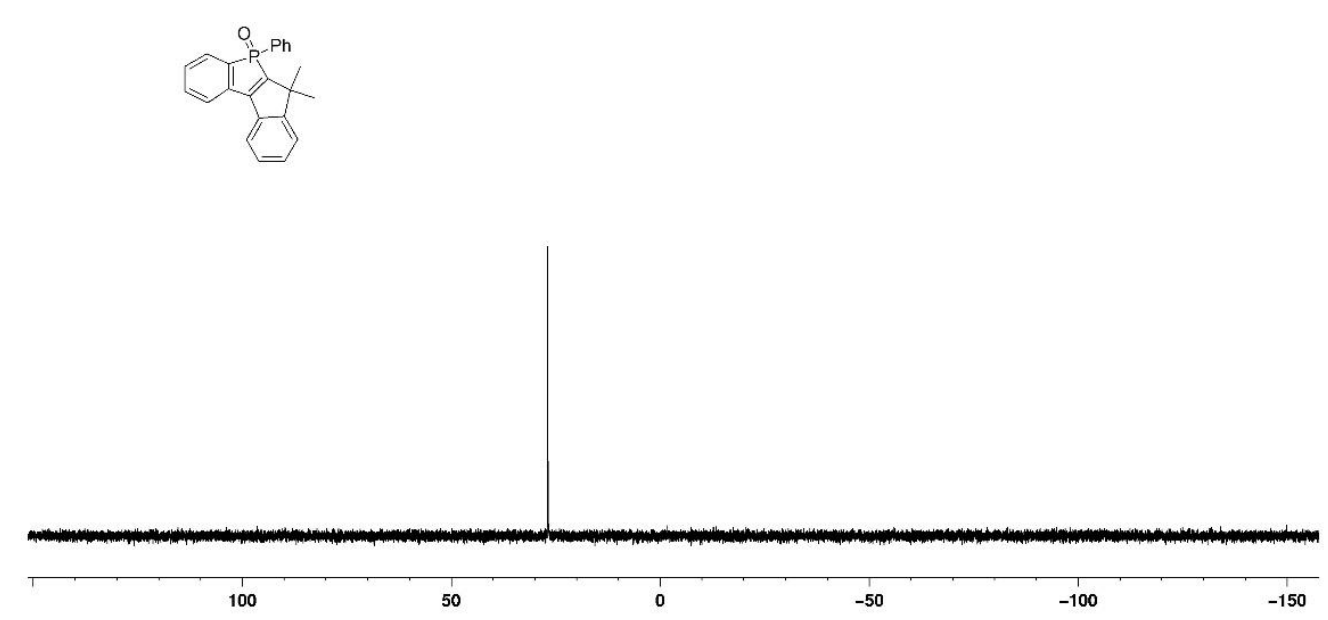

${ }^{31} \mathrm{P}$ NMR (400 MHz) spectrum of compound $4 \mathbf{a}$ in $\mathrm{CDCl}_{3}$

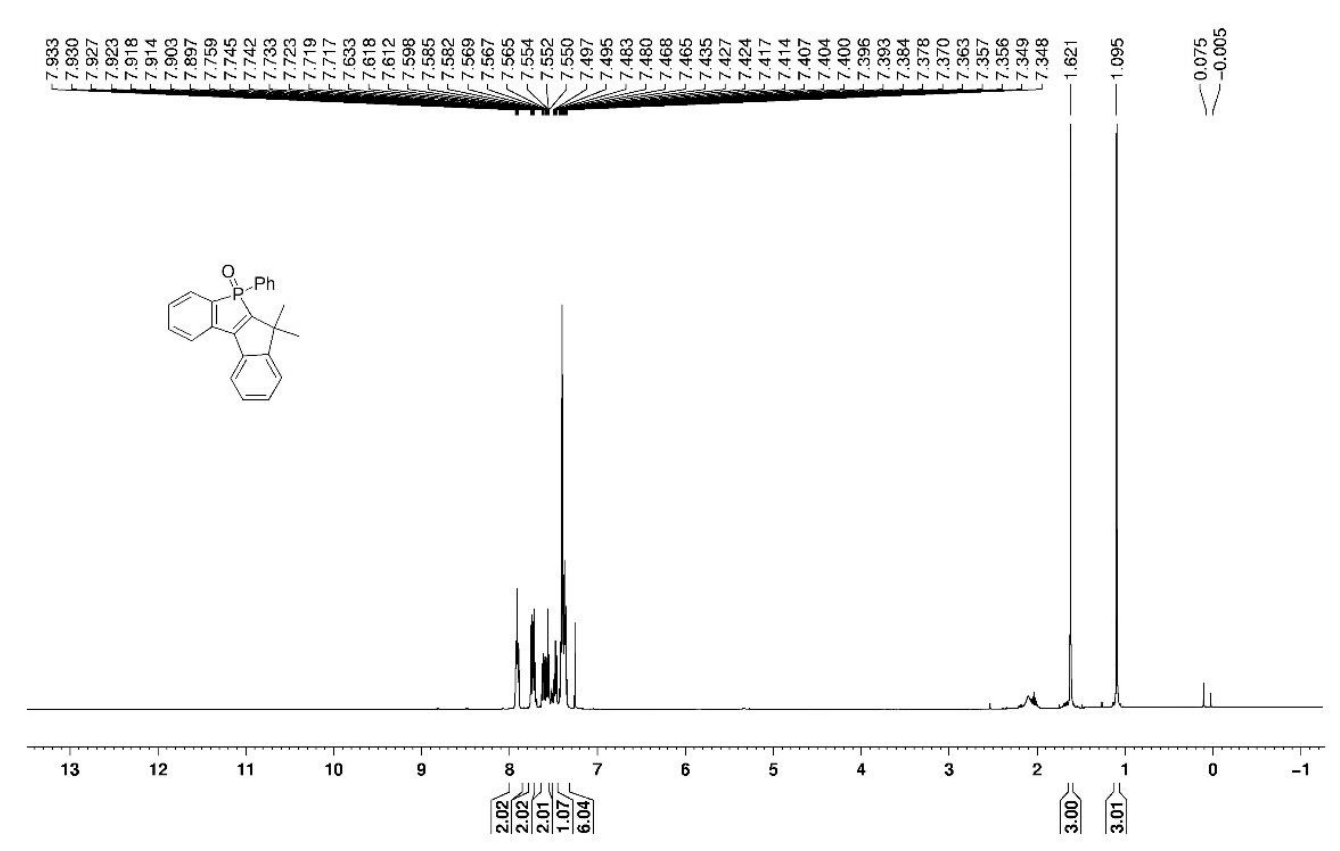

${ }^{1} \mathrm{H}$ NMR (400 MHz) spectrum of compound 4a in $\mathrm{CDCl}_{3}$ 


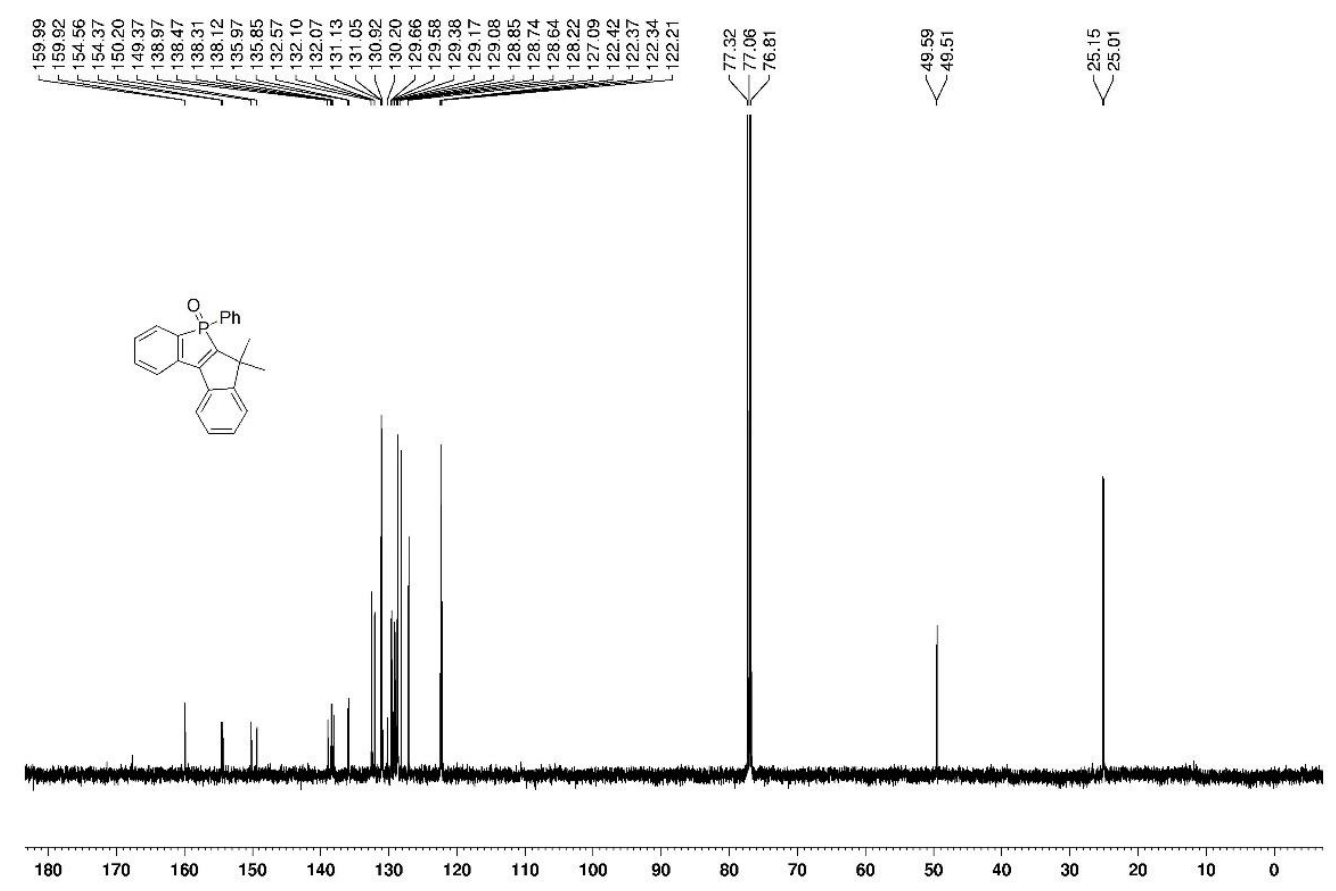

${ }^{13} \mathrm{C}$ NMR (400 MHz) spectrum of compound $\mathbf{4 a}$ in $\mathrm{CDCl}_{3}$

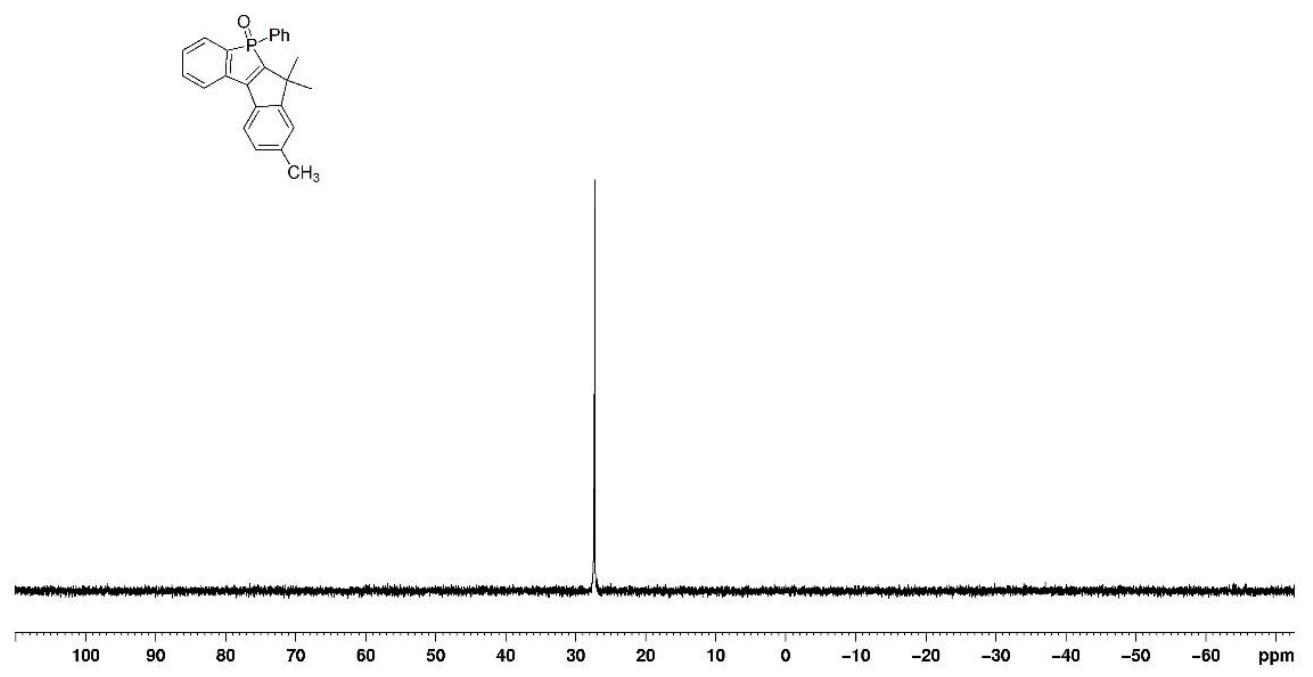

${ }^{31} \mathrm{P} \mathrm{NMR}(400 \mathrm{MHz})$ spectrum of compound $\mathbf{4 b}$ in $\mathrm{CDCl}_{3}$ 


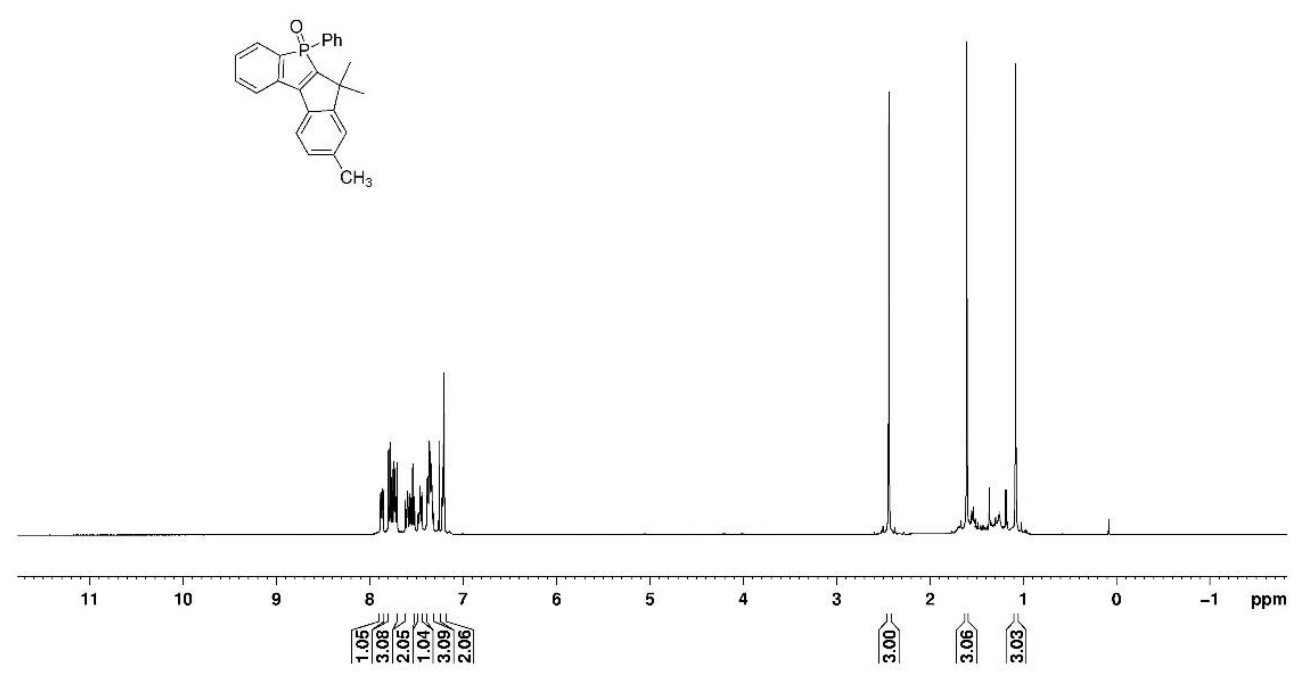

${ }^{1} \mathrm{H}$ NMR (400 MHz) spectrum of compound $\mathbf{4 b}$ in $\mathrm{CDCl}_{3}$

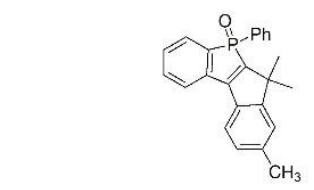

$\begin{array}{llllllllllllllllllllll}190 & 180 & 170 & 160 & 150 & 140 & 130 & 120 & 110 & 100 & 90 & 80 & 70 & 60 & 50 & 40 & 30 & 20 & 10 & 0 & -10 & \mathrm{ppm}\end{array}$

${ }^{13} \mathrm{C}$ NMR (500 MHz) spectrum of compound $\mathbf{4 b}$ in $\mathrm{CDCl}_{3}$ 

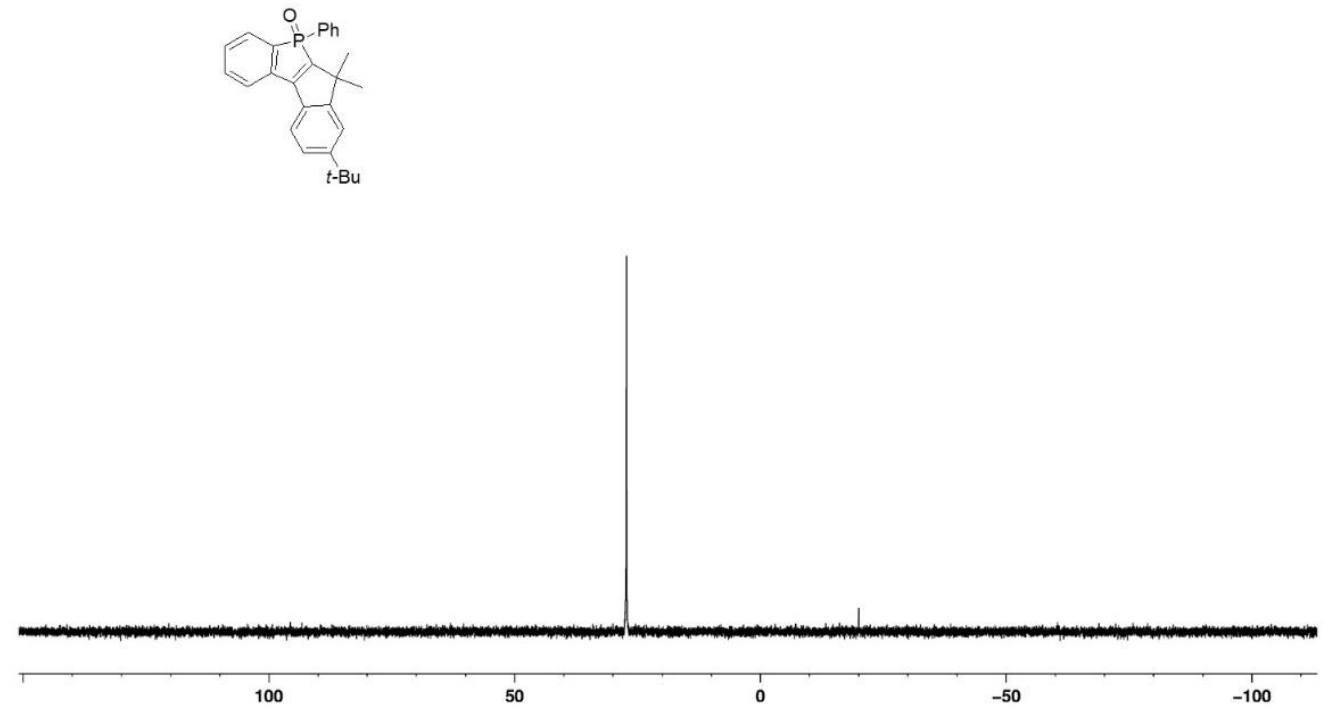

${ }^{31} \mathrm{P}$ NMR $(500 \mathrm{MHz})$ spectrum of compound $\mathbf{4 c}$ in $\mathrm{CDCl}_{3}$

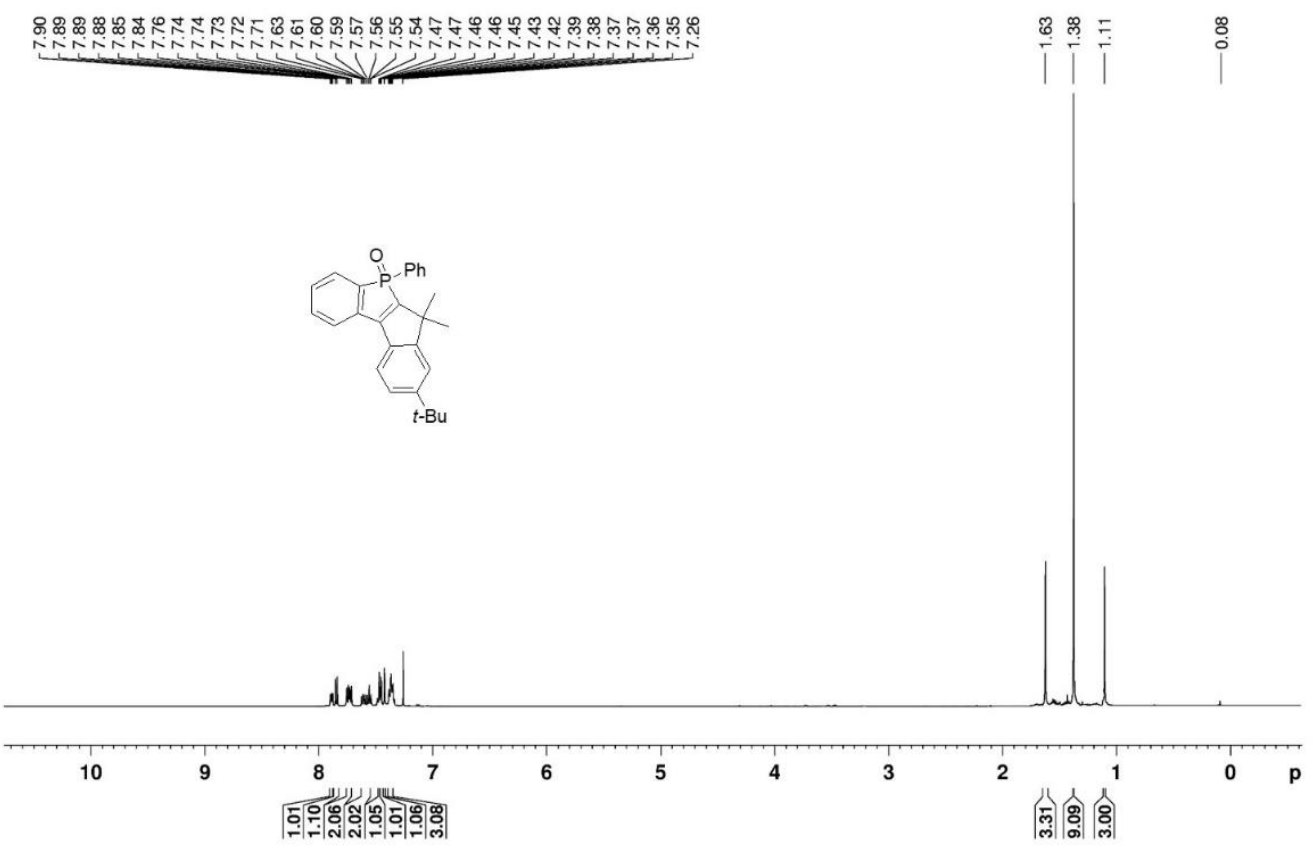

${ }^{1} \mathrm{H}$ NMR (500 MHz) spectrum of compound $\mathbf{4 c}$ in $\mathrm{CDCl}_{3}$ 


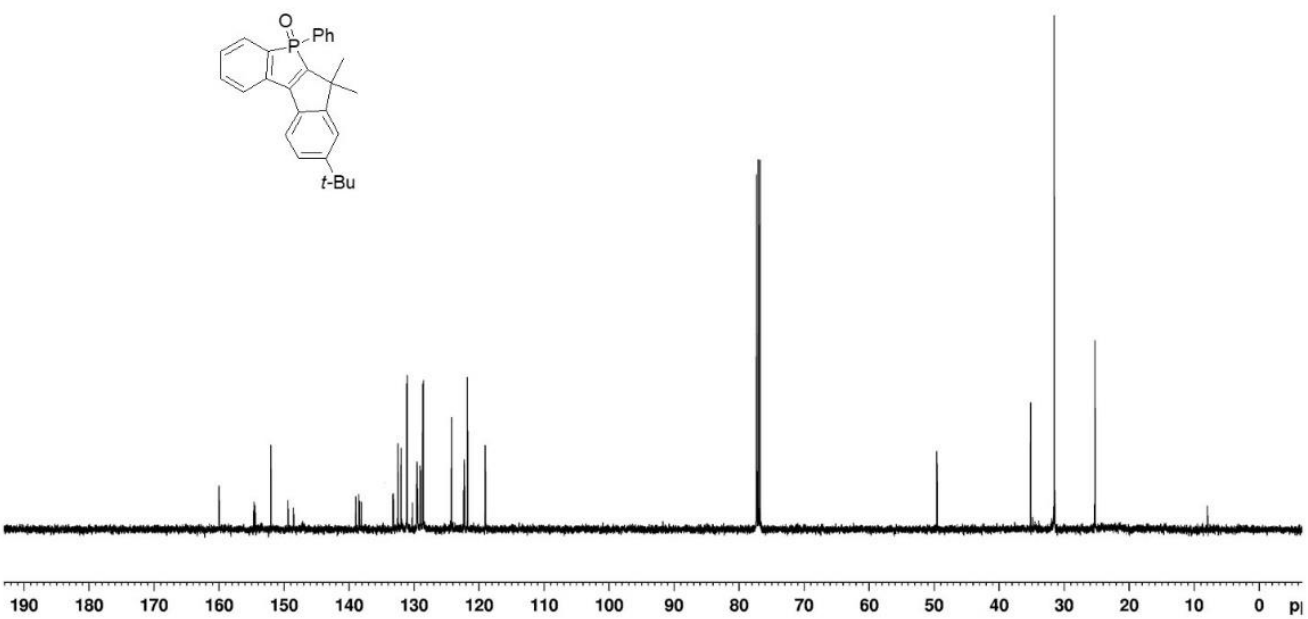

${ }^{13} \mathrm{C}$ NMR (500 MHz) spectrum of compound $\mathbf{4 c}$ in $\mathrm{CDCl}_{3}$

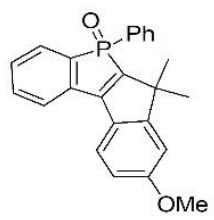

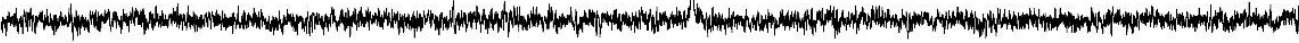
100 50 $-50$

${ }^{31} \mathrm{P}$ NMR (500 MHz) spectrum of compound $\mathbf{4 d}$ in $\mathrm{CDCl}_{3}$ 


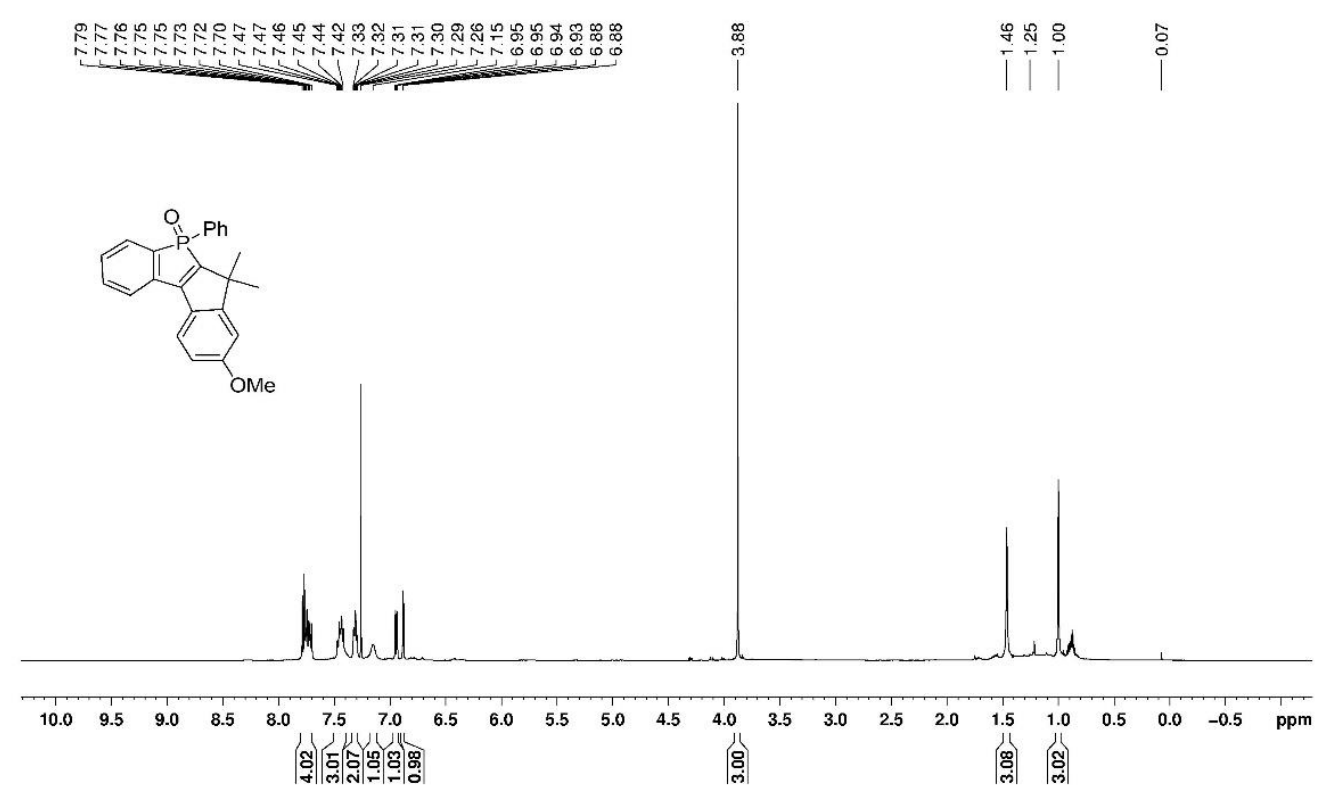

${ }^{1} \mathrm{H}$ NMR (500 MHz) spectrum of compound $\mathbf{4 d}$ in $\mathrm{CDCl}_{3}$

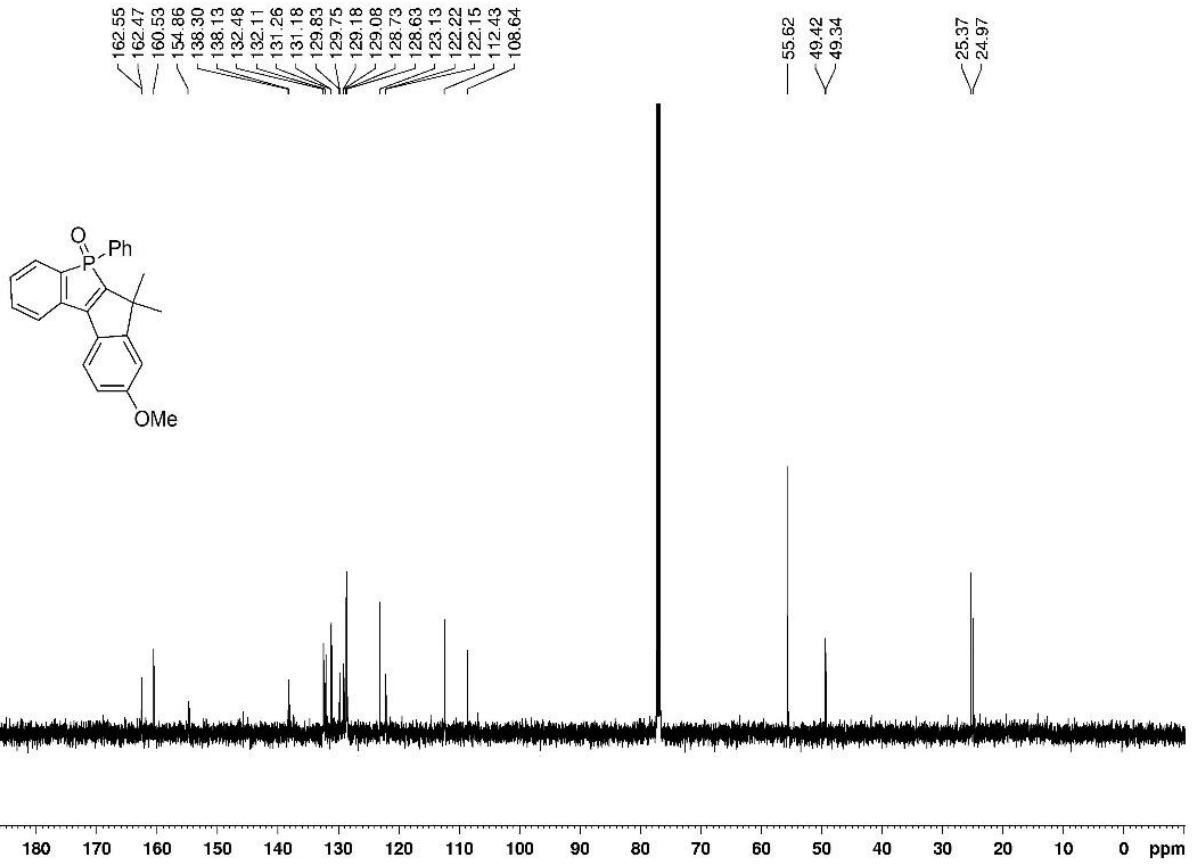

${ }^{13} \mathrm{C}$ NMR (500 MHz) spectrum of compound $\mathbf{4 d}$ in $\mathrm{CDCl}_{3}$ 


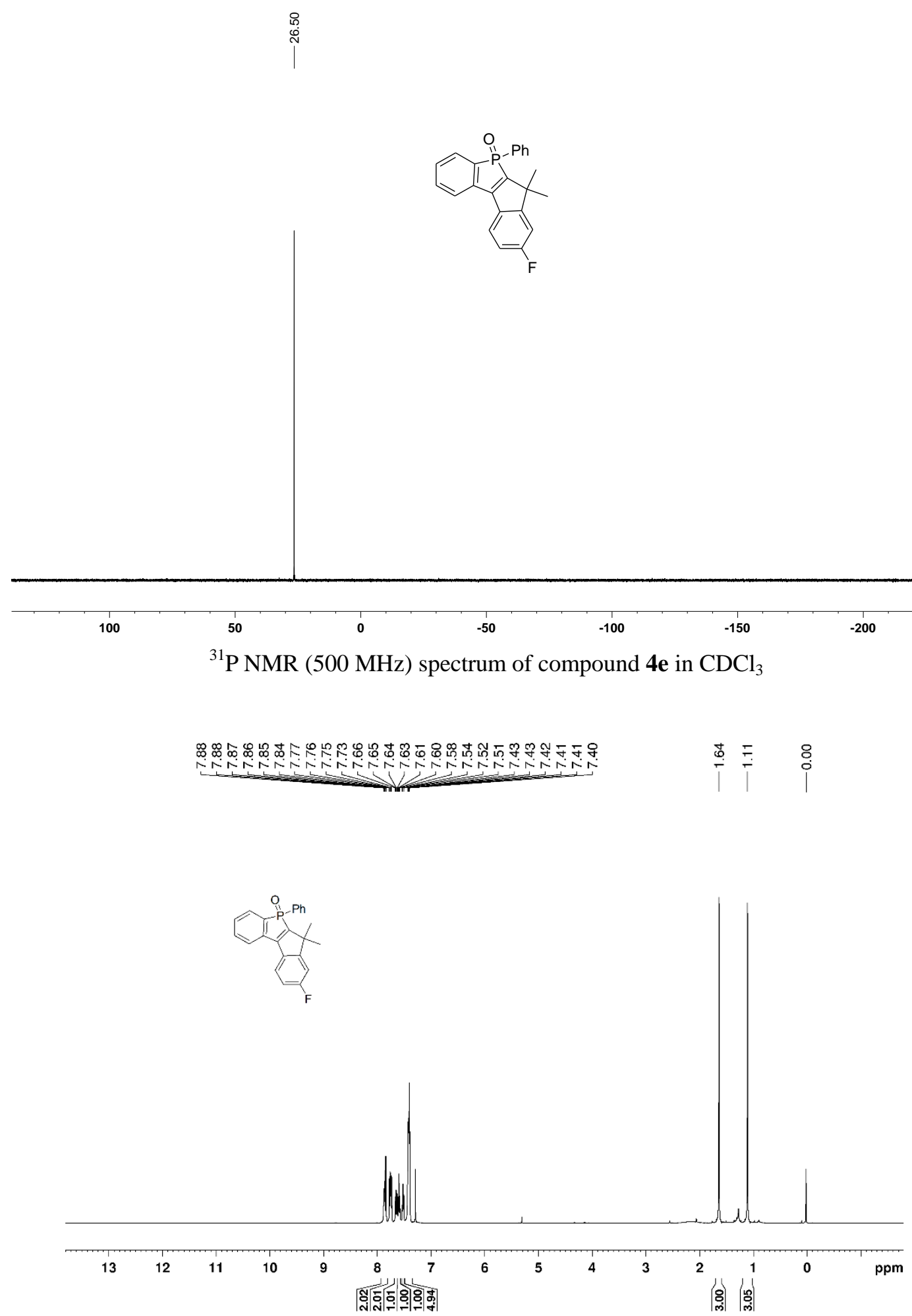

${ }^{1} \mathrm{H}$ NMR (500 MHz) spectrum of compound $4 \mathbf{e}$ in $\mathrm{CDCl}_{3}$ 


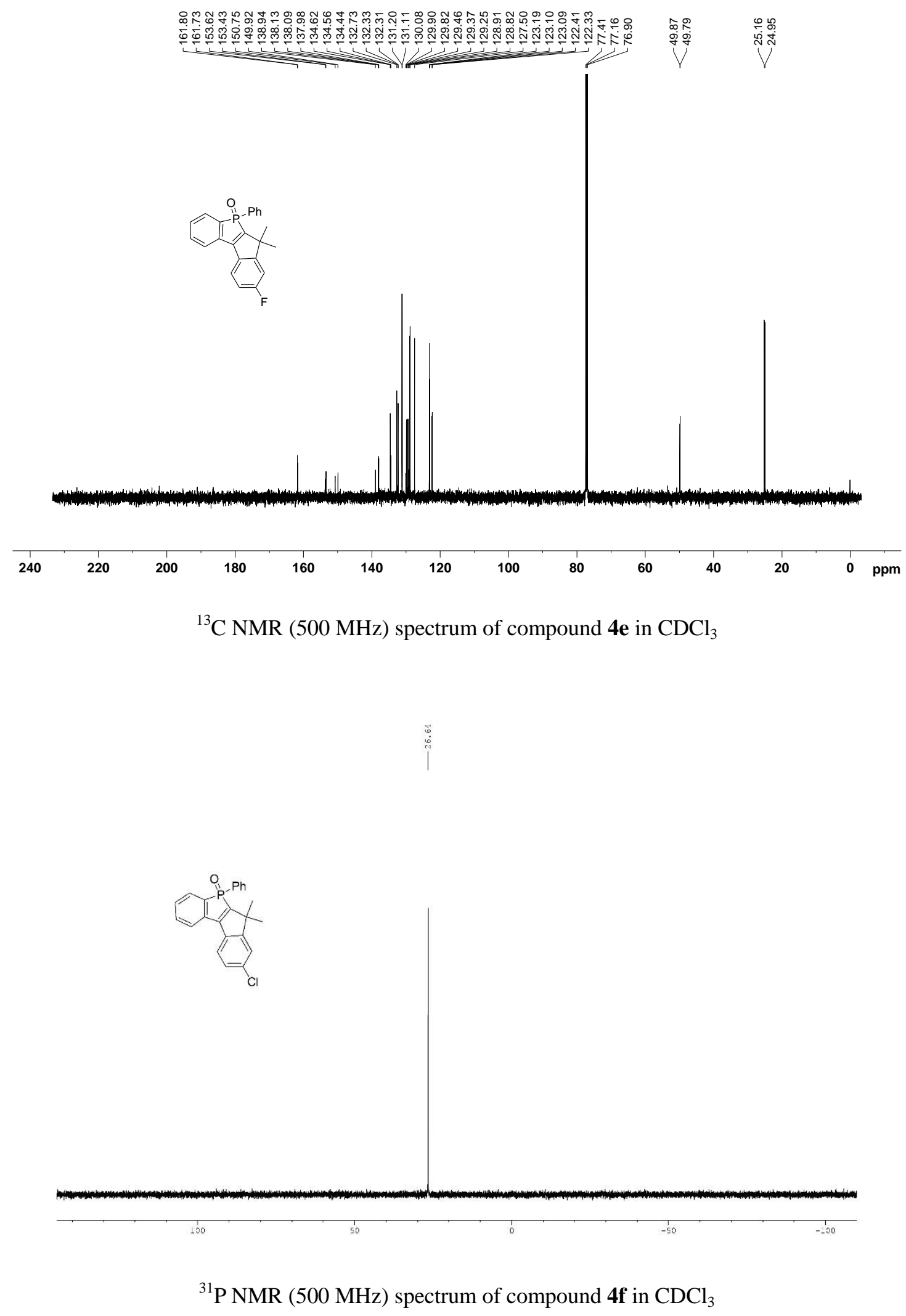



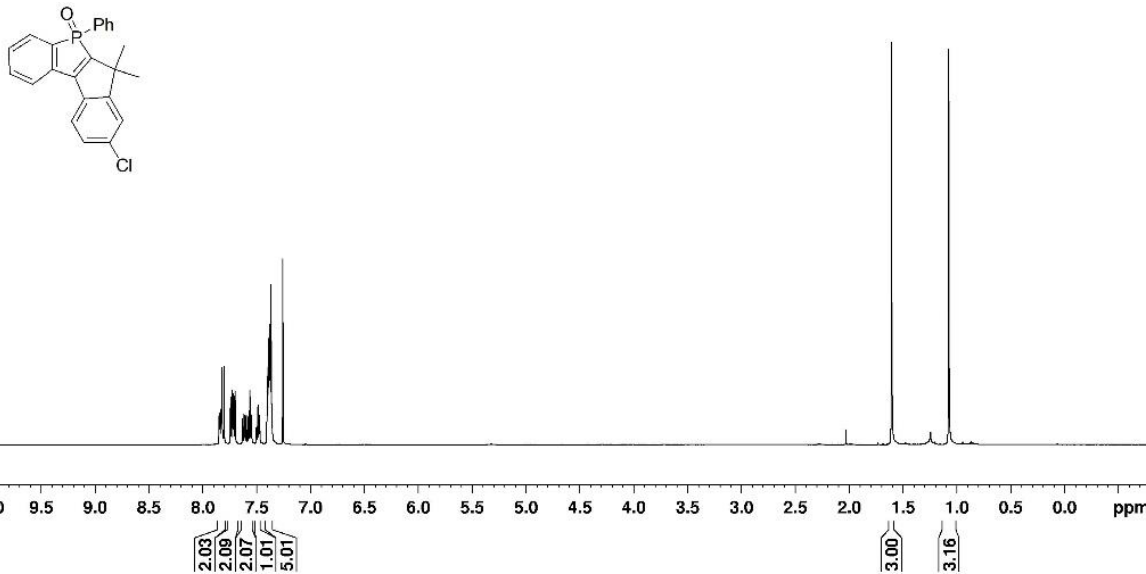

${ }^{1} \mathrm{H}$ NMR (500 MHz) spectrum of compound $\mathbf{4} \mathbf{f}$ in $\mathrm{CDCl}_{3}$

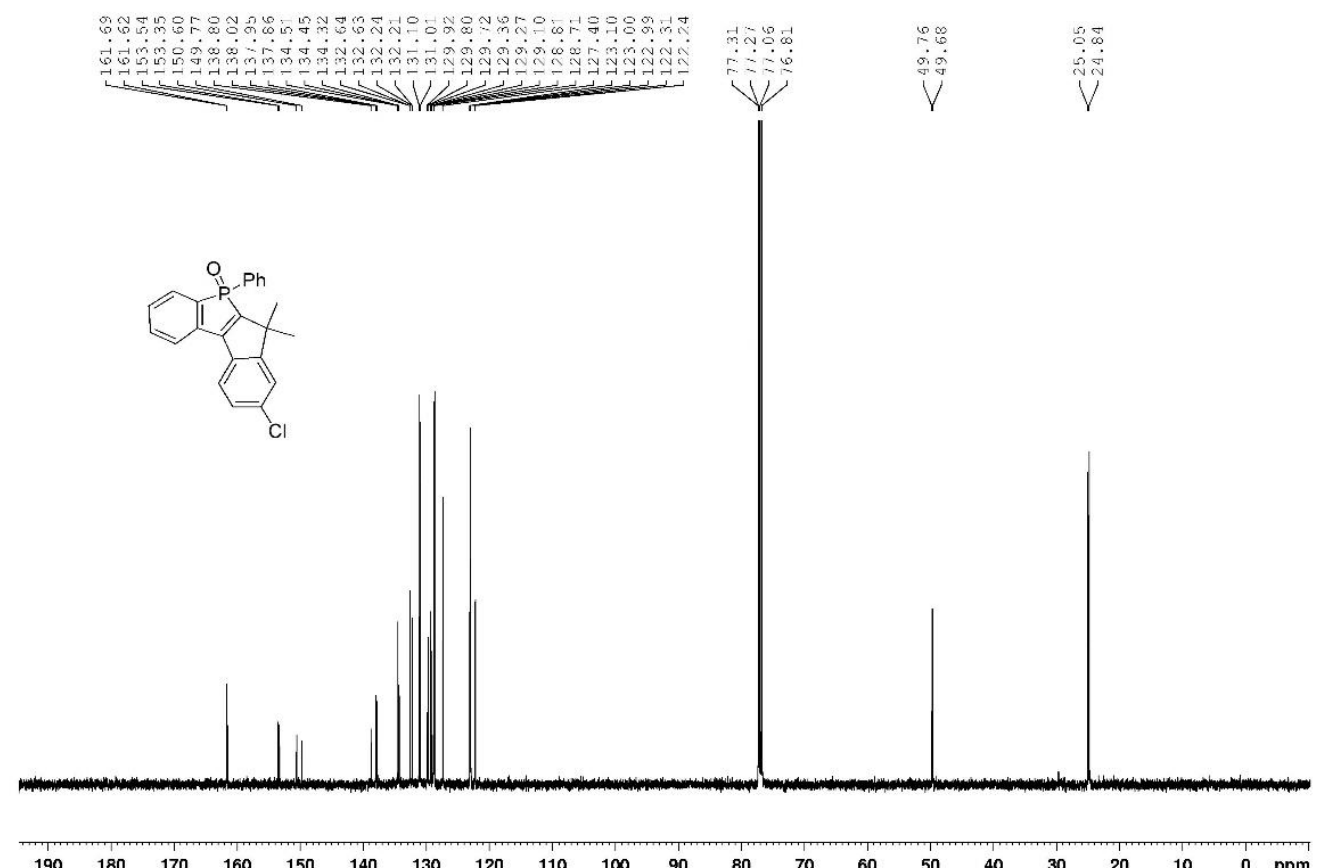

${ }^{13} \mathrm{C}$ NMR (500 MHz) spectrum of compound $\mathbf{4 f}$ in $\mathrm{CDCl}_{3}$ 


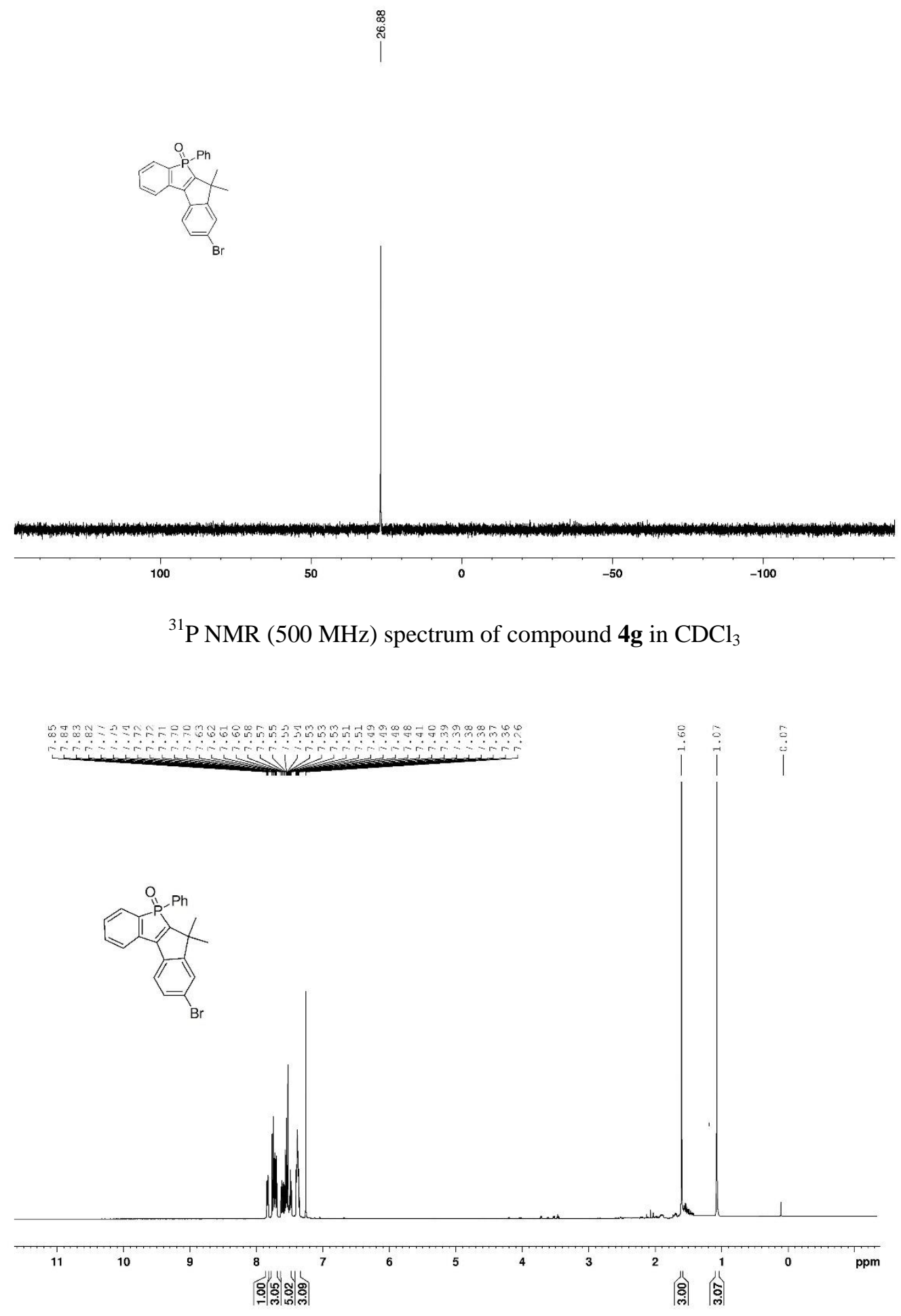

${ }^{1} \mathrm{H}$ NMR (400 MHz) spectrum of compound $\mathbf{4 g}$ in $\mathrm{CDCl}_{3}$ 


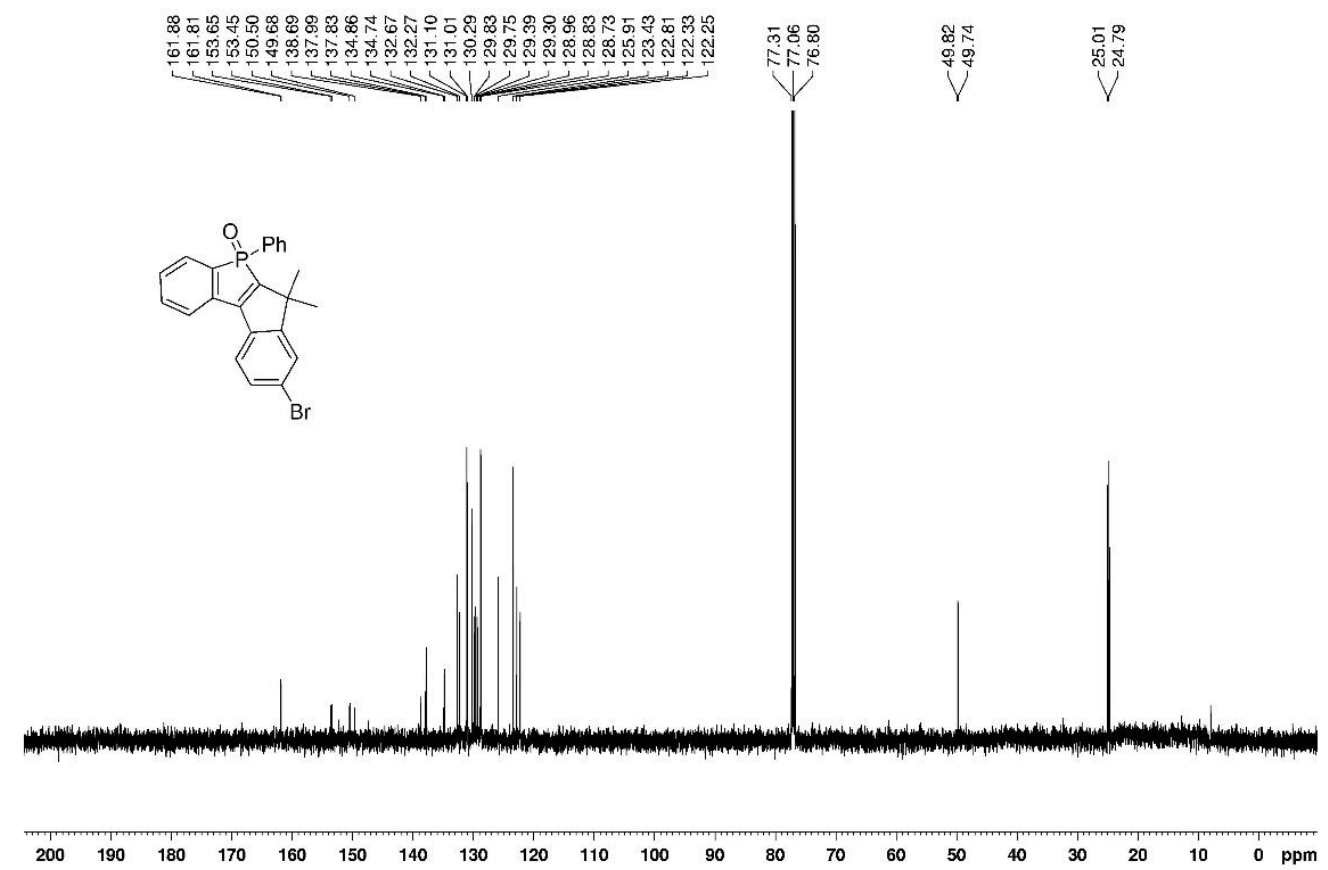

${ }^{13} \mathrm{C}$ NMR (400 MHz) spectrum of compound $\mathbf{4 g}$ in $\mathrm{CDCl}_{3}$

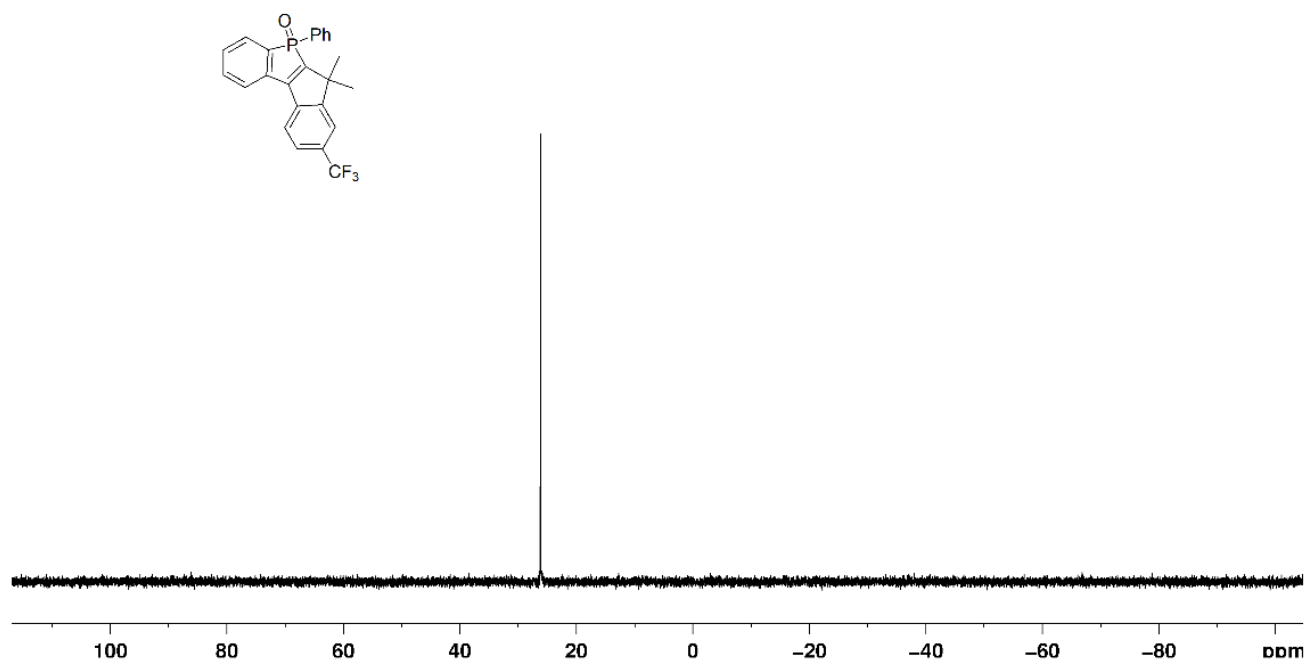

${ }^{31} \mathrm{P}$ NMR (400 MHz) spectrum of compound $\mathbf{4 h}$ in $\mathrm{CDCl}_{3}$ 


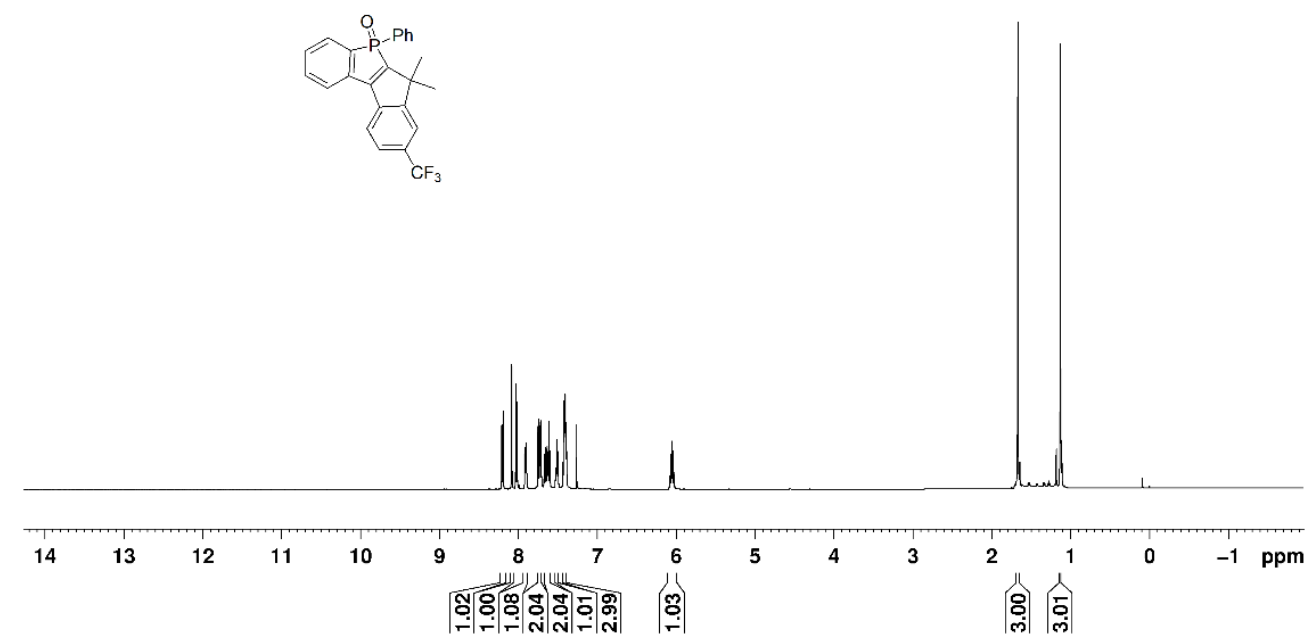

${ }^{1} \mathrm{H}$ NMR (400 MHz) spectrum of compound $\mathbf{4 h}$ in $\mathrm{CDCl}_{3}$
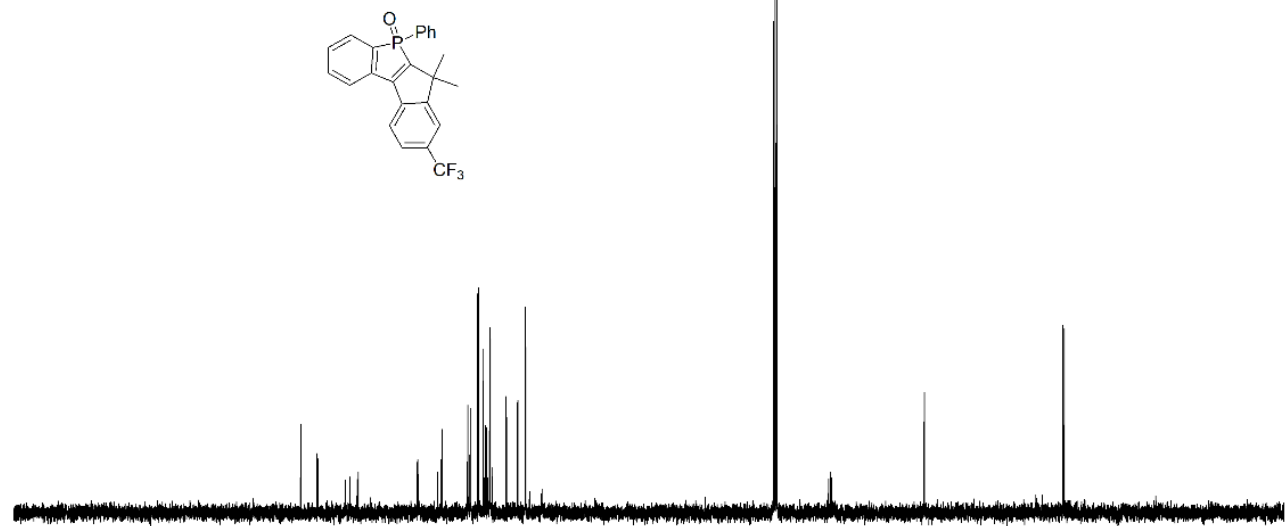

$\begin{array}{llllllllllllllllllllllll}210 & 200 & 190 & 180 & 170 & 160 & 150 & 140 & 130 & 120 & 110 & 100 & 90 & 80 & 70 & 60 & 50 & 40 & 30 & 20 & 10 & 0 & \mathrm{ppm}\end{array}$

${ }^{13} \mathrm{C}$ NMR (500 MHz) spectrum of compound $\mathbf{4 h}$ in $\mathrm{CDCl}_{3}$ 


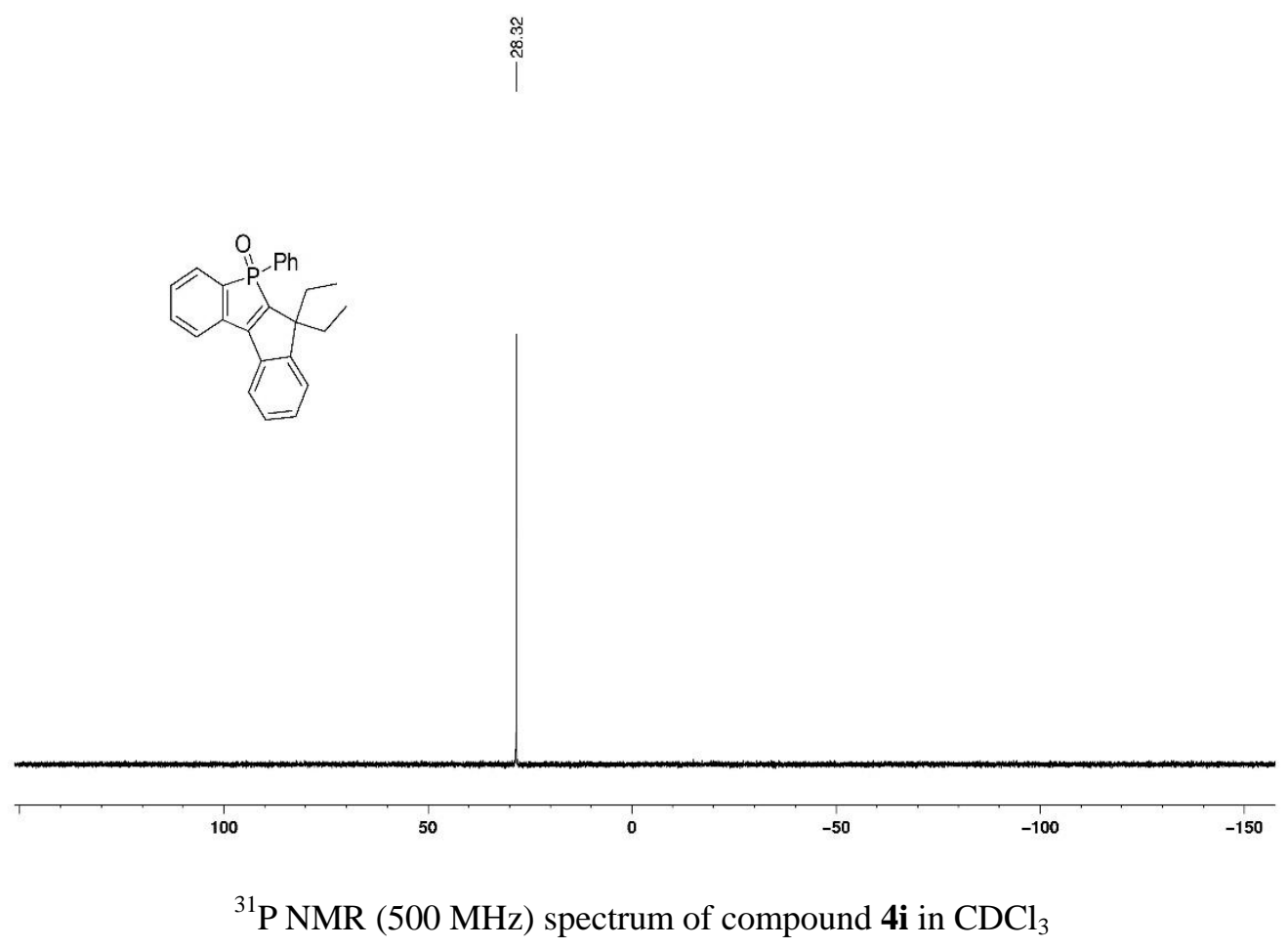

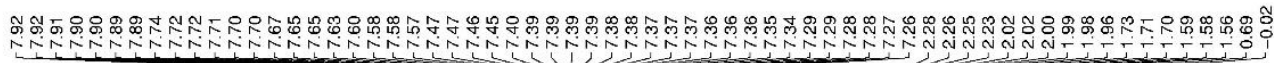

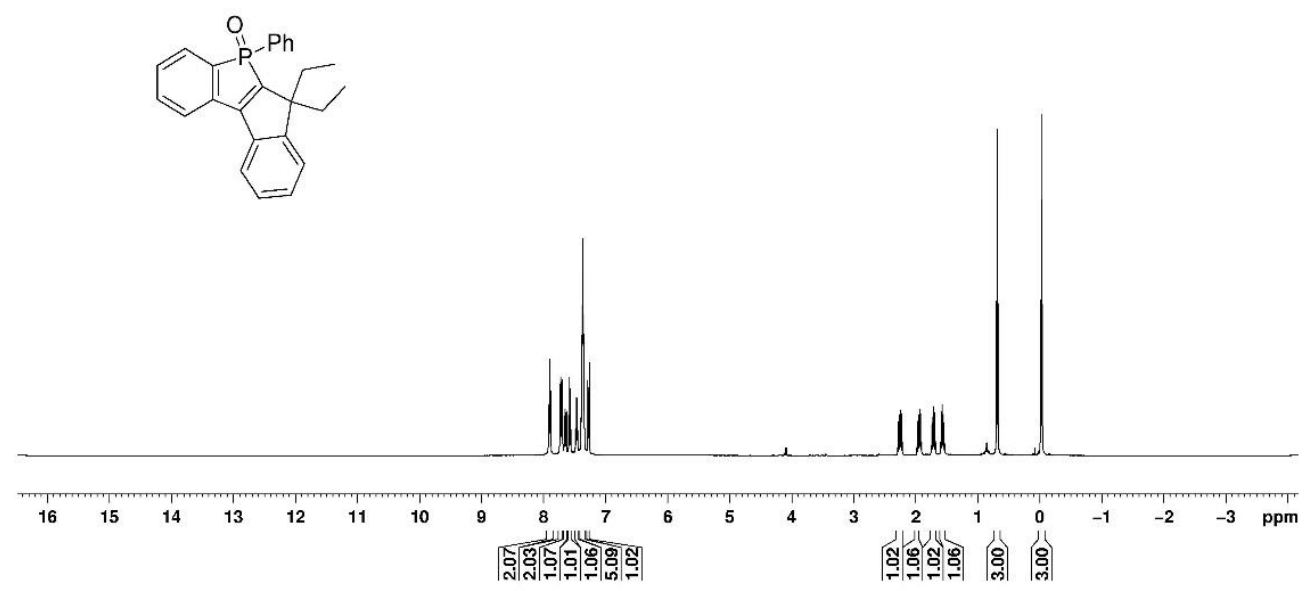

${ }^{1} \mathrm{H}$ NMR (400 MHz) spectrum of compound 4i in $\mathrm{CDCl}_{3}$ 

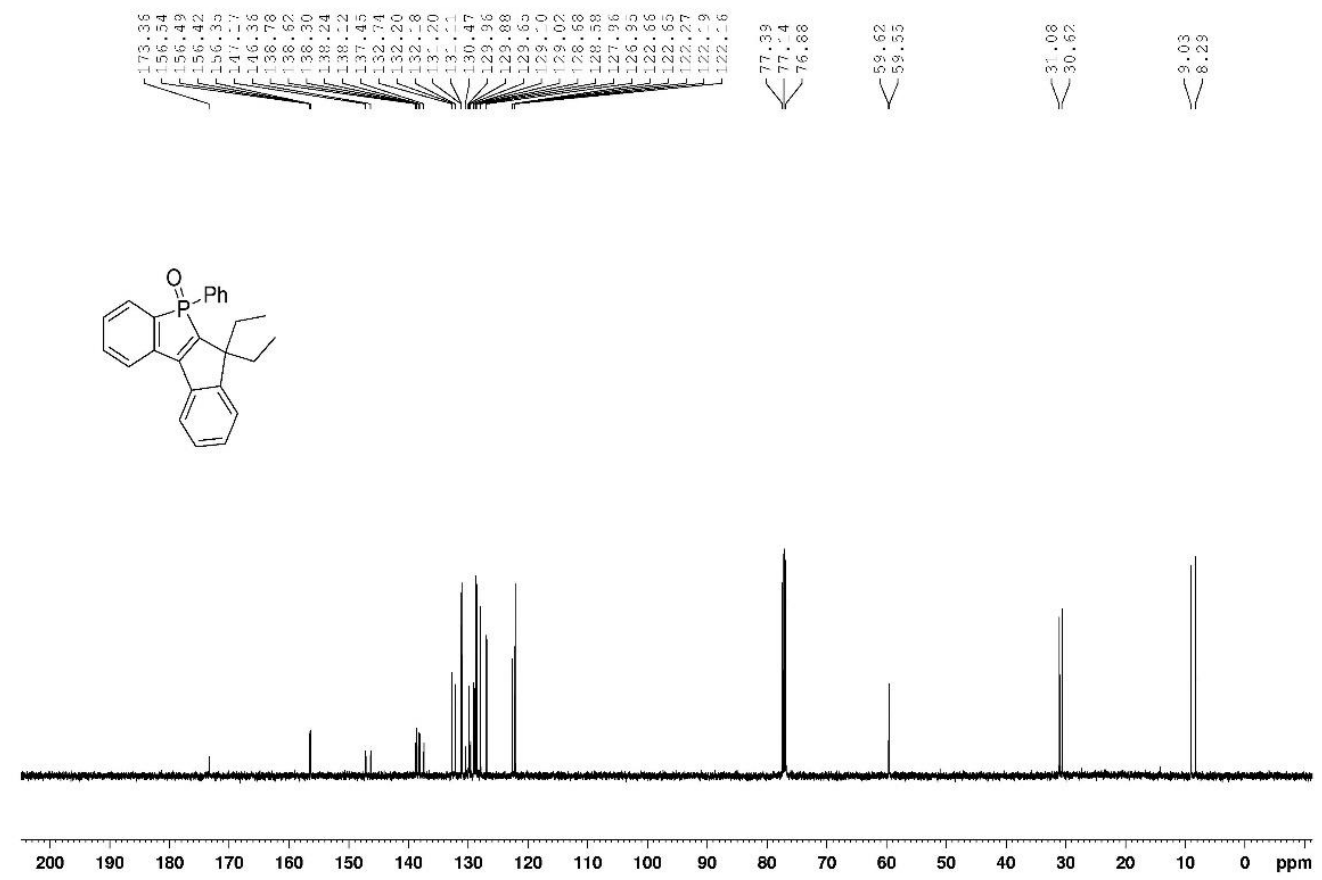

${ }^{13} \mathrm{C}$ NMR (500 MHz) spectrum of compound $4 \mathbf{i}$ in $\mathrm{CDCl}_{3}$
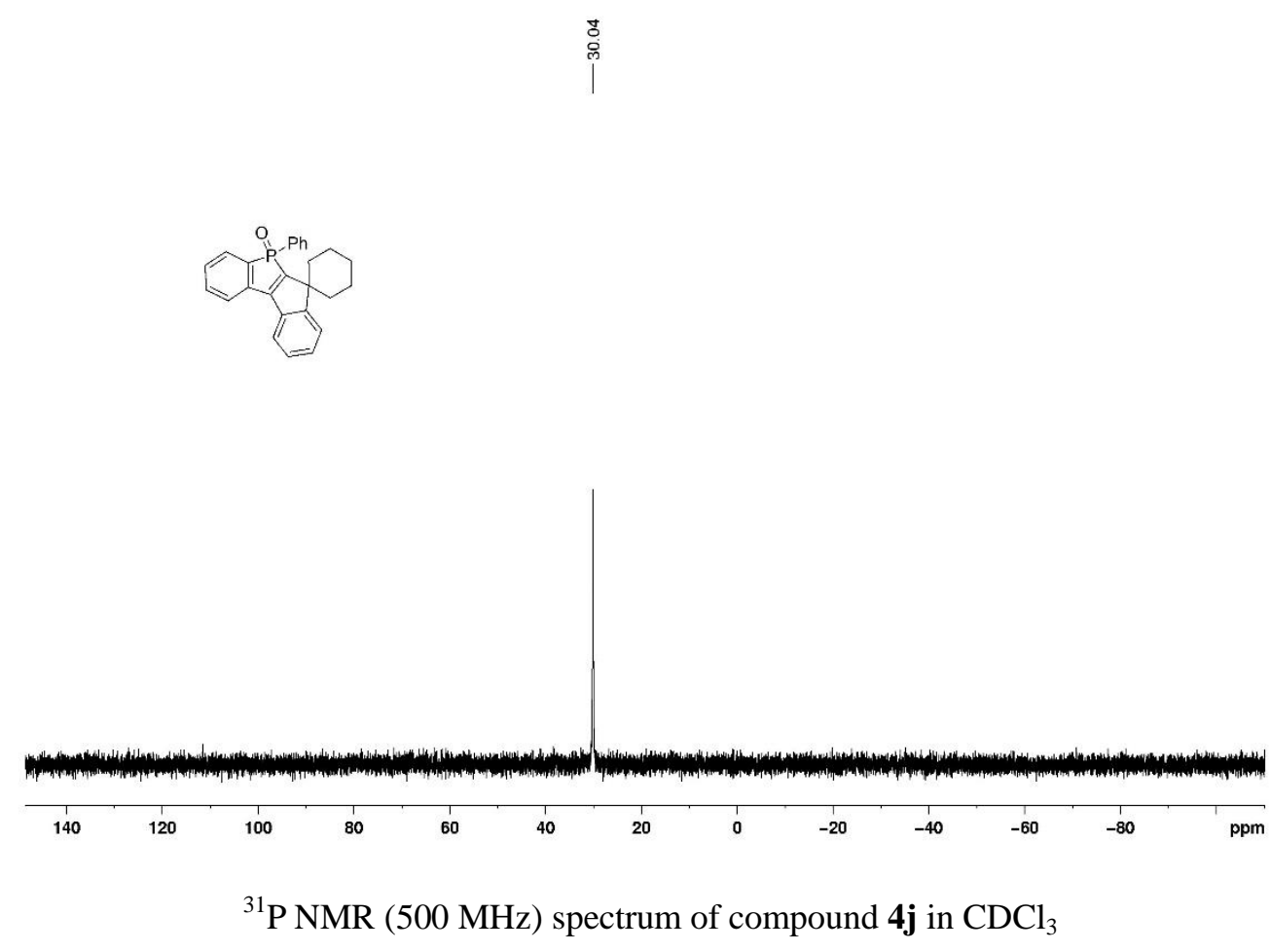

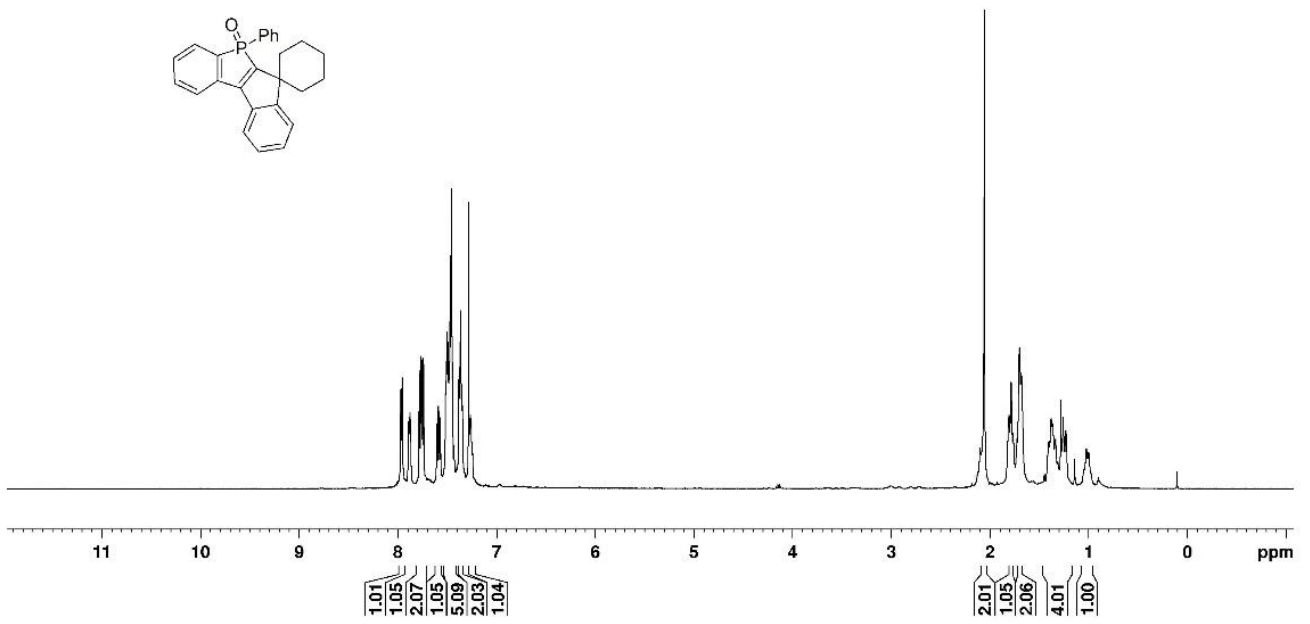

${ }^{1} \mathrm{H}$ NMR (500 MHz) spectrum of compound $\mathbf{4 j}$ in $\mathrm{CDCl}_{3}$

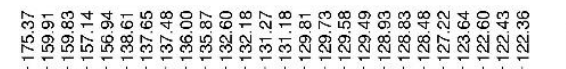

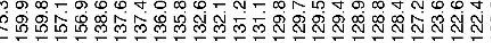

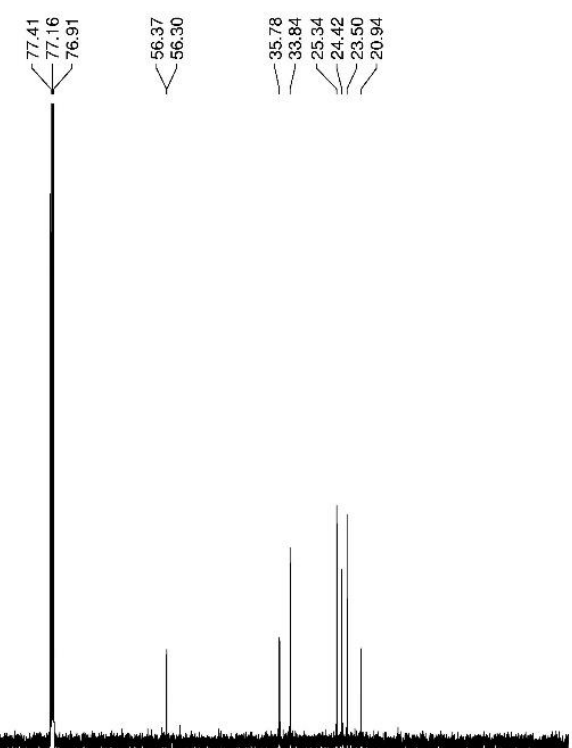

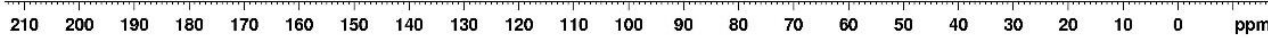

${ }^{13} \mathrm{C}$ NMR (500 MHz) spectrum of compound $\mathbf{4} \mathbf{j}$ in $\mathrm{CDCl}_{3}$ 


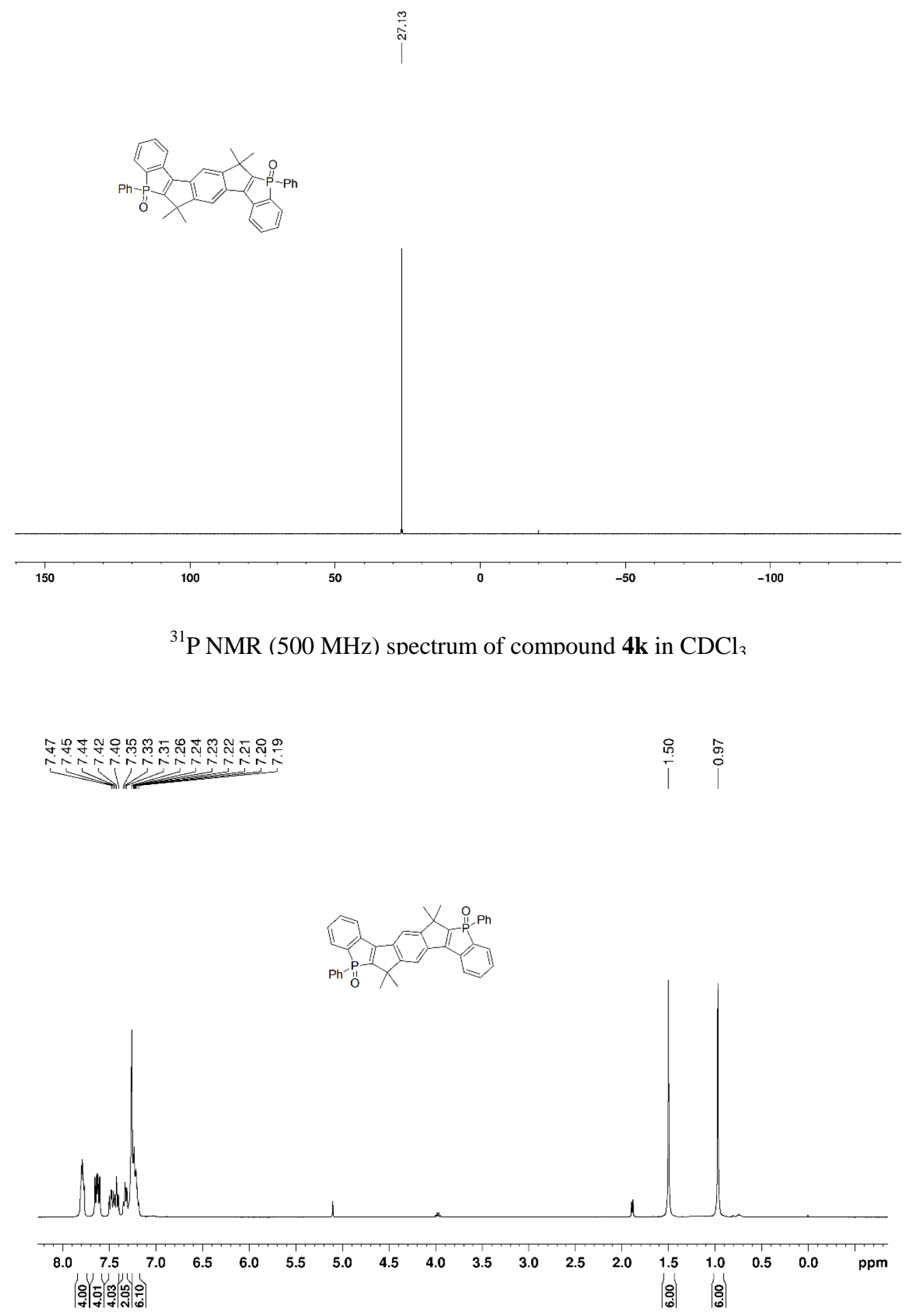

${ }^{1} \mathrm{H}$ NMR (500 MHz) spectrum of compound $\mathbf{4} \mathbf{k}$ in $\mathrm{CDCl}_{3}$ 

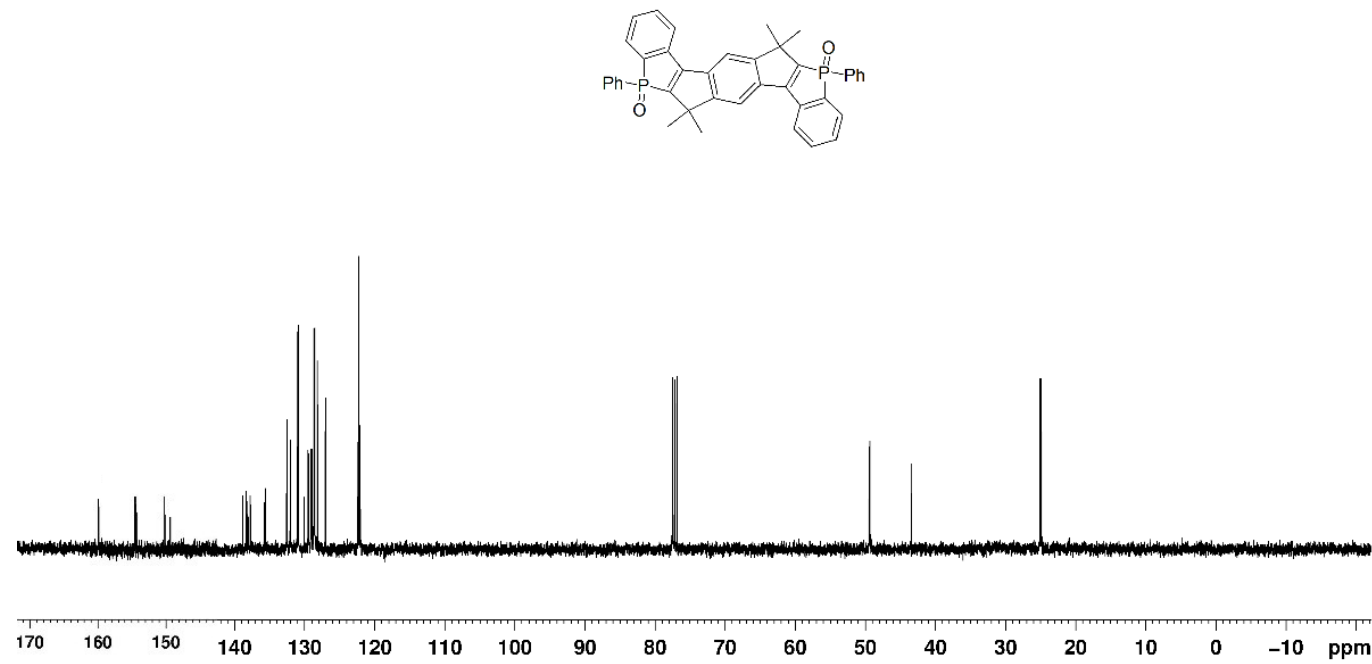

${ }^{13} \mathrm{C}$ NMR (500 MHz) spectrum of compound $\mathbf{4 k}$ in $\mathrm{CDCl}_{3}$

m.m.
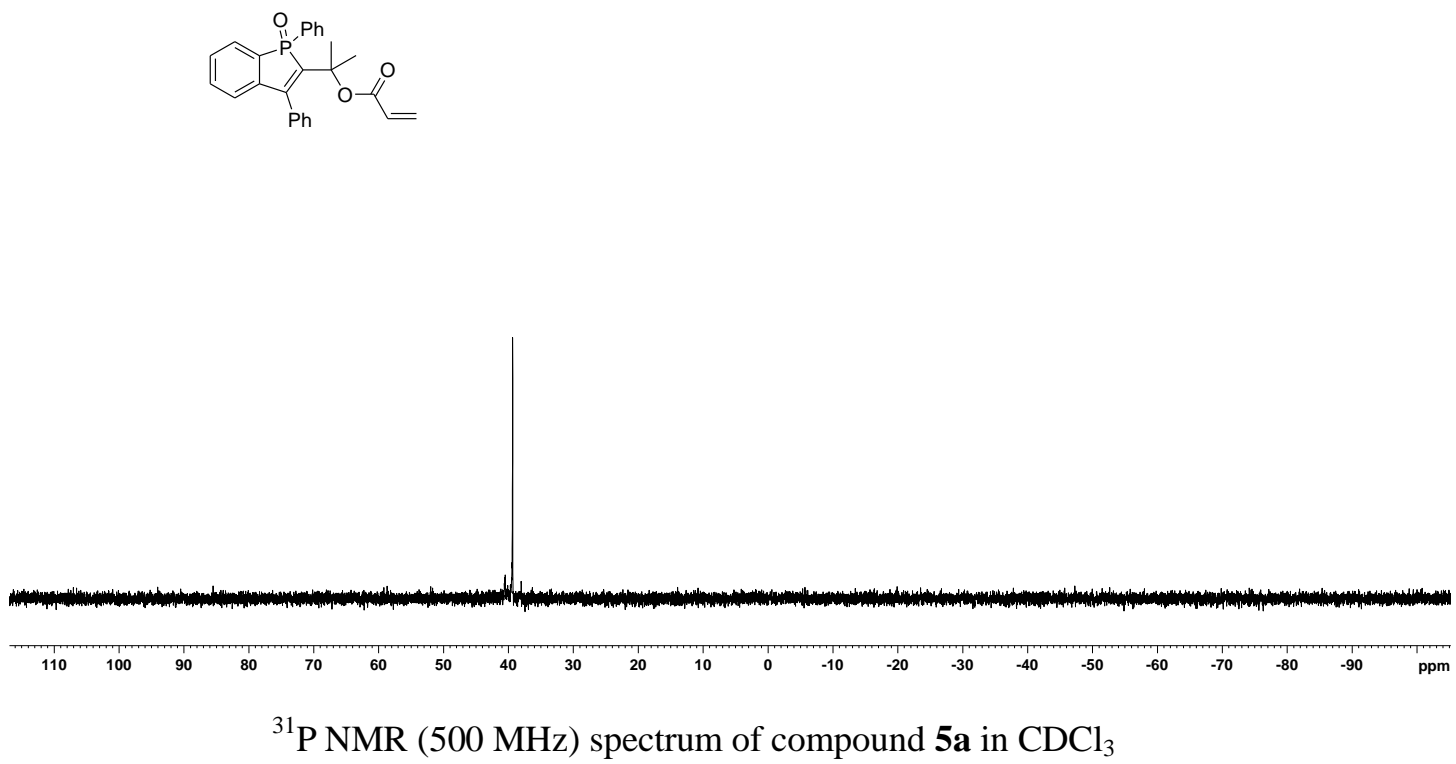

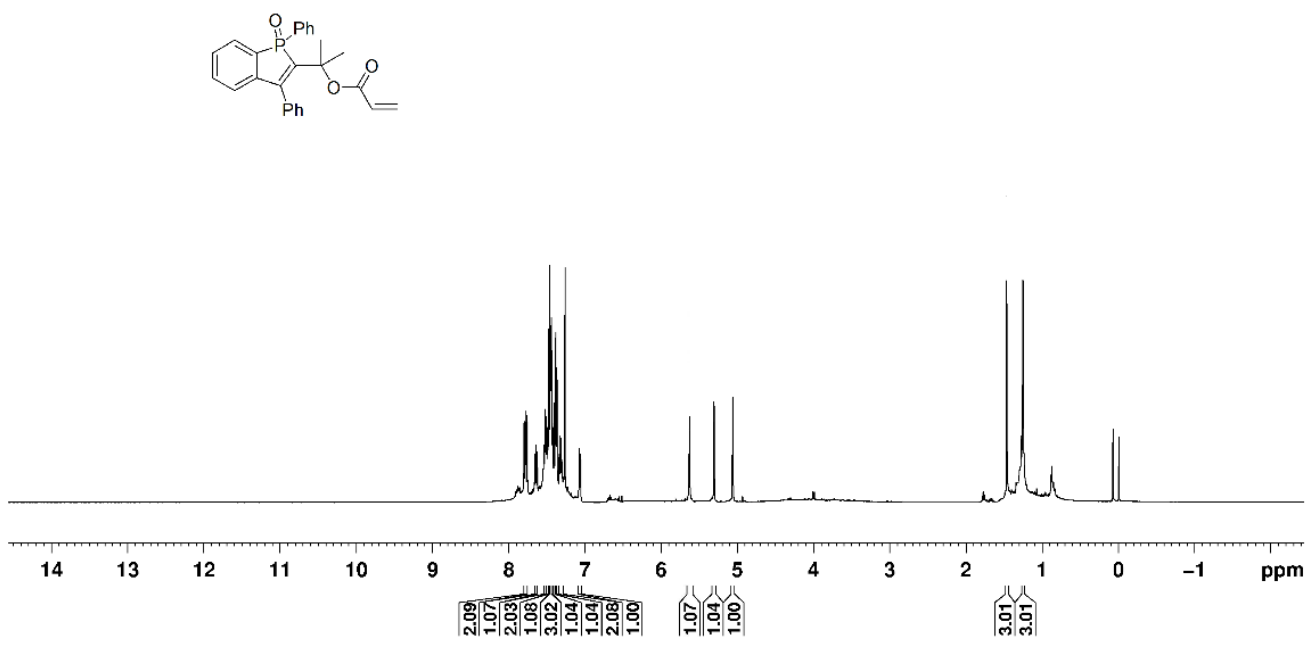

${ }^{1} \mathrm{H}$ NMR (400 MHz) spectrum of compound $\mathbf{5 a}$ in $\mathrm{CDCl}_{3}$

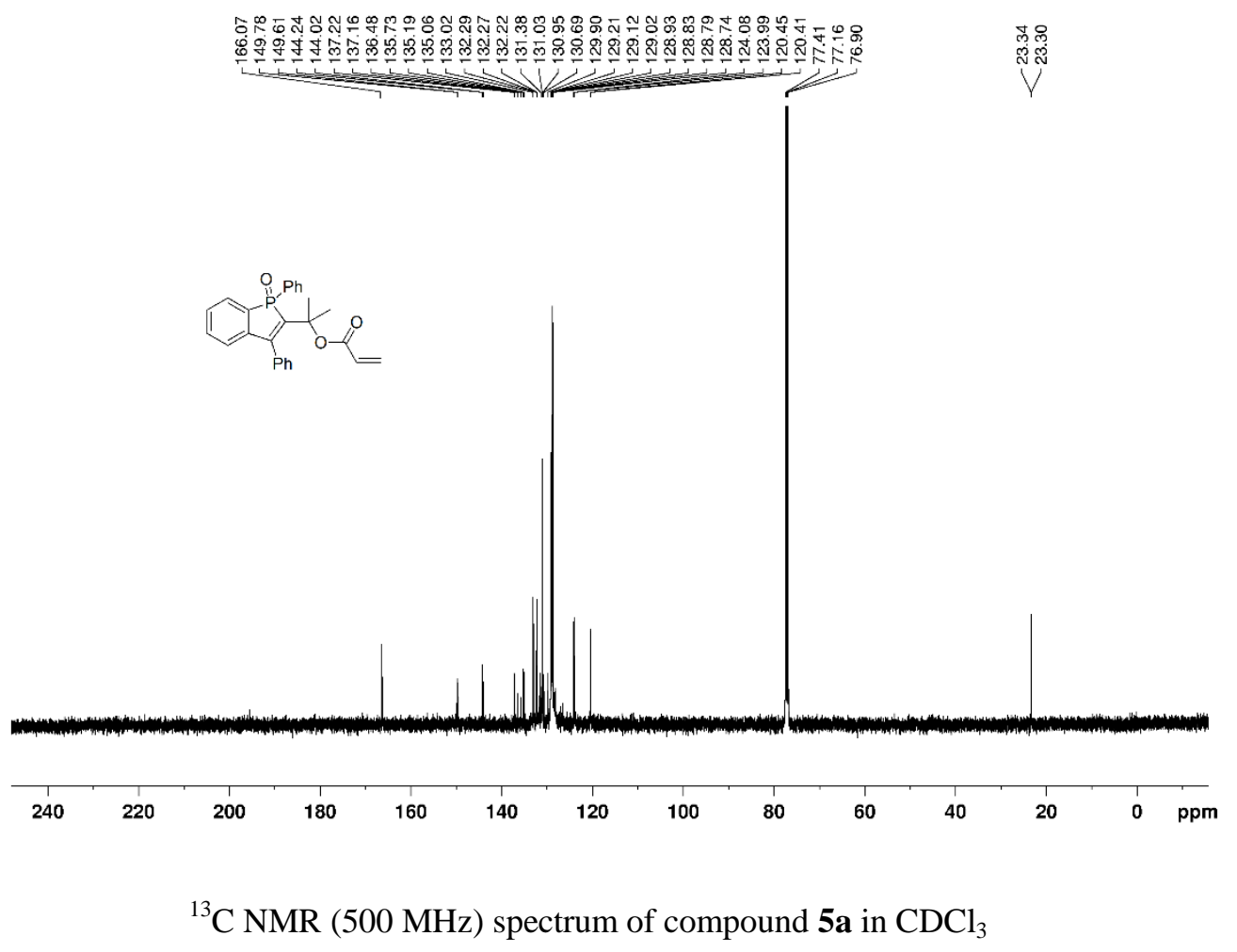




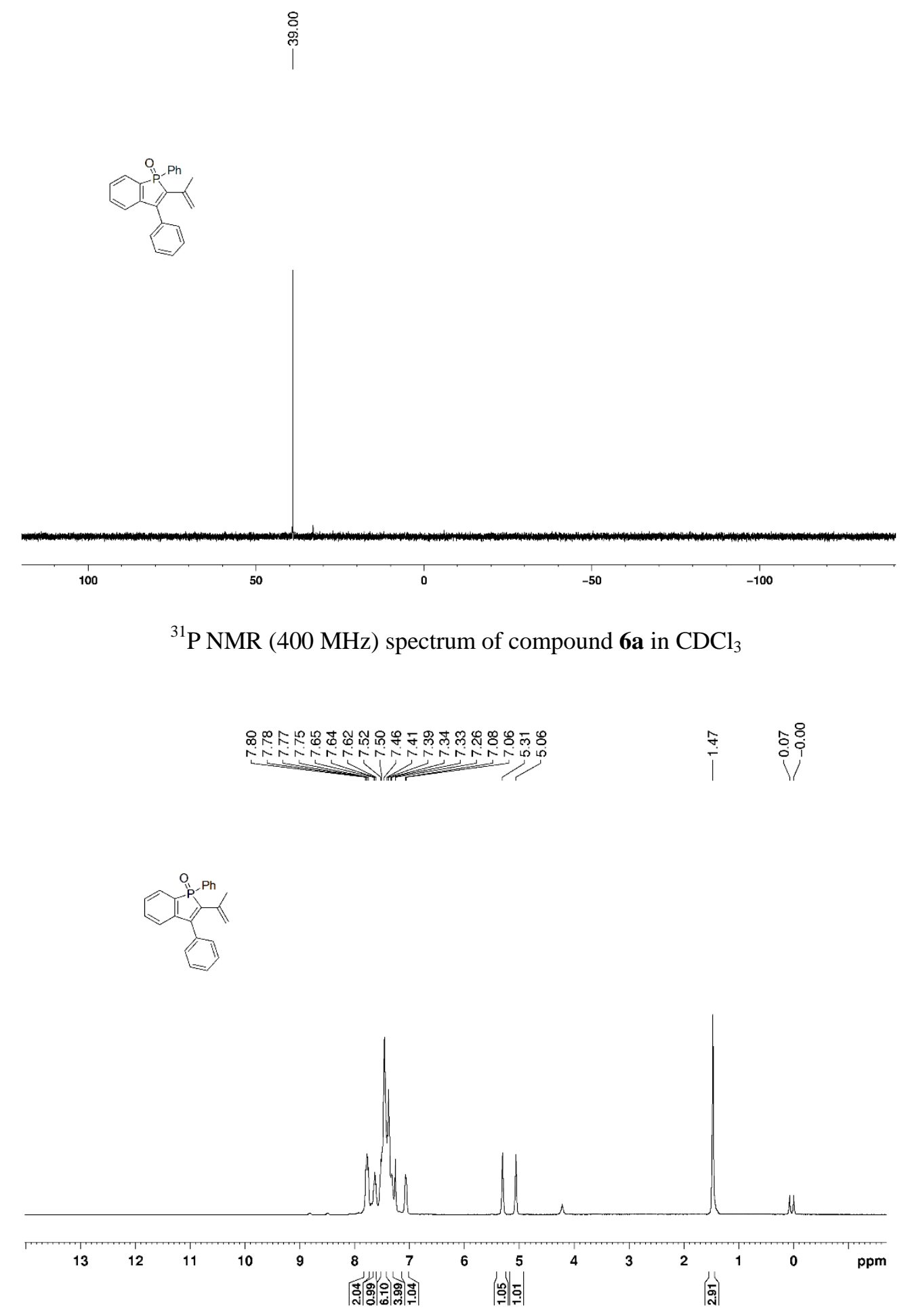

${ }^{1} \mathrm{H}$ NMR (400 MHz) spectrum of compound $\mathbf{6 a}$ in $\mathrm{CDCl}_{3}$ 


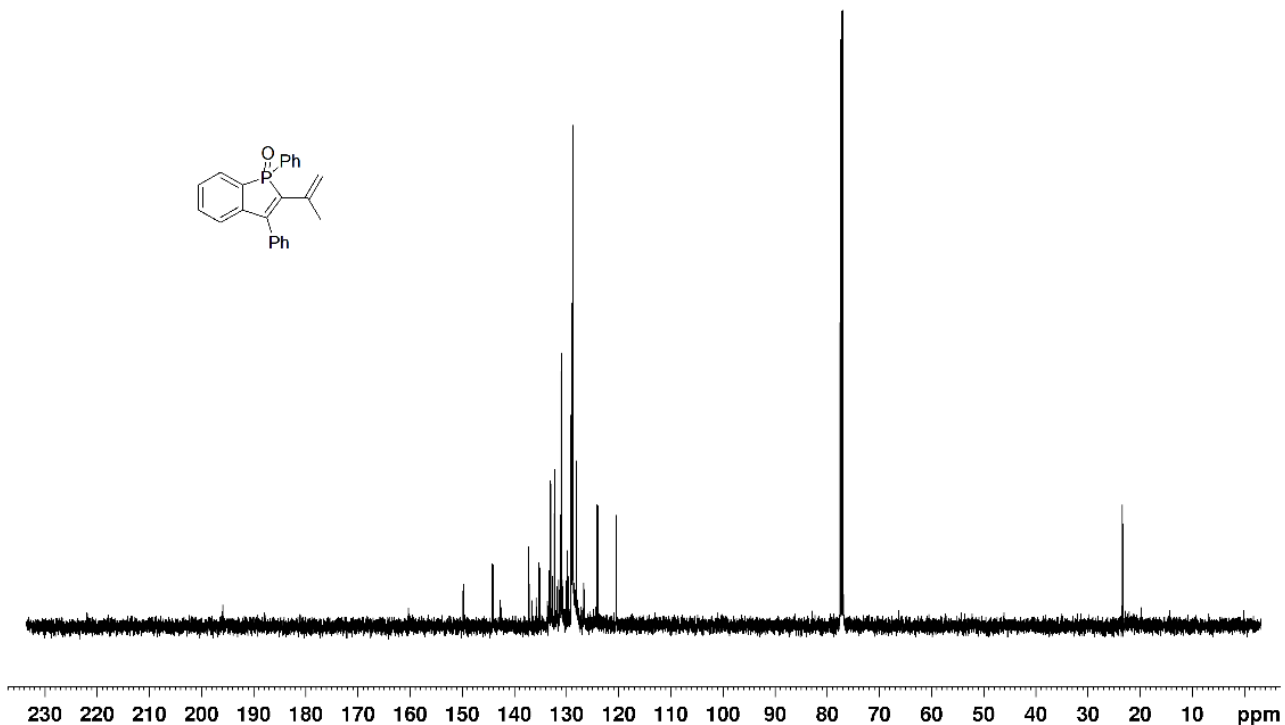

${ }^{13} \mathrm{C}$ NMR (500 MHz) spectrum of compound $\mathbf{6 a}$ in $\mathrm{CDCl}_{3}$ 